\title{
High temperature coatings based on $\beta-\mathrm{NiAl}$
}

\author{
by
}

Kevin Richard Severs

\begin{abstract}
A thesis submitted to the graduate faculty in partial fulfillment of the requirements for the degree of MASTER OF SCIENCE
\end{abstract}

Major: Materials Science and Engineering

Program of Study Committee:

Mufit Akinc, Co-major Professor

Matt Kramer, Co-major Professor

Pat Thiel

\author{
Iowa State University \\ Ames, Iowa
}

2012

Copyright (C) Kevin Richard Severs, 2012. All rights reserved. 


\section{TABLE OF CONTENTS}

LIST OF TABLES $\ldots \ldots \ldots \ldots \ldots \ldots \ldots \ldots$

LIST OF FIGURES $\ldots \ldots \ldots \ldots \ldots \ldots \ldots \ldots \ldots$

ACKNOWLEDGEMENTS $\ldots \ldots \ldots \ldots \ldots \ldots \ldots \ldots$ viii

CHAPTER 1. General Introduction . . . . . . . . . . . . . . 1

1.1 Thesis Organization $\ldots \ldots \ldots \ldots \ldots \ldots \ldots \ldots$

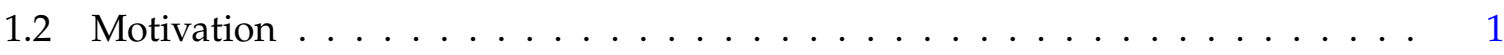

1.3 Literature Review . . . . . . . . . . . . . . . . . . . . 2

1.3.1 Oxidation Resistant Coatings .................. 2

1.3.2 $\beta-\mathrm{NiAl}$ as a Coating Material . . . . . . . . . . . . 6

1.3.3 NiAl-Boride Composites . . . . . . . . . . . . . . . 10

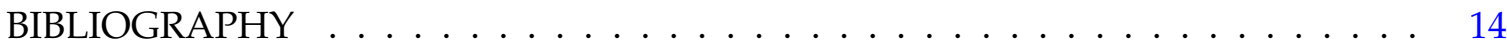

CHAPTER 2. Grain Size and Oxidation Performance of a NiAl-TiB 2 Composite . . 18

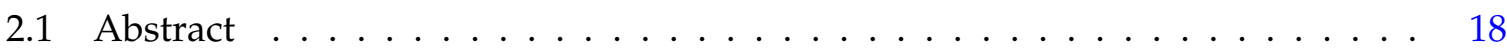

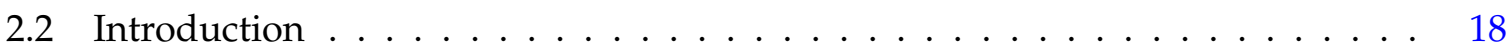

2.3 Experimental Details . . . . . . . . . . . . . . . . . . . . 19

2.3.1 Selection of Boride Phase . . . . . . . . . . . . . . . . 19

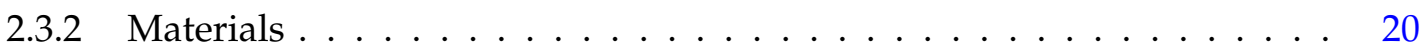

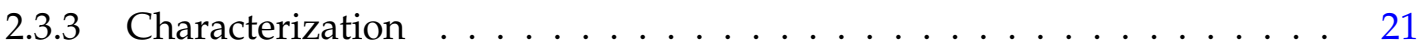

2.4 Results and Discussion . . . . . . . . . . . . . . . . . . . 21

2.4 .1 Phase Analysis . . . . . . . . . . . . . . . . . 21

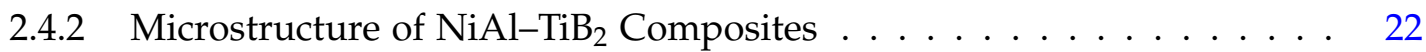

2.4 .3 OIM and Grain Size . . . . . . . . . . . . . . . . . . 24 
2.4 .4 Oxidation of $\mathrm{NiAl}^{-\mathrm{TiB}_{2}} \ldots \ldots \ldots \ldots \ldots \ldots$

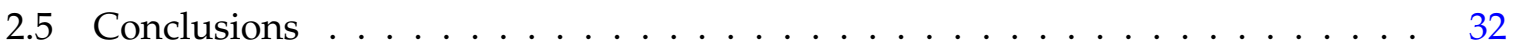

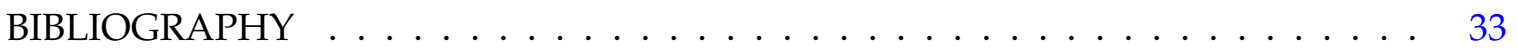

CHAPTER 3. Improvement of Oxidation Performance of Mo-Ni-Al Alloys by Pack

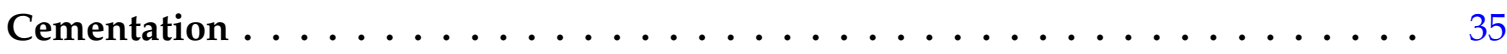

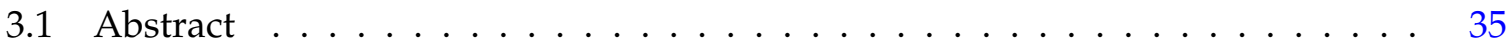

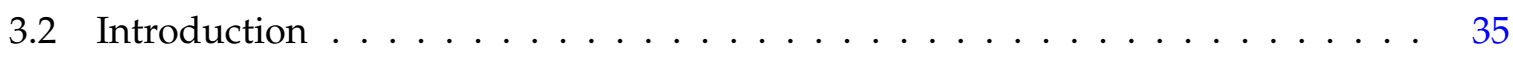

3.3 Experimental Details . . . . . . . . . . . . . . . . . . 37

3.3 .1 Substrate Materials . . . . . . . . . . . . . . 37

3.3 .2 Coating Process . . . . . . . . . . . . . . . 38

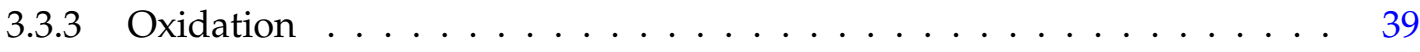

3.3.4 Grain Size Characterization . . . . . . . . . . . . . . . . . . 39

3.4 Results and Discussion . . . . . . . . . . . . . . . . . 40

3.4 .1 Alloy Synthesis . . . . . . . . . . . . . . . . . . 40

3.4 .2 Coating Optimization . . . . . . . . . . . . . . 40

3.4.3 Coating on (Mo)-NiAl Substrate . . . . . . . . . . . . . . 43

3.4.4 Oxidation Behavior at $1200^{\circ} \mathrm{C} \ldots \ldots \ldots \ldots \ldots$

3.4 .5 Initial Grain Size $\ldots \ldots \ldots \ldots \ldots$. . . . . . . . . . . . 47

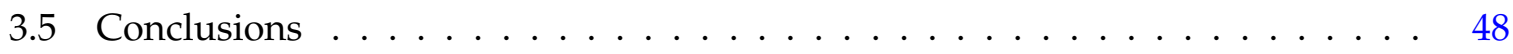

3.6 Acknowledgement . . . . . . . . . . . . . . . . . . . 49

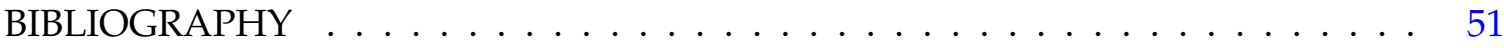

CHAPTER 4. Cyclic Oxidation of Coated and Uncoated Cast Mo-Ni-Al Alloys . . . 53

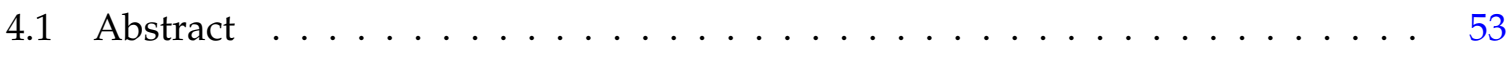

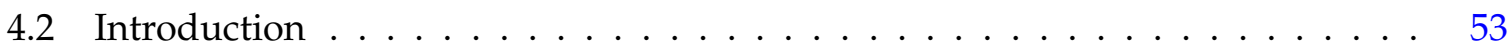

4.3 Experimental Details . . . . . . . . . . . . . . . . . . 54

4.3 .1 Materials and Synthesis . . . . . . . . . . . . . 54

4.3 .2 Oxidation Testing . . . . . . . . . . . . . . . 54

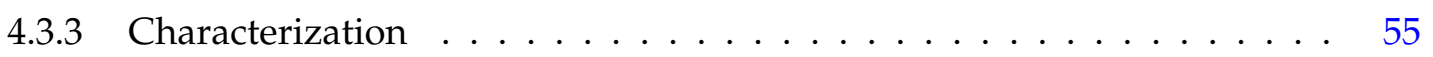


4.4 Results and Discussion . . . . . . . . . . . . . . . . . 55

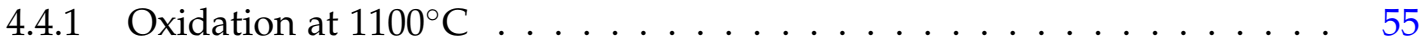

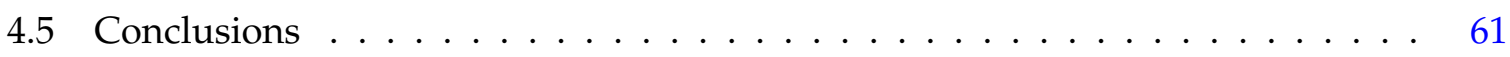

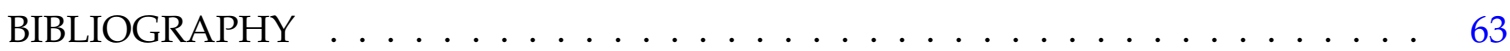

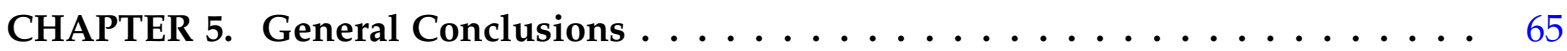

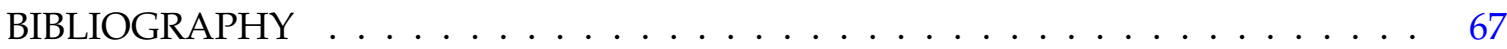

APPENDIX A. Design and Building of a Cyclic Oxidation Furnace . . . . . . . 68

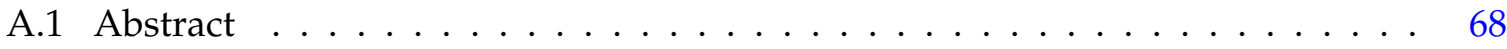

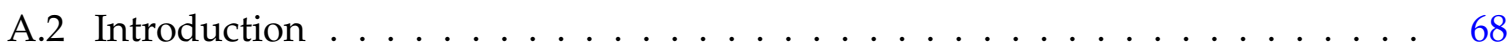

A.3 Design and Building . . . . . . . . . . . . . . . . . 69

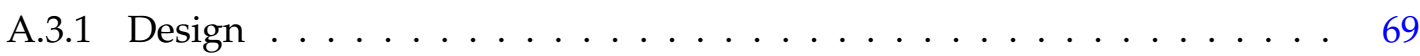

A.3.2 Fabrication and Assembly . . . . . . . . . . . . . 71

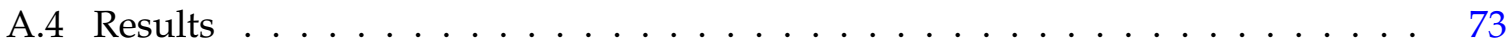

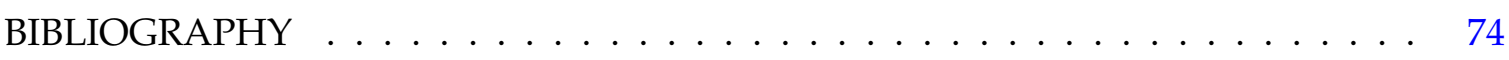

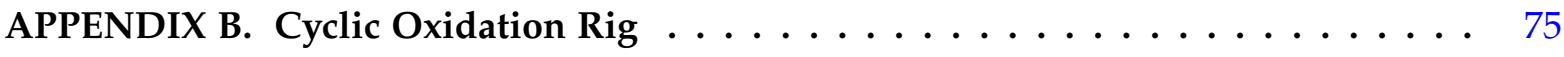

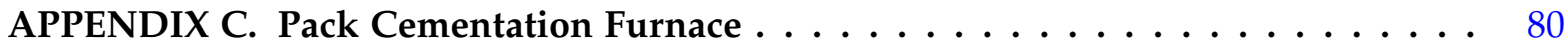

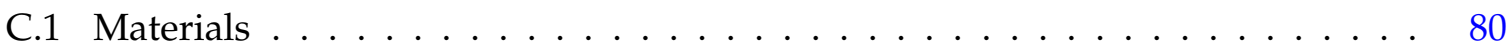

C.1.1 Furnace .............................. 80

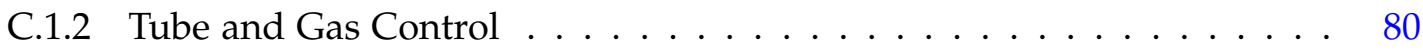

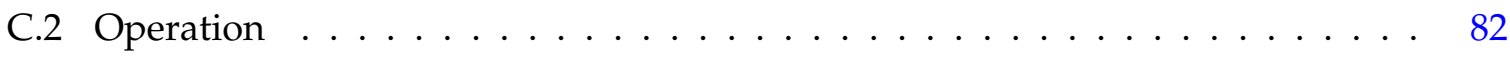




\section{LIST OF TABLES}

Table $1.1 \quad$ Enthalpy of Formation of $\mathrm{NiAl} \ldots \ldots \ldots \ldots$

Table $2.1 \quad$ Enthalpies of Formation $\ldots \ldots \ldots \ldots$

Table $2.2 \quad$ Grain Growth Constants . . . . . . . . . . . . . . . . . . . . . 26

Table 2.3 EDS of Spherical Oxide Particles shown in $2.9 b \ldots \ldots$. . . . . . 31

Table $3.1 \quad$ Ni Plating Solution $\ldots \ldots \ldots \ldots \ldots \ldots \ldots$

Table $3.2 \quad$ Pack Composition . . . . . . . . . . . . . . . . . . . . . 39

Table 3.3 Pack Cementation on Ni Samples . . . . . . . . . . . . . . . . . . . 41

Table 3.4 Composition of $3.5 a \ldots \ldots \ldots \ldots \ldots \ldots$

Table $4.1 \quad$ Mechanical and Thermal Properties of Mo and NiAl _ . . . . . . 59 


\section{LIST OF FIGURES}

Figure $1.1 \quad$ Alloying additions to superalloys $[1] \ldots \ldots \ldots$

Figure 1.2 Superalloy coating structure $[4] \ldots \ldots \ldots \ldots \ldots$

Figure 1.3 Typical low activity pack cementation coating [10] . . . . . . . . 5

Figure $1.4 \mathrm{Ni}-\mathrm{Al}$ Phase Diagram $[12] \ldots \ldots \ldots \ldots \ldots$

Figure $1.5 \quad \mathrm{CTE}$ of $\mathrm{NiAl}$ and $\mathrm{Al}_{2} \mathrm{O}_{3} \ldots \ldots \ldots \ldots \ldots$

Figure 1.6 Oxidation of $\mathrm{NiAl}-\mathrm{TiB}_{2}$ Composite from [36] . . . . . . . . . . . . . 12

Figure $2.1 \quad \mathrm{XRD}$ of $\mathrm{NiAl}-\mathrm{TiB}_{2}$ Composite $\ldots \ldots \ldots \ldots \ldots \ldots \ldots$

Figure $2.2 \quad \mathrm{SEM}$ of Annealed $\mathrm{NiAl}-\mathrm{TiB}_{2}$ Composites . . . . . . . . . . . . . . 23

Figure $2.3 \quad \mathrm{NiAl}-\mathrm{TiB}_{2}$ Composite: $1300^{\circ} \mathrm{C}$ Anneal for 70 hours . . . . . . . . . . 24

Figure 2.4 OIM of $\mathrm{NiAl}-\mathrm{TiB}_{2}$ Composite, highlighting the grains of $\beta-\mathrm{NiAl} .500 \mathrm{x} \quad 25$

Figure 2.5 OIM Phase Analysis of $\mathrm{NiAl}-\mathrm{TiB}_{2}$ Composite . . . . . . . . . . . . . 26

Figure 2.6 Grain Growth Kinetics . . . . . . . . . . . . . . . . . . . . . 27

Figure 2.7 Coupon Surface after $1100^{\circ} \mathrm{C}$ Oxidation $\ldots \ldots \ldots \ldots$

Figure 2.8 Cross Section of Oxide Scale at $1100^{\circ} \mathrm{C} \ldots \ldots \ldots$

Figure 2.9 Coupon Surface after $1200^{\circ} \mathrm{C}$ Oxidation . . . . . . . . . . . . . 30

Figure 2.10 Cross Section of $1200^{\circ} \mathrm{C}$ Oxide Scale . . . . . . . . . . . . . . . 31

Figure 3.1 NiAl-Mo Psuedobinary Phase Diagram [16] . . . . . . . . . . . . 37

Figure $3.2 \quad$ SEM Micrographs of $(\mathrm{Mo})-\mathrm{NiAl}$ Alloys $\ldots \ldots \ldots$. . . . . . . . . . 40

Figure $3.3 \quad$ Ni Plating Rate . . . . . . . . . . . . . . . . . . . . 41

Figure 3.4 Pack Cementation . . . . . . . . . . . . . . . . 42

Figure 3.5 Coating on 20 at.\% Alloy . . . . . . . . . . . . . . . 43

Figure 3.6 Coating on 75 at.\% Mo Alloy $\ldots \ldots \ldots \ldots \ldots$ 
Figure 3.7 Isothermal Oxidation Comparison of Coated and Uncoated (Mo)-NiAl

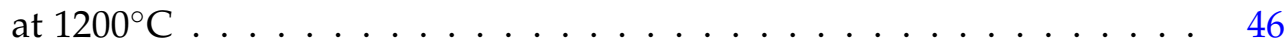

Figure 3.8 Coated Sample after 100 hours Isothermal Oxidation . . . . . . . . . 47

Figure 3.9 Coated Sample after 100 hours Isothermal Oxidation . . . . . . . . . 48

Figure 3.10 OIM of $\beta-\mathrm{NiAl}$ Coating $\ldots \ldots \ldots \ldots$

Figure 3.11 SEI of $\beta-\mathrm{NiAl}$ Coating $\ldots \ldots \ldots \ldots \ldots \ldots$

Figure 4.1 Cyclic Oxidation at $1100^{\circ} \mathrm{C}$ of coated $20-$ Mo Alloy . . . . . . . . . . 56

Figure $4.2 \quad$ XRD of Oxidized Coated Samples . . . . . . . . . . . . . . 57

Figure 4.3 Oxide Scale after 2 Cycles $\ldots \ldots \ldots \ldots \ldots$

Figure $4.4 \quad$ Oxide Scale after 5 Cycles . . . . . . . . . . . . . . . . . . . . 59

Figure 4.5 Thermal Stress between $\mathrm{NiAl}$ and $\mathrm{Mo} \ldots \ldots$. . . . . . . . . . . 60

Figure 4.6 Stress required for fracture of $\beta-\mathrm{NiAl}$ Coatings . . . . . . . . . . . . 62

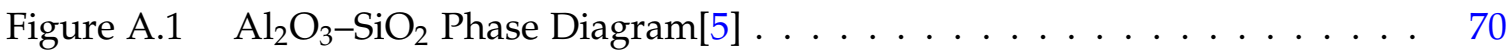

Figure A.2 ATS Model 3420 Furnace . . . . . . . . . . . . . . . . . . 72

Figure A.3 Stepper Motor Configuration . . . . . . . . . . . . . . 73

Figure A.4 Part 7, Guide Block . . . . . . . . . . . . . . . . 73

Figure C.1 Pack Cementation Apparatus End . . . . . . . . . . . . . . 81

Figure C.2 Pack Cementation Schematic . . . . . . . . . . . . . . . 81

Figure C.3 Inconel Tray $\ldots \ldots \ldots \ldots \ldots$. . . . . . . . . . . 82 


\section{ACKNOWLEDGEMENTS}

I would like to take this opportunity to express my thanks to those who helped me conduct research and write this thesis. Special thanks to Dr. Mufit Akinc and Dr. Matt Kramer who guided me through the research process. Their help was invaluable over the last two years. I thank Dr. Pat Thiel for serving on my committee. I am extremely thankful that they allowed me to write my thesis with $\mathrm{LT}_{\mathrm{E}} \mathrm{X}$ which made the entire writing process much easier. I would like to thank Dr. Pratik Ray for his constant guidance with experiments throughout the entire process.

Thanks to Karen DeRocher for help with synthesis of some of the coatings, Travis Brammer for guidance with the TGA and other instruments, Alexa Oser for help with the NiAl$\mathrm{TiB}_{2}$ composites, Kevin Dennis for guidance with the pack cementation furnace, Jim Anderegg for helping me keep the lab up and running, and Fran Laabs for carrying out OIM

measurements. All of these people made this research possible and I am very thankful for them.

This work was performed at the Ames Laboratory under contract number DE-AC0207CH11358 with the U.S. Department of Energy. The document number assigned to this thesis is IS-T 3051 


\section{CHAPTER 1. General Introduction}

\subsection{Thesis Organization}

This thesis is written in a alternate format. It is composed of an introduction, original manuscripts, and a general conclusion. References are included at the end of each chapter. Figures and tables are sequentially numbered throughout the entire document.

The general introduction will give a review of high temperature alloys, focusing on current superalloys and their coatings. Chapter 2 explains the synthesis, characerization, and oxidation performance of a $\mathrm{NiAl}-\mathrm{TiB}_{2}$ composite. Chapter 3 examines a novel coating process for Mo-Ni-Al alloys for improved oxidation performance. Chapter 4 discusses the cyclic oxidation performance of coated and uncoated Mo-Ni-Al alloys. The thesis concludes with Chapter 5, which summarizes the important results of the work.

Although M. Akinc, M. Kramer, and P.K. Ray are listed in some of the manuscripts in this thesis, the work is primarily conducted by Kevin Severs. Kevin Severs is also the primary author of all the manuscripts.

\subsection{Motivation}

High temperature alloys are the workhorse materials of the modern age. They are essential to the aerospace, power generation, and many other industries. The unique combination

of high temperature strength along with oxidative stability make high temperature alloys a tough materials challenge.

Current nickel based superalloys are the material of choice for these aggressive conditions. One major limiting factor for current superalloys are their incipient melting points. Some superalloys have incipient melting temperatures as low as $1204^{\circ} \mathrm{C}$ [1].The power gen- 
eration and aerospace industries are always looking to push the engine temperatures hotter in order to gain higher efficiencies. Due to superalloys inherent limitation of melting temperature, recent research has been conducted to determine new alloy systems to use in place of current superalloys [2]. There is an initiative set forth by the National Energy Technology Laboratory (NETL) FutureGen program, to attain an operating temperature around $1300^{\circ} \mathrm{C}$

\subsection{Literature Review}

The current alloys of choice for high temperature applications are nickel based superalloys, which are composed of a Ni solid solution $(\gamma)$ with $\gamma^{\prime}$ precipitates. The $\gamma^{\prime}$ precipitates are formed from $\mathrm{Al}$ and $\mathrm{Ti}$ reacting with the $\mathrm{Ni}$ to form $\mathrm{Ni}_{3}(\mathrm{Al}, \mathrm{Ti})$. This $\gamma^{\prime}$ phase is the main contributor to the high temperature strength of the alloys [1]. There are typically many other elements in the superalloy system such as $\mathrm{Ta}, \mathrm{W}$, and $\operatorname{Re}$ in the $\gamma$ solid solution, as well as $\mathrm{Cr}$ for corrosion resistance as you can see in Figure 1.1.

The majority of the alloy development for the Ni based superalloys has focused on increasing the high temperature strength. This has lowered the amount of $\mathrm{Cr}$ and $\mathrm{Al}$ in the alloys and increased refractory metal additions ( $\mathrm{Ta}, \mathrm{Mo}, \mathrm{Re})$, which in turn has given the superalloys inherently poor oxidation resistance [3]. In order to provide the necessary corrosion and oxidation resistance, multiple coatings are implemented. These coatings include an oxidation resistant phase along with a ceramic thermal barrier coating to decrease the temperature that the alloy is exposed to[4, 3, 5]. See Figure 1.2 for a schematic of the coatings on top of a conventional superalloy.

\subsubsection{Oxidation Resistant Coatings}

As stated earlier, due to the focus on mechanical properties of the superalloys, their inherent oxidation resistance is relatively poor. In order to increase the oxidation resistance of these alloys, coatings based on an oxidatively stable phase are put on the alloy to provide the

oxidation resistance. Generally these phases are good $\mathrm{Al}_{2} \mathrm{O}_{3}$ or $\mathrm{Cr}_{2} \mathrm{O}_{3}$ formers. In the case of the $\mathrm{Ni}-\mathrm{Al}$ system, this phase is the $\beta-\mathrm{NiAl}$ phase. The formation of the oxide inhibits further 


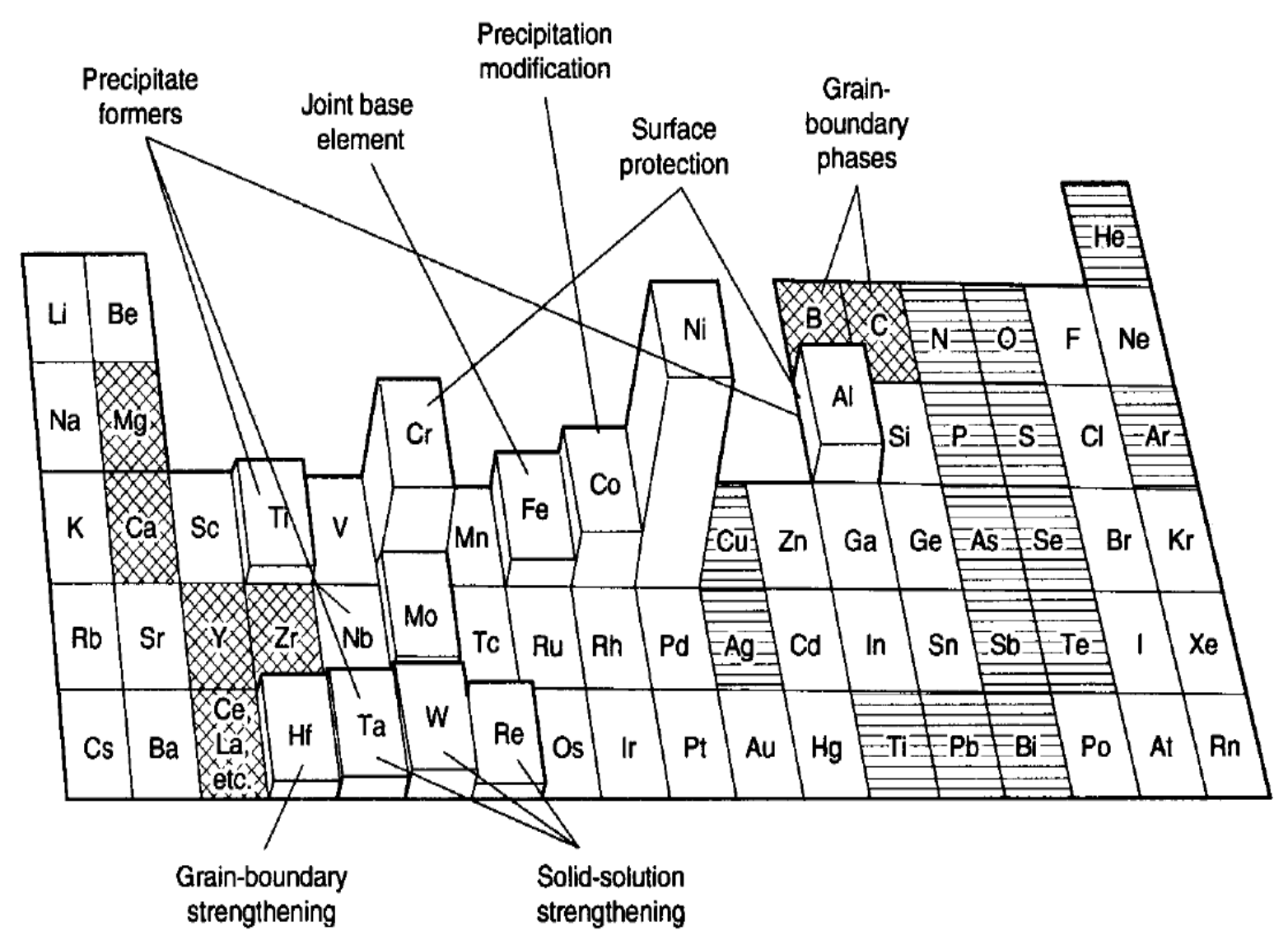

Figure 1.1: Alloying additions to superalloys [1]

oxygen diffusion into the base metal, thereby protecting the alloy from further oxidation. Application of oxidation resistant coatings can be separated into two categories: diffusion coatings, and overlay coatings[3].

\subsubsection{Diffusion Coatings}

Diffusion coatings are based on a chemical vapor deposition (CVD) like process. These processes can include CVD, aluminizing, chromizing, or even co-deposition of elements[3]. One general method of producing a diffusion coating is known as pack cementation. Pack cementation is a very flexible coating technique in which one or more elements can be deposited on the surface of a part by reacting the element to be deposited with a halide activator. The halide activator forms a metal halide vapor, which then deposits the metal onto the surface of the part. This process is highly controllable by adjusting the pack activator, 


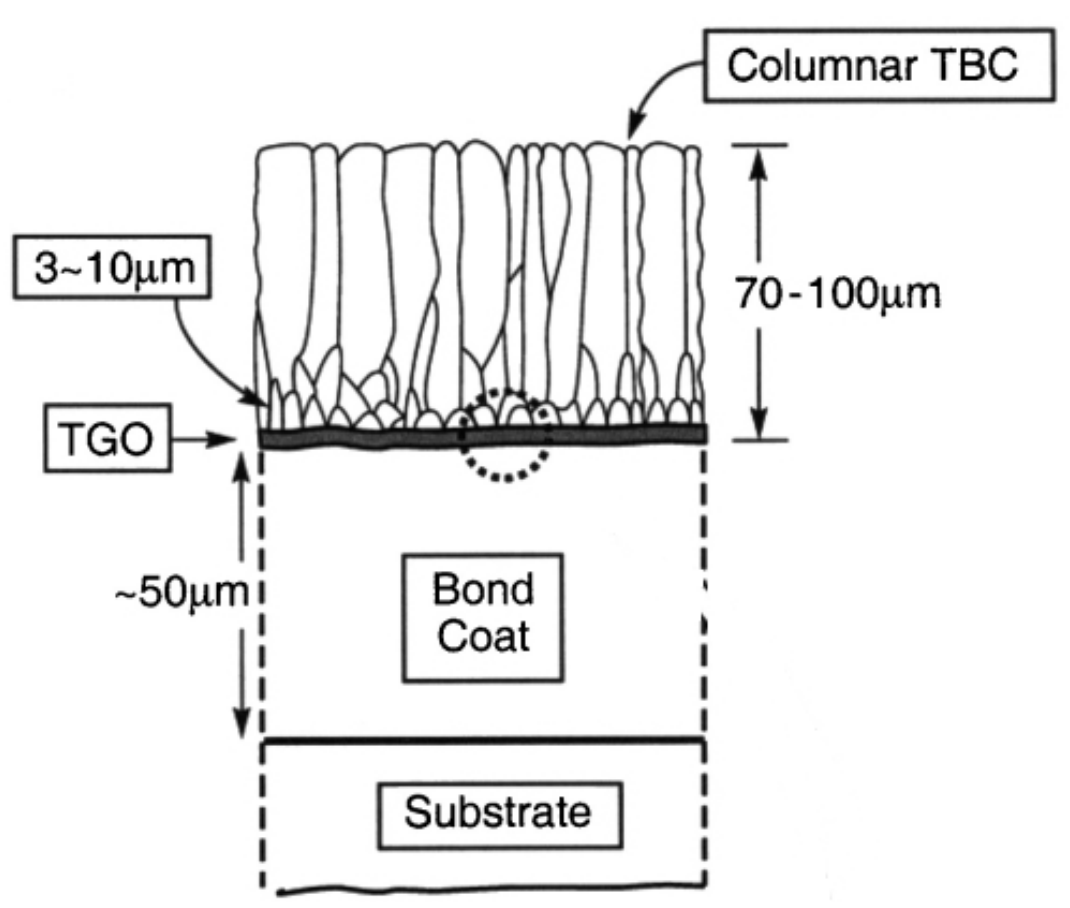

Figure 1.2: Superalloy coating structure [4]

time, temperature, and composition[6]. The metal of interest in most pack cementation processes is aluminum because of its contribution to oxidation resistance. The activity of the aluminum can be adjusted by the pack composition and temperature, which allows control over the deposition rate and amount of the aluminum onto the substrate[7]. Since the aluminum is being deposited from the vapor phase, the pack cementation process is well suited for complex geometries where it would be difficult to use a line of sight technique. The pack cementation process can be split into low activity and high activity processes. The differentiation between the two processes occurs from the relative activity of aluminum in the vapor phase. The aluminum chloride vapors in the high activity pack cementation has a higher activity than in low activity pack cementation, and is therefore the main diffusing species[8].

Low Activity Pack Cementation In low activity pack cementation on nickel based superalloys, the main diffusing species is nickel[9]. This process takes place at higher temperatures than the high activity pack cementation. The outward diffusing nickel forms a $\beta-\mathrm{NiAl}$ layer on the outer layer of the part, with a nickel depleted region towards the core. The 
outward diffusion of the $\mathrm{Ni}$ causes formation of a $\mathrm{Ni}$ rich $\beta-\mathrm{NiAl}$ zone with other phases such as carbides and $\sigma$-phases[7]. Due to the formation of the undesired intermetallics and carbides a subsequent anneal is generally required to restore a favorable microstructure. One other disadvantage of low activity pack cementation is that because the oxidatively resistant phase grows outward, some pack particles can become stuck inside the coating as seen in Figure 1.3[7].

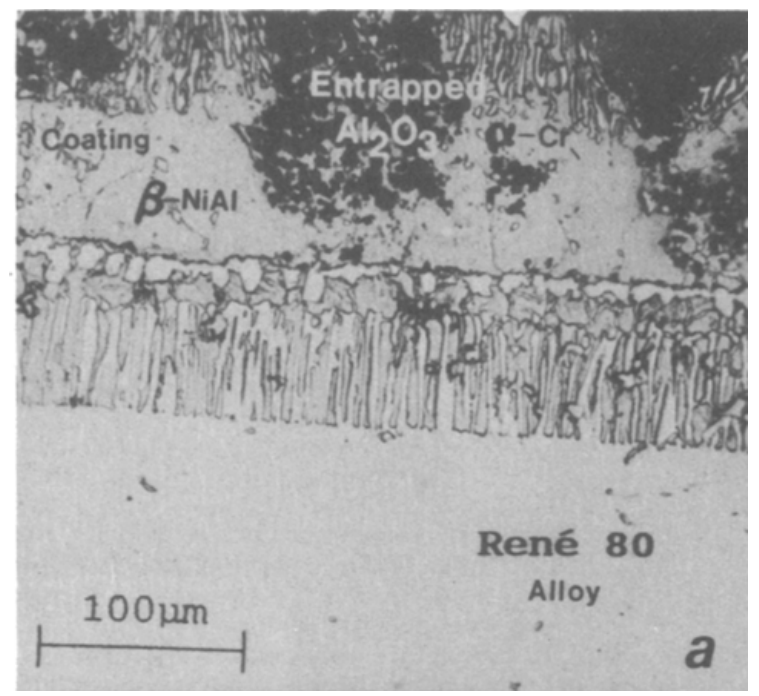

Figure 1.3: Typical low activity pack cementation coating [10]

High Activity Pack Cementation Opposite of low activity pack cementation, the main diffusing species in low activity pack cementation is aluminum. The oxidatively resistant phase grows inward rather than outward, which alleviates the problem of entrapped pack

particles. These processes typically form hyper-stoichiometric $\beta-\mathrm{NiAl}$ or $\delta-\mathrm{Ni}_{2} \mathrm{Al}_{3}$ at the surface. In both of these intermetallics, Al is the main diffusing species[8]. Like in low activity pack cementation, a post heat treatment is required to eliminate the $\delta-\mathrm{Ni}_{2} \mathrm{Al}_{3}$ and form the final $\beta-\mathrm{NiAl}$ phase.

\subsubsection{Overlay Coatings}

As opposed to diffusion coatings, overlay coatings do not rely on thermochemical processes to obtain the final coating. Instead the coating is applied with a procedure such 
as thermal spray. These coatings are strictly line of sight, so they cannot be used on extremely complex geometries. The coatings are typically multiphase and consist of $\beta$ and $\gamma^{\prime}$ intermetallics in a $\gamma$ matrix. The chemistry of the coating can be altered depending on the required mechanical and oxidation properties[3]. One unique way overlay coatings can be used where diffusion coating could not be is in so called "Smart Coatings." These coatings are compositionally different along the turbine blade to account for differences in operating conditions (temperature, combustion environment), so they can provide a more tailored coating to the type of application[11]. For instance, the coating can have more $\mathrm{Cr}$ and $\mathrm{Al}$ in an area exposed to high temperatures, while an area that is exposed to relatively lower temperatures can have less $\mathrm{Cr}$ and $\mathrm{Al}$ because the oxidation conditions are not as severe.

\subsection{2 $\beta-\mathrm{NiAl}$ as a Coating Material}

$\beta-\mathrm{NiAl}$ has many properties that make it suitable for use as the oxidatively stable phase in the $\mathrm{Ni}-\mathrm{Al}$ system. It has the highest melting point in the entire $\mathrm{Ni}-\mathrm{Al}$ system $\left(1638^{\circ} \mathrm{C}\right)$ as seen in Figure 1.4. $\beta-\mathrm{NiAl}$ also has low density, good thermal conductivity, and good oxidation resistance. All of these properties make it a desirable material to be used as a coating for high temperature applications. The following sections go into more detail of each relevant property.

\subsubsection{Crystal Structure}

The crystal structure of $\beta-\mathrm{NiAl}$ is the primitive cubic $\mathrm{CsCl}$ structure, which can be thought of as two inter-penetrating simple cubic lattices, one that is $\mathrm{Ni}$ and the other $\mathrm{Al}$. One unique property of this phase is the relatively wide range of stoichiometry that can still result in the B2 compound, from 45 to 60 at.\% Ni. Some properties such as density, interdiffusion coefficients, and creep behavior are effected by changes in the stoichiometry.

\subsubsection{Thermodynamic Properties}

As stated earlier $\beta-\mathrm{NiAl}$ has the highest melting temperature of the entire $\mathrm{Ni}-\mathrm{Al}$ system. The melting temperature of $1638^{\circ} \mathrm{C}$ is approximately $430^{\circ} \mathrm{C}$ higher that the incipient melting 


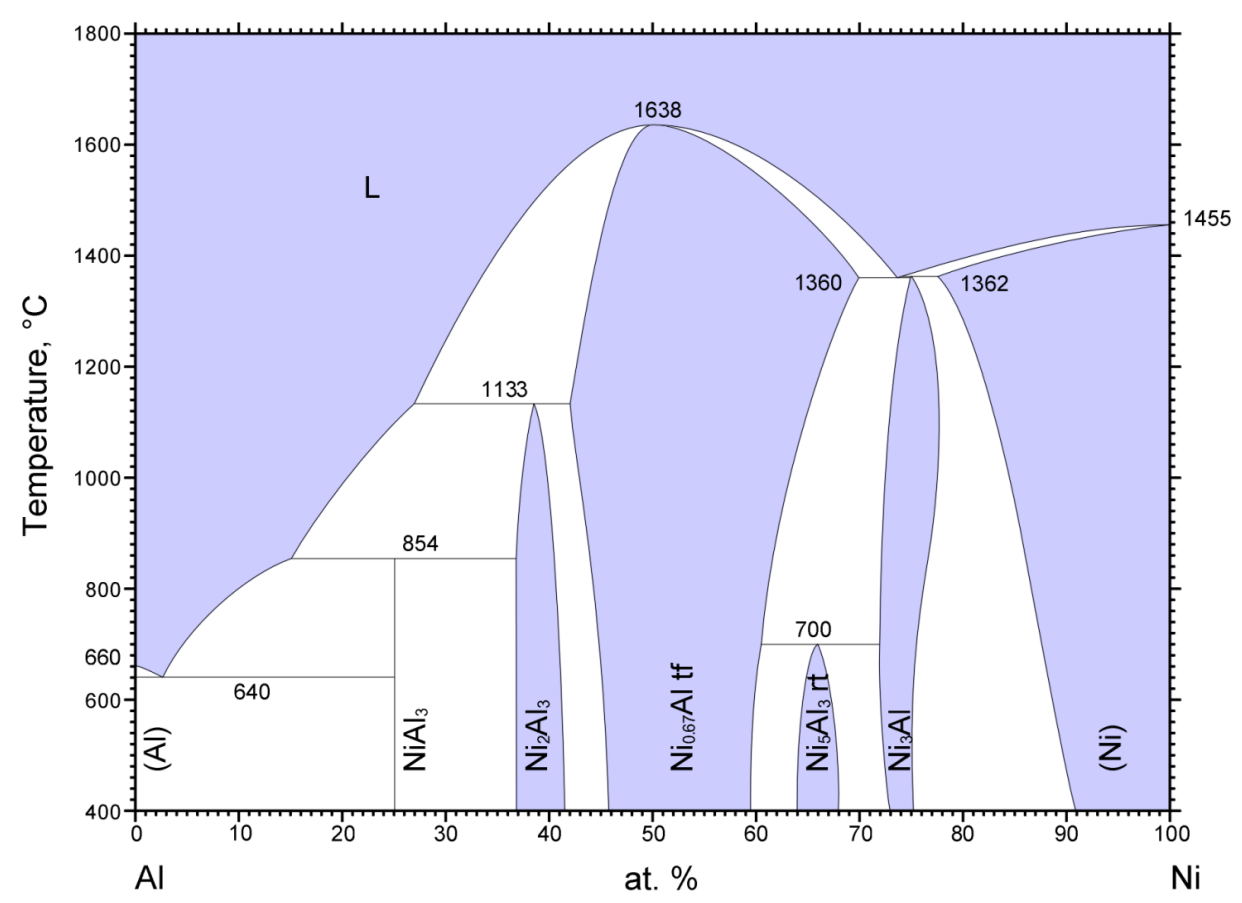

Figure 1.4: Ni-Al Phase Diagram [12]

point of the current $\mathrm{Ni}$ based superalloys. The formation enthalpy of $\beta-\mathrm{NiAl}$ has been characterized both experimentally and theoretically with a summary in Table 1.1[13]. This highly negative formation enthalpy demonstrates how strong the bonding is between the aluminum and nickel atoms in the lattice. $\beta-\mathrm{NiAl}$ has one of the most negative formation enthalpies for all B2 aluminide compounds[14]. Another clue to the stability of $\beta-\mathrm{NiAl}$ is that even when quenched at extremely high rates up to $10^{8} \mathrm{~K} \mathrm{~s}^{-1}$ the B2 structure still forms[15].

Table 1.1: Experimental and Theoretical Values for the Enthalpy of Formation of NiAl[13]

\begin{tabular}{lcc}
\hline Method & Formation Enthalpy, kJ/mol of atoms & Reference \\
\hline Calorimetry & $-66.4 \pm 2.0$ & {$[16]$} \\
EMF Measurements & -62.0 & {$[17]$} \\
Ab initio & -71 & {$[18]$} \\
\hline
\end{tabular}




\subsubsection{Physical Properties}

Elastic Properties Due in part to the B2 crystal structure, the elastic properties of $\beta-\mathrm{NiAl}$ are highly anisotropic. The degree of anisotropy

$$
A=\frac{2 C_{44}}{\left(C_{11}-C_{12}\right)}
$$

is dependant on the composition, which can vary from 1.85 for aluminum rich compositions to 5.67 for nickel rich compositions[19]. Interestingly enough, the Young's modulus for $\beta-\mathrm{NiAl}$ is not greatly effected by composition, but is more sensitive to processing technique and temperature[15]. Samples produced by Harmouche and Wolfenden[20] and Hellmann et al.[21] showed minimal changes in the elastic constant as a function of composition. Samples produced by extrusion had the highest Young's modulus, which can be explained through preferential $\langle 111\rangle$ texturing[22]. The room temeperature Young's modulus is routinely cited as $237 \mathrm{GPa}[20]$. The modulus decreases linearly with temperature, and decreases to approximately $170 \mathrm{GPa}$ at $1030^{\circ} \mathrm{C}$.

Density Lower density, especially for aerospace applications, is an important consideration. Current Ni based superalloys that use refractory metals such as Mo, W, and Re are approaching densities of up to $9 \mathrm{~g} / \mathrm{cm}^{3}$. Stoichiometric $\beta-\mathrm{NiAl}$ has a density of $5.9 \mathrm{~g} / \mathrm{cm}^{3}$. Off stoichiometric compositions have lower density towards more Al rich compositions and have higher densities towards Ni rich compositions[15].

Thermal Conductivity With the high temperatures these coatings will be exposed to, thermal conductivity is an important consideration. $\beta-\mathrm{NiAl}$ has a thermal conductivity $4-8$ times greater than current Ni based superalloys. This extremely large value of $92 \frac{W}{m K}[23]$ was a major driving force behind researching turbine blade materials based on $\beta-\mathrm{NiAl}[15]$. Having a high thermal conductivity could mean needing less active cooling of the turbine blade, which would therefore increase the operating efficiencies of the engines.

Coefficient of Thermal Expansion When considering $\beta$-NiAl for a high temperature coating the coefficient of thermal expansion becomes an important factor. As shown ear- 
lier in Figure 1.2, there are many distinct layers used in modern superalloys. Each of these layers have different coefficients of thermal expansion, so there can be some large stresses induced when the part temperature is changed from ambient to up to the operating temperature. When exposed to air at the operating temperatures of turbine engines, $\beta-\mathrm{NiAl}$ forms a protective $\mathrm{Al}_{2} \mathrm{O}_{3}$ scale. When the part is thermally cycled the stress at the $\beta-\mathrm{NiAl}-\mathrm{Al}_{2} \mathrm{O}_{3}$ interface can be enough to cause the oxide layer to spall off. Once the oxide scale has spalled off, a fresh surface is exposed for further oxidation. Figure 1.5 shows the difference in the CTE of $\beta-\mathrm{NiAl}$ and $\mathrm{Al}_{2} \mathrm{O}_{3}$ as a function of temperature.

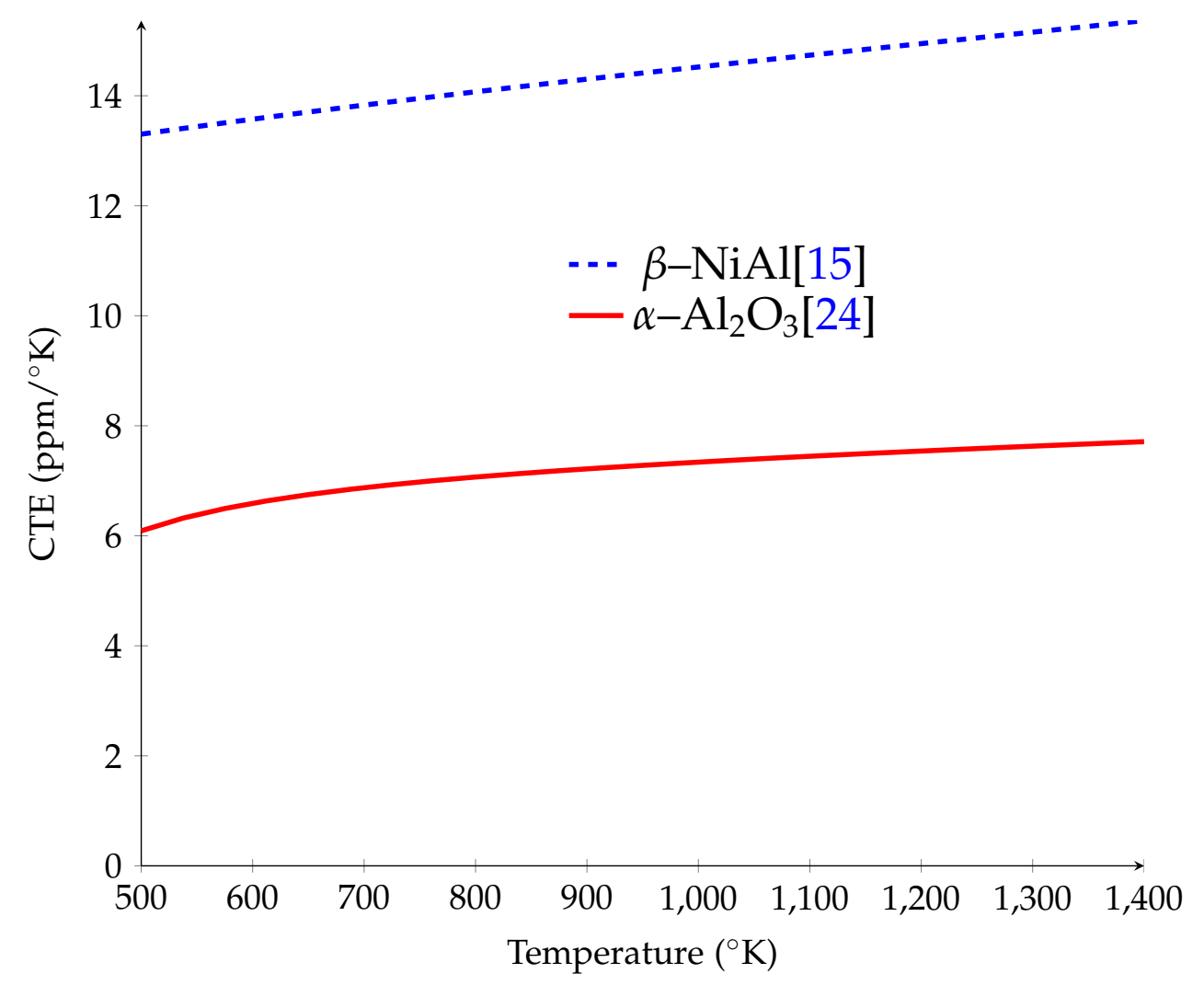

Figure 1.5: Coefficients of thermal expansion of $\mathrm{NiAl}$ and $\mathrm{Al}_{2} \mathrm{O}_{3}$ as a function of temperature

Oxidation Perhaps the most important property when considering materials for high temperature applications is oxidation resistance. Even if the material has good mechanical properties at elevated temperatures, it is useless unless it is oxidatively stable. One way to determine whether a material will have a protective oxide is to examine the Pilling-Bedworth 
ratio[25]. This ratio relates the volume of oxide formed to the volume of metal consumed.

$$
P B R_{\mathrm{NiAl}}=\frac{V_{\mathrm{Al}_{2} \mathrm{O}_{3}}}{V_{\mathrm{NiAl}}}
$$

When a system has a Pilling-Bedworth ratio above 1 the scale that is formed is under compression, and is typically protective. If the ratio is too far above 1 the scale is not protective. Prefereably the Pilling-Bedworth ratio should be under 2[26] Although the Pilling-Bedworth ratio is a good tool to estimate the kind of stress in a scale, it is not applicable when trying to determine the amount of stress in an oxide scale. The Pilling-Bedworth ratio for NiAl has been determined to be 1.67-1.78 [27], which implies that the oxide scale will be protective.

The oxidation of $\beta-\mathrm{NiAl}$ follows parabolic oxidation kinetics, which follows the rate law:

$$
\left(\frac{\Delta m}{A}\right)^{2}=k_{p} t
$$

Where $k_{p}$ is the parabolic rate constant, $t$ is time, $\Delta m$ is the mass change, and $A$ is the area of the sample. $\alpha-\mathrm{Al}_{2} \mathrm{O}_{3}$ is the stable oxide formed during high temperature oxidation of $\beta-\mathrm{NiAl}$, although several other transient oxides $\left(\gamma-\mathrm{Al}_{2} \mathrm{O}_{3}\right.$ and $\left.\theta-\mathrm{Al}_{2} \mathrm{O}_{3}\right)$ form[28]. The transformation from the transient oxides to the final stable $\alpha-\mathrm{Al}_{2} \mathrm{O}_{3}$ is sluggish at temperatures below $1000^{\circ} \mathrm{C}$, but is much faster at higher temperatures[28]. NiAl that has been doped with reactive metals ( $\mathrm{Y}, \mathrm{La}, \mathrm{Zr}$, and $\mathrm{Hf}$ ) has been shown to increase the transformation rate from transient oxides to the final $\alpha-\mathrm{Al}_{2} \mathrm{O}_{3}[29]$.

Growth stresses in the $\alpha-\mathrm{Al}_{2} \mathrm{O}_{3}$ scale were measured by Schumann et al.[30] and found to be within the experimental error, or essentially zero. Once the $\beta-\mathrm{NiAl}$ was cooled from $1150^{\circ} \mathrm{C}$ the stress of the scale was measured to be between 3.3 and $3.5 \mathrm{GPa}$ in compression[30]. This thermal stress is close to the stresses predicted by the difference in the coefficient of thermal expansion between the oxide and the underlying intermetallic.

\subsubsection{NiAl-Boride Composites}

In chapter 2 the characterization of a $\mathrm{NiAl}-\mathrm{TiB}_{2}$ composite is discussed in terms of the effect of dispersed boride particles on grain growth and oxidation. Borides have gained importance in temperature materials because of their extrodinarily high melting points, and 
low densities. Boride additions have been investigated to increase the strength and ductility of $\beta-\mathrm{NiAl}$ to make it a more suitable material for high temperature applications [31].

\subsubsection{Mechanical Properties}

Early attempts at creating a dispersion strengthened alloy by Jha and Ray[32], demonstrated an increase in the tensile strength of $\mathrm{NiAl}-\mathrm{TiB}_{2}$ composites over unmodified $\mathrm{NiAl}$ at $1033 \mathrm{~K}$. These alloys contained $0.25,1.5$, and 2 weight percent $\mathrm{TiB}_{2}$ particles and were synthesized using rapid solidification. However a later study by Whittenberger et al.[33] showed that the composites did not perform any better than fine grained NiAl. To determine the effect of dispersed boride particles on high temperature strength a study was done with both $\mathrm{HfB}_{2}$ and $\mathrm{TiB}_{2}$ particles at $2 \mathrm{wt.} \%[34]$. The study found that most, if not all of the strengthening due to dispersed $\mathrm{TiB}_{2}$ particles was due to grain refinement. $\mathrm{HfB}_{2}$ did provide additional strengthening over pure grain refinement. However, the mechanical strengthening is a com-

plex phenomenon because of the different strengthening mechanisms present. The role of particle size and spacing was not studied, so there are additional factors that could play a role.

Other studies by Wang and Arsenault[35] found that areas of NiAl around high concentrations of $\mathrm{TiB}_{2}$ particles had high dislocation densities. The $\mathrm{TiB}_{2}$ particles also had high dislocation densities, but were accompanied by a surrounding NiAl matrix of relatively low dislocation density. Although this study did not determine an exact strengthening mechanism, it did show that the situation is complex, and not fully understood.

Later work by Guo and Xing[31], produced 20 vol. $\% \mathrm{TiB}_{2}$ dispersed composites by hotpressing aided exothermic synthesis. The technique involved mixing elemental powders in appropriate amounts followed by cold pressing into a $30-40 \%$ dense compact. The green body was then put into vacuum at $300^{\circ} \mathrm{C}$ and pressed further. The whole die (graphite) was then heated to $1500^{\circ} \mathrm{C}$. This method produced dispersed $\mathrm{TiB}_{2}$ particles with a size range of $0.5-3 \mu \mathrm{m}$. No consistent orientation relationship between the $\mathrm{TiB}_{2}$ and $\mathrm{NiAl}$ was found, although most interfaces were found to be parallel to the low index plans of $\mathrm{TiB}_{2},\{01 \overline{1} 0\}$ and $\{0001\}$. Vickers hardness of the composites almost doubled compared to unmodified 
NiAl. Tensile strength, yield stress, and compressive ductility were also shown to increase compared to unmodified NiAl.

\subsubsection{Oxidation}

As discussed in section 1.3.2.3 one of the main reasons for investigating $\mathrm{NiAl}$ as a materials for high temperature applications is its oxidation resistance. The goal of most research conducted on boride dispersed $\mathrm{NiAl}$ has been to increase the strength and ductility at high temperatures. However, if the increase in mechanical properties is done at the expense of the oxidation performance, then the effort is not worthwhile.

Pregger et al.[36] studied the oxidation performance of $\mathrm{NiAl}-\mathrm{TiB}_{2}$ composites, with $\mathrm{TiB}_{2}$ content of 0,10 , and $20 \mathrm{vol}$. \%. The isothermal oxidation of the composites was performed at 1000,1100 , and $1200^{\circ} \mathrm{C}$ in dry air. The oxidation kinetics still followed a parabolic behavior, just like unmodified $\mathrm{NiAl}$, although the $\mathrm{TiB}_{2}$ containing materials gained more mass as shown in Figure 1.6. After prolonged exposure it was shown that the $\mathrm{TiB}_{2}$ containing

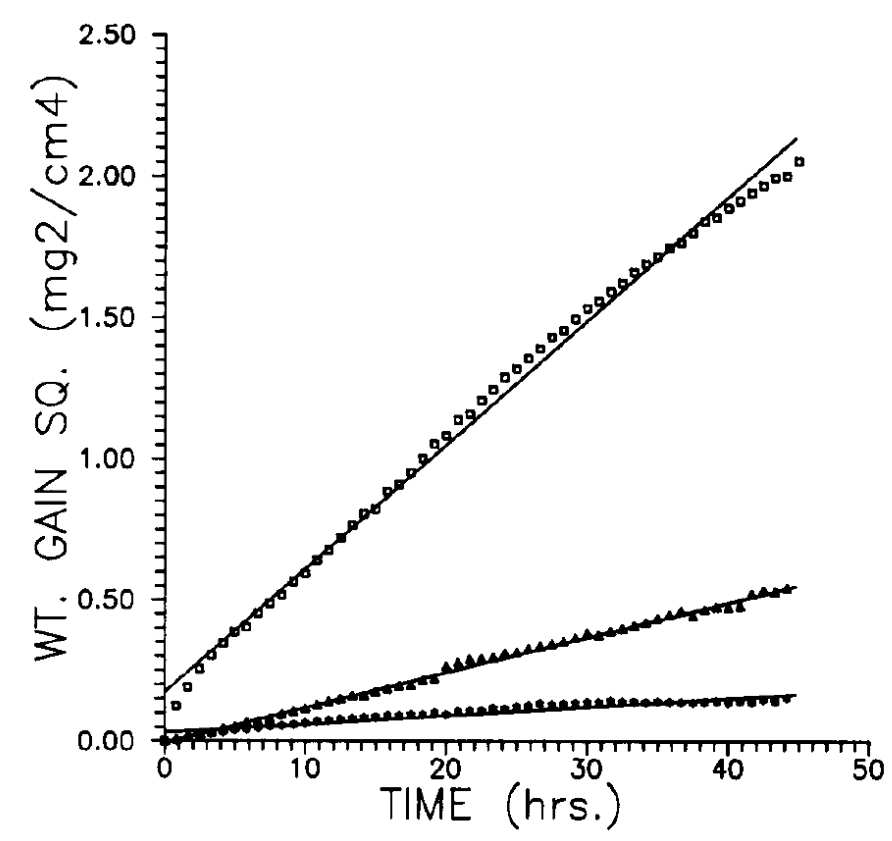

Figure 1.6: Oxidation of $\mathrm{NiAl}-\mathrm{TiB}_{2}$ Composite from [36]

samples were more prone to spallation due to void formation at the metal-oxide interface. 
The oxide scale consisted of multiple oxides, with the main species being $\mathrm{Al}_{2} \mathrm{O}_{3}$ and $\mathrm{TiO}_{2}$. The $\mathrm{TiO}_{2}$ formed on top of the $\mathrm{Al}_{2} \mathrm{O}_{3}$, in amounts that relatively corresponded to the amount of $\mathrm{TiB}_{2}$ in the alloy. Other oxides that were present according to $\mathrm{x}$-ray diffraction included $\mathrm{Al}_{5}\left(\mathrm{BO}_{3}\right) \mathrm{O}_{6}, \mathrm{Al}_{2} \mathrm{TiO}_{5}$, and $\mathrm{NiAl}_{2} \mathrm{O}_{4}$.

Overall, the oxidation of the $\mathrm{NiAl}-\mathrm{TIB}_{2}$ composites was inferior to unmodified $\mathrm{NiAl}$, due to the presence of the $\mathrm{TiB}_{2}$, which complicates the oxidation process. However, the strength of the NiAl- $\mathrm{TiB}_{2}$ composites is substantially improved from NiAl. The improvement comes from a combination of grain refinement, and introducing higher dislocation densities near the $\mathrm{TiB}_{2}$ particles. 


\section{BIBLIOGRAPHY}

[1] Matthew J Donachie. Superalloys - A Technical Guide (2nd Edition). ASM International, Materials Park, Ohio, 2002.

[2] P.K. Ray, T. Brammer, Y.Y. Ye, M. Akinc, and M.J. Kramer. A multi-stage heirarchical approach to alloy design. Journal of Materials, 62, 2010.

[3] M.J. Pomeroy. Coatings for gas turbine materials and long term stability issues. Materials and Design, 26, 2005.

[4] A.G. Evans, D.R. Mumm, J.W. Hutchinson, G.H Meier, and F.S Pettit. Mechanisms controlling the durability of thermal barrier coatings. Progress in Materials Science, 46: 505-553, 2001.

[5] Thomas E. Strangman. Thermal barrier coatings for turbine airfoils. Thin Solid Films, 127(1), 1985.

[6] S. R. Levine and R. M. Caves. Thermodynamics and kinetics of pack aluminide coating formation on IN-100. Journal of the Electrochemical Society, 121(8):1051-1064, 1974.

[7] R. Mevrel, C. Duret, and R. Pichoir. Pack cementation processes. Materials Science and Technology, 2:201-206, 1986

[8] S. Shankar and L. L. Seigle. Interdiffusion and intrinsic diffusion in the $\mathrm{NiAl}(\delta)$ phase of the Al-Ni system. Metallurgical and Materials Transactions A, 9(10):1467-1476, 1978.

[9] A. Strang, E. Lang, and R Pichoir. Practical implications of the use of aluminide coatings for the corrosion protection of superalloys in gas turbines. In Materials Substitution and Recycling, pages 11.1-11.35, 1984.

[10] Robert Bianco and Robert A. Rapp. Pack cementation aluminide coatings on superalloys: codeposition of Cr and reactive elements. J Electrochemical Society, 140(4):1181-1190, 1993. 
[11] J.R. Nicholls, N.J. Simms, W.Y. Chan, and H.E. Evans. Smart overlay coatings - concept and practice. Surface and Coatings Technology, 149(2), 2002.

[12] Okamoto H. Al-Ni (Aluminum-Nickel). Journal of Phase Equillibria and Diffusion, 14: 257-259, 1993.

[13] K. Rzyman and Z. Moser. Calorimetric studies of the enthalpies of formation of $\mathrm{Al}_{3} \mathrm{Ni}_{2}$, AlNi and $\mathrm{AlNi}_{3}$. Progress in Materials Science, 49(3):581 - 606, 2004. ISSN 0079-6425.

[14] S.V. Meschel and O.J. Kleppa. Standard enthalpies of formation of $5 \mathrm{~d}$ aluminides by high-temperature direct synthesis calorimetry. Journal of Alloys and Compounds, 197(1):75 - 81, 1993. ISSN 0925-8388.

[15] R. D. Noebe, R. R. Bowman, and M. V. Nathal. Physical and mechanical properties of the B2 compound NiAl. International Materials Reviews, 38(4):193-232, 1993-01-01T00:00:00.

[16] H.D. Dannohl and H.L Lukas. Z. Metall., 65:642, 1974.

[17] Kubaschewski O. and Dench W.A. The heats of formation in the system titaniumaluminum and titanium iron. Acta Metallurgica, 3(4):339-346, 1955.

[18] Z. W. Lu, S.-H. Wei, Alex Zunger, S. Frota-Pessoa, and L. G. Ferreira. First-principles statistical mechanics of structural stability of intermetallic compounds. Phys. Rev. B, 44: 512-544, Jul 1991.

[19] N. Rusovic and H. Warlimont. The elastic behaviour of B2-NiAl alloys. Physica Status Solidi (A), 44(2):609-619, 1977. ISSN 1521-396X.

[20] M.R. Harmouche and A. Wolfenden. Temperature and composition dependence of young's modulus in polycrystalline B2 NiAl. Journal of Testing and Evaluation, 15(2): 101-104, 1987. ISSN 1945-7553.

[21] J.R. Hellmann, D.A. Koss, C.A. Moose, R.R. Petrich, and M.N. Kallas. HITEMP Review1990. NASA, 1990. 
[22] P. Khadkikar, G. Michal, and K. Vedula. Preferred orientations in extruded nickel and iron aluminides. Metallurgical and Materials Transactions A, 21:279-288, 1990. ISSN 10735623. $10.1007 /$ BF02782408.

[23] Yoshihiro Terada, Kenji Ohkubo, Kiyotaka Nakagawa, Tetsuo Mohri, and Tomoo Suzuki. Thermal conductivity of B2-type aluminides and titanides. Intermetallics, 3(5):347 - 355, 1995. ISSN 0966-9795.

[24] Y.S. Touloukian. Thermophysical properties of high temperature solid materials. 1967.

[25] Pilling N.B. and Bedworth R.E. The oxidation of metals at high temperatures. J Inst. Met., 29(3):529-582, 1923.

[26] G. Zhang. Applications of protective ceramics, November 17 1998. US Patent 5,838,530.

[27] C. Xu and W. Gao. Pilling-bedworth ratio for oxidation of alloys. Materials Research Innovations, 3:231-235, 2000. ISSN 1432-8917. 10.1007/s100190050008.

[28] M.W. Brumm and H.J. Grabke. The oxidation behaviour of NiAl-I. phase transformations in the alumina scale during oxidation of $\mathrm{NiAl}$ and $\mathrm{NiAl}-\mathrm{Cr}$ alloys. Corrosion Science, 33(11):1677 - 1690, 1992. ISSN 0010-938X.

[29] H.J Grabke. Oxidation of NiAl and FeAl. Intermetallics, 7(10):1153 - 1158, 1999. ISSN 0966-9795.

[30] E. Schumann, C. Sarioglu, J. R. Blachere, F. S. Pettit, and G. H. Meier. High-temperature stress measurements during the oxidation of nial. Oxidation of Metals, 53:259-272, 2000.

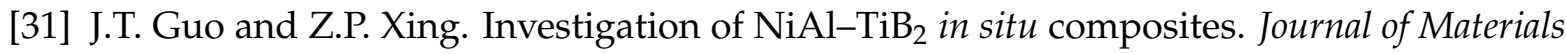
Research, 12(4):1083-1090, 1996.

[32] S. C. Jha and R. Ray. Dispersion strengthened NiAl alloys produced by rapid solidification processing. Journal of Materials Science Letters, 7:285-288, 1988. ISSN 0261-8028. 10.1007/BF01730200. 
[33] J.D. Whittenberger, D.J. Gaydosh, and K.S. Kumar. 1300 K compressive properties of several dispersion strengthened NiAl materials. Journal of Materials Science, 25:27712776, 1990.

[34] J.D. Whittenberger, R. Ray, S.C. Jha, and S. Draper. 1000-1300 K slow strain rate properties of $\mathrm{NiAl}$ containing dispersed $\mathrm{TiB}_{2}$ and $\mathrm{HfB}_{2}$. Materials Science and Engineering, $\mathrm{A} 138$ : 83-93, 1991.

[35] L. Wang and R.J. Arsenault. Microstructure of $\mathrm{TiB}_{2}-\mathrm{NiAl}$. Materials Science and Engineering, 127:91-98, 1990.

[36] B.A. Pregger, T. Kircher, and A. Khan. Oxidation behavior of a NiAl/ $\mathrm{TiB}_{2}$ intermetallic composite. Materials Science and Engineering, 153:567-572, 1992. 


\title{
CHAPTER 2. Grain Size and Oxidation Performance of a NiAl-TiB 2 Composite
}

\author{
Kevin Severs, Matt Kramer, Mufit Akinc \\ Ames Laboratory and Department of Materials Science and Engineering \\ Iowa State University, Ames, IA 50011 \\ To be submitted to: Intermetallics
}

\begin{abstract}
2.1 Abstract
A NiAl-2TiB 2 (at.\%) composite was prepared by conventional drop casting. The resulting alloy consisted of a $\beta-\mathrm{NiAl}$ matrix with $\mathrm{TiB}_{2}$ particles throughout the matrix, mostly segregating to the grain boundaries. When subjected to long term, high temperature annealing at $1300^{\circ} \mathrm{C}$, the $\mathrm{NiAl}$ grains showed little growth as compared to unalloyed NiAl. The oxidation performance of the $\mathrm{NiAl}$ was not improved by the addition of $\mathrm{TiB}_{2}$ but the performance was still adequate up to $1200^{\circ} \mathrm{C}$.
\end{abstract}

\subsection{Introduction}

High temperature alloys based on $\beta-\mathrm{NiAl}$ have gained attention in recent time because of their high melting temperature, oxidative stability, and low density. One drawback is the low fracture toughness and ductility of the $\beta-\mathrm{NiAl}$. It has been reported that the addition of $10-20$ vol. $\% \mathrm{TiB}_{2}$ of $\mathrm{HfB}_{2}$ particles can increase the strength and toughness compared to the unalloyed $\mathrm{NiAl}[1,2]$. However, this study is focusing on using NiAl as a coating material where the mechanical properties are not as much of a consideration.

Oxidation studies have been conducted on $\mathrm{NiAl}-\mathrm{TiB}_{2}$ composites, but with $\mathrm{TiB}_{2}$ content at 10-20 vol.\% [3]. Again, these studies were more concerned with using NiAl- $\mathrm{TiB}_{2}$ composites 
as a bulk material instead of a coating. The study found that the $\mathrm{NiAl}-\mathrm{TiB}_{2}$ composites were inferior to unmodified $\mathrm{NiAl}$ during high temperature oxidation, due to the large amount of $\mathrm{TiB}_{2}$, which produced a alumina-titania scale which was not entirely protective.

Synthesis of $\mathrm{NiAl}-\mathrm{TiB}_{2}$ composites is typically carried out using some form of powder processing. Bhaumik et al.[4] used elemental aluminum and nickel powders, which were subsequently ball milled to produce a master alloy powder. This master alloy was combined with the desired amount of $\mathrm{TiB}_{2}$ and pressed with a pressure of $3 \mathrm{GPa}$. The samples were then heated up to $800-900^{\circ} \mathrm{C}$ to obtain the final alloy. Through this synthesis method, the samples obtained $99.5 \%$ density, with homogeneously dispersed $\mathrm{TiB}_{2}$ particles. Guo and Xing[1] synthesized the alloys similarly to Bhaumik et al., but did not ball mill a master alloy of nickel and aluminum powders. Instead the elemental powders were pressed under 25 $\mathrm{MPa}$ of pressure and heated up to $1500^{\circ} \mathrm{C}$. This processing resulted in a composite that was $98.4 \%$ dense, and contained uniformly dispersed particles with a size between $0.5-3 \mu \mathrm{m}$.

Recent work by Brammer[5] has shown that grain size plays an important role in the oxidation kinetics of $\beta-\mathrm{NiAl}$. Brammer tested both cast and melt-spun samples of $\mathrm{NiAl}$ and found that the melt-spun samples performed better. The melt spun samples had a substantially smaller grain size than the cast samples $(126 \mu \mathrm{m}$ vs. $635 \mu \mathrm{m}$ respectively). The focus of this study is to determine how $\mathrm{TiB}_{2}$ particles can act as grain pinning agents, and their affect on oxidation.

\subsection{Experimental Details}

\subsubsection{Selection of Boride Phase}

In order to bypass a large number of experiments involving synthesizing $\mathrm{NiAl}-\mathrm{XB}_{y}(\mathrm{X}=$ transition metal) phase diagrams and formation enthalpies of many transition metal boride compounds were examined to determine the best grain pinning material. As seen in Table 2.1, $\mathrm{NiAl}$ and $\mathrm{TiB}_{2}$ have the most negative formation enthalpies of any compounds in the $\mathrm{Ni}-\mathrm{Al}-\mathrm{Ti}-\mathrm{B}$ system. From a thermodynamic standpoint, both of the compounds are the most stable, and should form. 
Table 2.1: Enthalpies of Formation of Relevant Phases in the Ni-Al-Ti-B System[6]

\begin{tabular}{cc}
\hline Compound & $\Delta \mathrm{H}_{f}(\mathrm{~kJ} / \mathrm{mol})$ \\
\hline $\mathrm{NiAl}$ & -118.4 \\
$\mathrm{TiB} 2$ & -315.9 \\
$\mathrm{NiTi}$ & -66.5 \\
$\mathrm{AlTi}$ & -75.3 \\
$\mathrm{Ni}_{3} \mathrm{~B}$ & -88.9 \\
$\mathrm{Ni}_{2} \mathrm{~B}$ & -63.8 \\
$\mathrm{AlB}_{2}$ & -16 \\
\hline
\end{tabular}

The Ti-B phase diagram is relatively simple, and has three different intermetallic compounds, with essentially no solubility in either $\mathrm{Ti}$ or $\mathrm{B}$. The highest melting boride is $\mathrm{TiB}_{2}$ $\left(3225^{\circ} \mathrm{C}\right) . \mathrm{TiB}_{2}$ also has a slight phase field width, which can be beneficial from a processing standpoint, so even if the composition is slightly off stoichiometry, the compound will still form.

Another benefit to choosing $\mathrm{TiB}_{2}$ is the advantages of $\mathrm{Ti}$ in $\beta-\mathrm{NiAl}$. Ti additions to $\mathrm{NiAl}$ around $2.5-3.0$ at.\% can reduce the creep rate by a factor of six[7][8], which is typically a concern in NiAl. So, $\mathrm{TiB}_{2}$ is a good choice for a grain pinning material because of its high melting temperature, thermodynamic stability relative to $\mathrm{NiAl}$, and benefits of $\mathrm{Ti}$ additions in NiAl.

\subsubsection{Materials}

The NiAl- $\mathrm{TiB}_{2}$ composites were formed by a multi-step arc melting and casting process. The samples contained 2 at. $\% \mathrm{TiB}_{2}$ particles in NiAl. The alloys were created by first arc melting $\mathrm{Ti}$ and Ni pieces cut from bulk metal sheets. Ni was obtained from the Materials Preparation Center (USDOE, Ames Laboratory, Ames, Iowa), Ti was from Alfa Aesar, both with a purity $99.7 \%$ or better. $\mathrm{Al}$ and $\mathrm{B}$ were then melted together by using $\mathrm{Al}$ sheets obtained from the Materials Preparation Center, and B from Alfa Aesar. The B was wrapped in the sheet of $\mathrm{Al}$ to mitigate the loss of $\mathrm{B}$ during the initial melting. The Ti and Ni were melted together. The amount of $\mathrm{Ti}$ was low enough to be able to form a solid solution with the $\mathrm{Ni}$, which was used to ensure even distribution of the $\mathrm{Ti}$, leading to uniform dispersion $\mathrm{TiB}_{2}$ 
in the composite. Each button of $\mathrm{Ni}-\mathrm{Ti}$ and $\mathrm{Al}-\mathrm{B}$ were melted three times using a nonconsumable tungsten electrode on a chilled copper hearth in an Ar atmosphere. The two buttons were then combined and re-melted three more times. These samples were then drop-cast into a $10 \mathrm{~mm}$ diameter cylinder in an Ar atmosphere. The resulting rod was cut into $5 \mathrm{~mm}$ long pieces and annealed in an inert atmosphere at $1300^{\circ} \mathrm{C}$ for times of $0,6,40,70$, and 110 hours. Isothermal oxidation was performed in ambient atmosphere in a horizontal tube furnace.

\subsubsection{Characterization}

SEM was used to characterize the microstructure of the samples. Phase analysis was performed using $x$-ray diffraction with a Philips PANalytical x-ray diffractometer (Panalytical

Almelo, Netherlands) with a Bragg-Brentano geometry and $\mathrm{Cu} \mathrm{K} \alpha 1$ radiation. Grain size of the NiAl- $\mathrm{TiB}_{2}$ compostites were determined using an AmRay 1845FE scanning electron microscope (SEM) utilizing an EDAX-TSL Delphi 2.5 Geneses model EBSD-EXX for orientation imaging microscopy (OIM). Grain size from micrographs was determined using the Lineal Intercept Procedure described in Section 11 of the ASTM E112 standard[9].

\subsection{Results and Discussion}

\subsubsection{Phase Analysis}

Before annealing the samples, XRD of powder crushed from the casting was analyzed to determine the phases present. As seen in Figure 2.1, there are only $\mathrm{NiAl}$ and $\mathrm{TiB}_{2}$ peaks present (sharp peak at $32^{\circ}$ is from contamination from mortar and pestle used to grind the powder.)

Because main peak of both the $\beta-\mathrm{NiAl}$ and $\mathrm{TiB}_{2}$ phase overlap, and the low intensity of the other $\mathrm{TiB}_{2}$ peaks the relative phase fractions were unreliable when calculated with Reitveld refinement. 


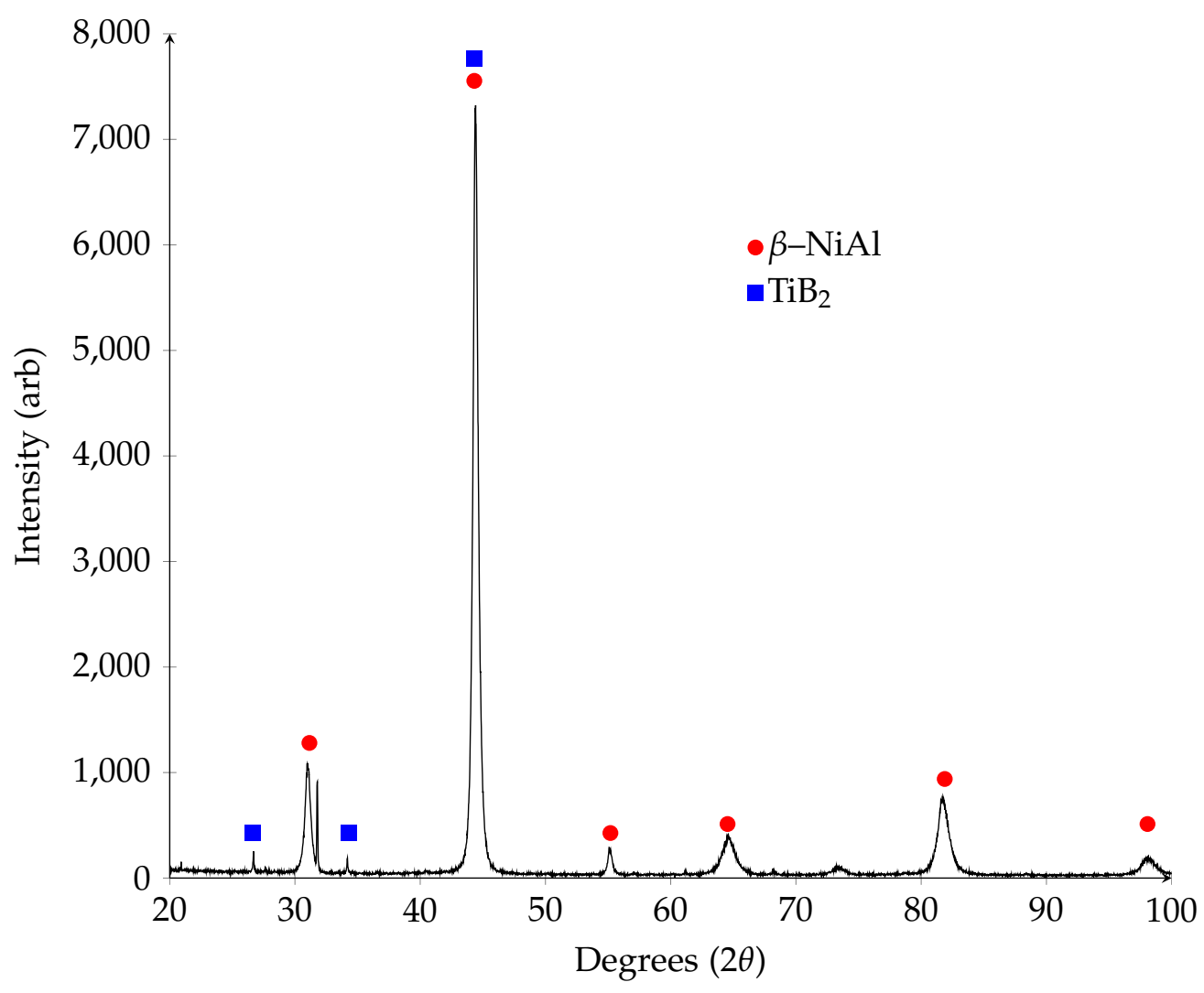

Figure 2.1: $\mathrm{XRD}$ of $\mathrm{NiAl}-\mathrm{TiB}_{2}$ Composite. $\beta-\mathrm{NiAl}$ is identified with red dots, while $\mathrm{TiB}_{2}$ is identified with blue squares

\subsubsection{Microstructure of NiAl-TiB 2 Composites}

The samples that had been annealed for the time schedule described above were examined with a SEM to determine the phase assembly and morphology of the $\mathrm{TiB}_{2}$ phase.

As seen in Figure 2.2 the $\mathrm{TiB}_{2}$ is the darker phase, while the NiAl phase is the lighter phase, as expected due to the difference in electron density of the two phases. The $\mathrm{TiB}_{2}$ phase is present in either plate or large particle morphology. The large particles range from 10$30 \mu \mathrm{m}$. These particles do not appear to coarsen appreciably during the long term annealing, and some show clear faceting. The particles with the plate like morphology as seen in Figure 2.2a where initially round, but assume a plate like morphology after 40 hours of annealing. These particles keep the plate like morphology throughout the entire annealing process.

Examining the particles closer in Figure 2.3 shows that the particles remain thin $(<1 \mu \mathrm{m})$, and only grow in the long direction. $\mathrm{TiB}_{2}$ is hexagonal (Space group $\mathrm{P6} / \mathrm{mmm}$ ), so these 


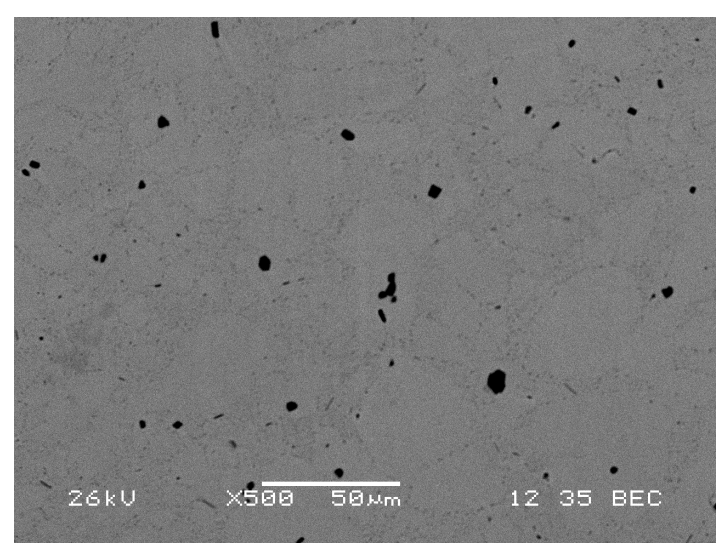

(a) 6 hours

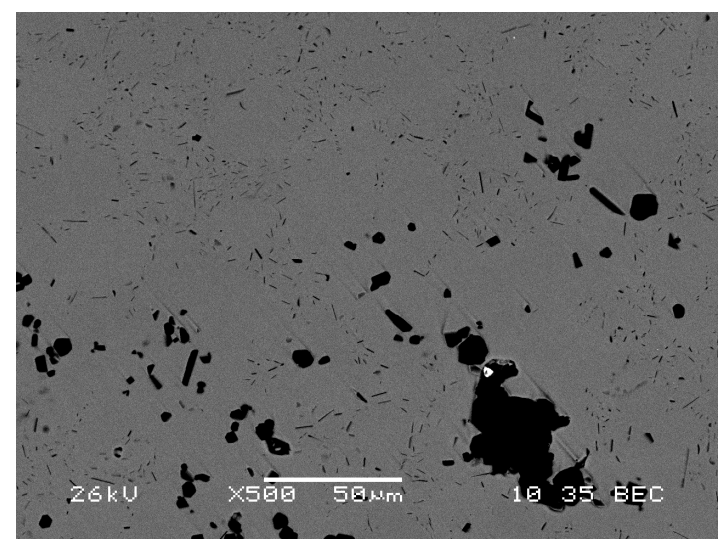

(c) 70 hours

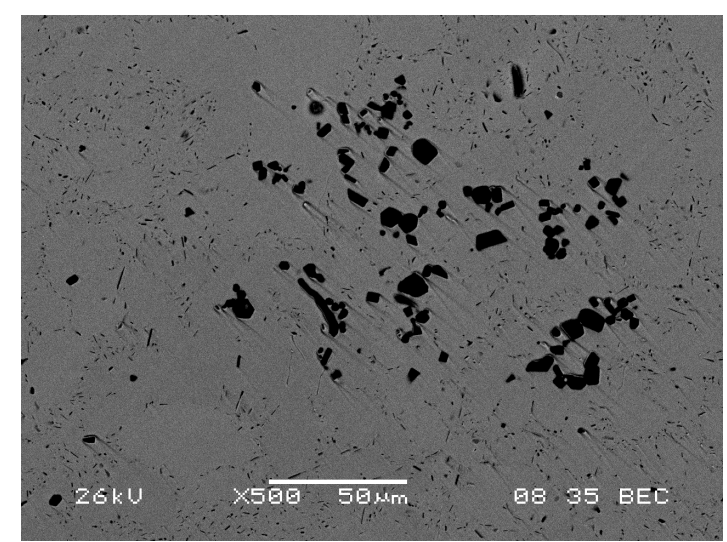

(b) 40 hours

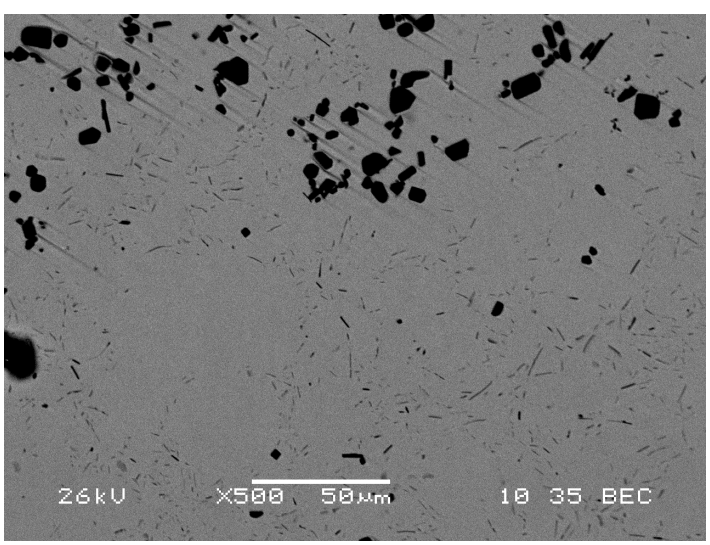

(d) 110 hours

Figure 2.2: $\mathrm{SEM}$ of Annealed $\mathrm{NiAl}-\mathrm{TiB}_{2}$ Composites. Notice that the large $\mathrm{TiB}_{2}$ phases remain approximately the same size. The samller $\mathrm{TiB}_{2}$ particles are initially spherical, but coarsen to a plate-like morphology at 40 hours, at which point growth slows substantially.

particles are most likely growing in the basal plane direction.

Between the plate-like $\mathrm{TiB}_{2}$ particles there is a noticeable absence of other $\mathrm{TiB}_{2}$ particles, leaving just NiAl. This information combined with the fact that the $\mathrm{TiB}_{2}$ particles grow in the one direction suggests that the plate morphology $\mathrm{TiB}_{2}$ particles decorate the grain boundaries. To determine if this is the case OIM was conducted on the samples to determine the $\mathrm{NiAl}$ grain structure. 


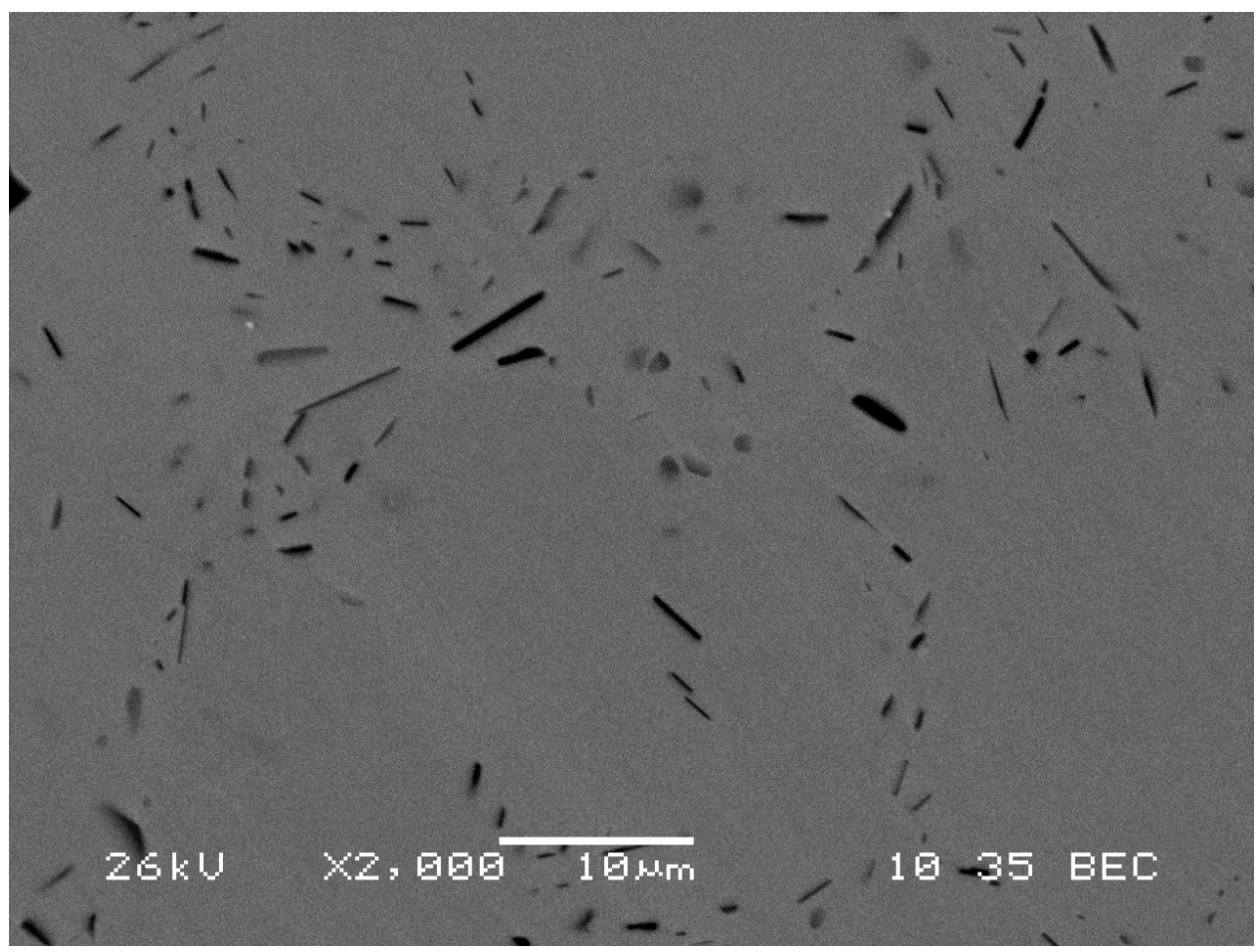

Figure 2.3: $\mathrm{NiAl}-\mathrm{TiB}_{2}$ Composite: $1300^{\circ} \mathrm{C}$ Anneal for 70 hours

\subsubsection{OIM and Grain Size}

The microstructures of the $\mathrm{NiAl}-\mathrm{TiB}_{2}$ composites appear as if the $\mathrm{TiB}_{2}$ particles decorate the grain boundaries of the $\mathrm{NiAl}$, due to their morphology and location within the sample. To confirm this observation, OIM was performed on the 70 hour sample to determine the location of the $\mathrm{TiB}_{2}$ and the grain size of the composite.

Figure 2.4 highlights the grain boundaries of the NiAl. The grains are approximately an order of magnitude finer than cast $\mathrm{NiAl}(635 \mu \mathrm{m}[5])$.

Figure 2.5 shows phase analysis of the $\mathrm{NiAl}$ and $\mathrm{TiB}_{2}$ at $1500 \mathrm{x}$. Comparing the images shows that the $\mathrm{TiB}_{2}$ particles are mostly located at the grain boundaries, with some located intragranularly. By examining the previous SEM images, the plate-like $\mathrm{TiB}_{2}$ particles are located at the grain boundaries, while the larger particles are located within the grains. The intragranular $\mathrm{TiB}_{2}$ would form first during the solidification process and provide a nucleation site for the NiAl to start solidifying, which is why they are present at the interior of the grain. These initial $\mathrm{TiB}_{2}$ particles would begin to solidify at a much higher temperature than $\mathrm{NiAl}$, 


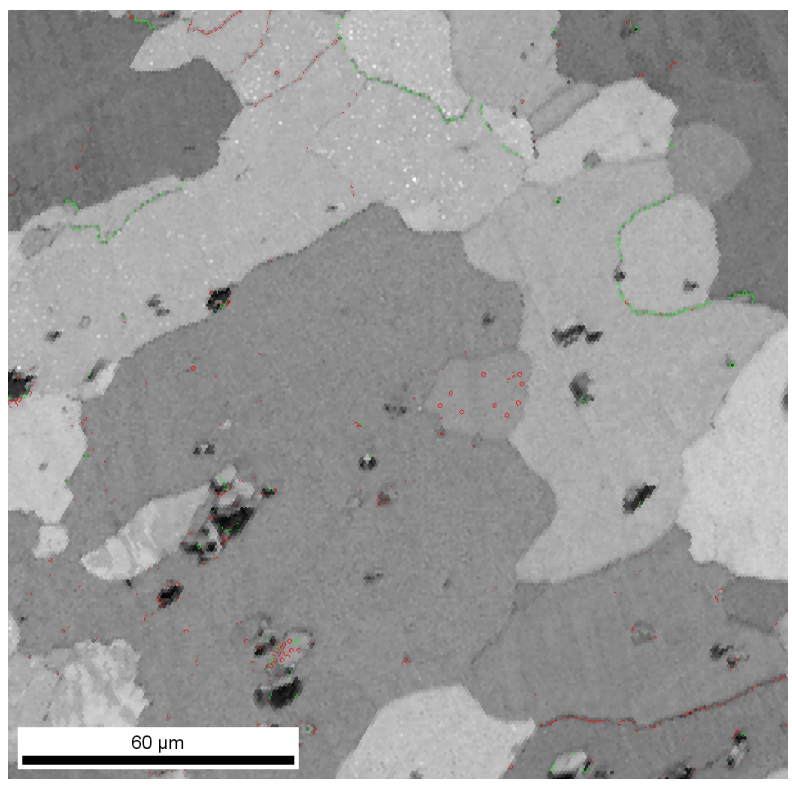

Figure 2.4: $\mathrm{OIM}$ of $\mathrm{NiAl}-\mathrm{TiB}_{2}$ Composite, highlighting the grains of $\beta-\mathrm{NiAl}$. 500x

and would continue to grow throughout the solidification process. The NiAl would start to solidify and push the $\mathrm{B}$ and $\mathrm{Ti}$ solutes [10] out resulting in $\mathrm{TiB}_{2}$ the the grain boundaries (Ti has $10 \%$ solubility in $\mathrm{NiAl}[11])$.

The grain size of the composites throughout the annealing procedure at $1300^{\circ} \mathrm{C}$ is shown in Figure 2.6 compared to annealing of NiAl-9\% Ir+Hf alloy from work by Brammer. The $\mathrm{TiB}_{2}$ particles substantially decrease the grain size of the $\mathrm{NiAl}$ and effectively pin the grains. There is grain growth over time as seen in the SEM micrographs, but the grains stay much smaller than unmodified NiAl. These small grains are not ideal for creep resistance, but this alloy is being developed for use in a coating, so small creep properties of the coating are not a serious concern. As stated earlier, the addition of $\mathrm{Ti}$ to $\mathrm{NiAl}$ increases the creep resistance, so the loss in creep strength due to the small grains will be somewhat mitigated by the addition of Ti. However, smaller grained NiAl is has higher strength compared to larger grained NiAl. For ideal grain growth the temperature dependant growth constant $k$ can be determined by[10]

$$
d^{2}-d_{0}^{2}=k t
$$

The grain growth constant for the $\mathrm{NiAl}-\mathrm{TiB}_{2}$ alloys was calculated and compared to the alloys 


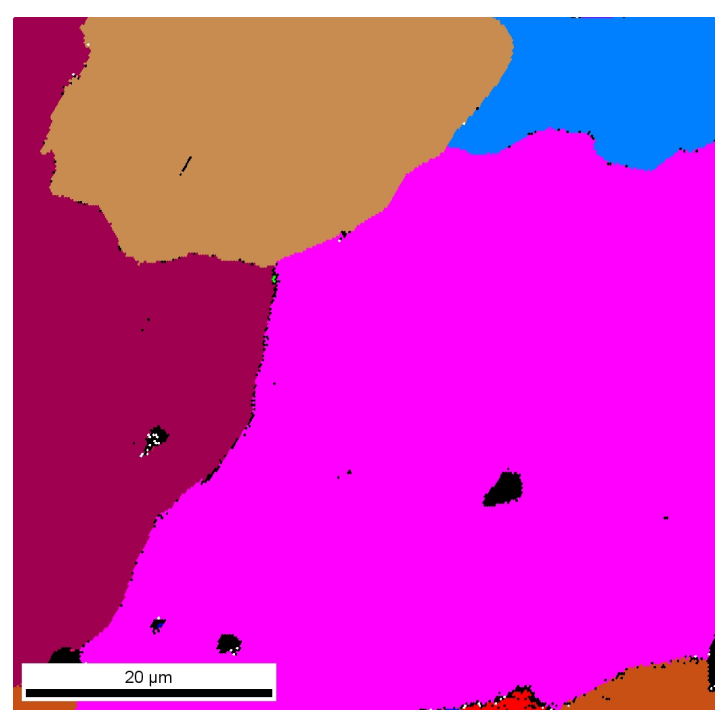

(a) $\mathrm{NiAl}$

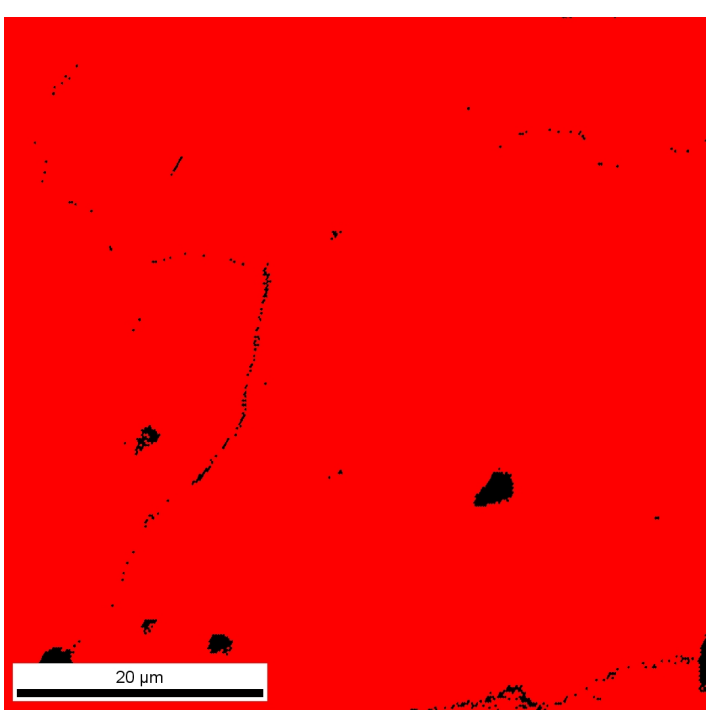

(b) $\mathrm{TiB}_{2}$

Figure 2.5: OIM Phase Analysis of $\mathrm{NiAl}-\mathrm{TiB}_{2}$ Composite. (a) Highlights the $\beta-\mathrm{NiAl}$ grains in various colors. (b) indicated the $\mathrm{TiB}_{2}$ phase in black.

prepared by Brammer[5] in Table 2.2 There is almost an order of magnitude reduction in

Table 2.2: Grain Growth Constant Comparison of this $\mathrm{NiAl}-\mathrm{TiB}_{2}$ composite compared to NiAl-9\%Ir+Hf alloy produced by Brammer[5]

\begin{tabular}{lc}
\hline Material & $k\left(\mu \mathrm{m}^{2} / \mathrm{hr}\right)$ \\
\hline NiAl-9\%Ir+Hf & $327[5]$ \\
NiAl-TiB 2 & 3.7
\end{tabular}

the temperature dependant growth constant, $k$, which shows that $\mathrm{TiB}_{2}$ particles are more effective at pinning grains than the addition of both Ir and Hf.

Although the $\mathrm{TiB}_{2}$ particles are not spherical, there is a model which predicts the maximum grain size of a given material that has grains pinned by secondary particles:[12, 10]

$$
\bar{D}_{\max }=\frac{4 r}{3 f}
$$

where $r$ is the radius of the secondary particles and $f$ is the volume fraction. The volume fraction of $\mathrm{TiB}_{2}$ particles was found to be $7 \%$ by analyzing Figure 2.3, using a superimposed $25 \times 25$ grid. Using this information in conjunction with a maximum grain size of $28 \mu \mathrm{m}$, found from the annealing study, the radius of the particles was estimated to be $1.5 \mu \mathrm{m}$. Although, 


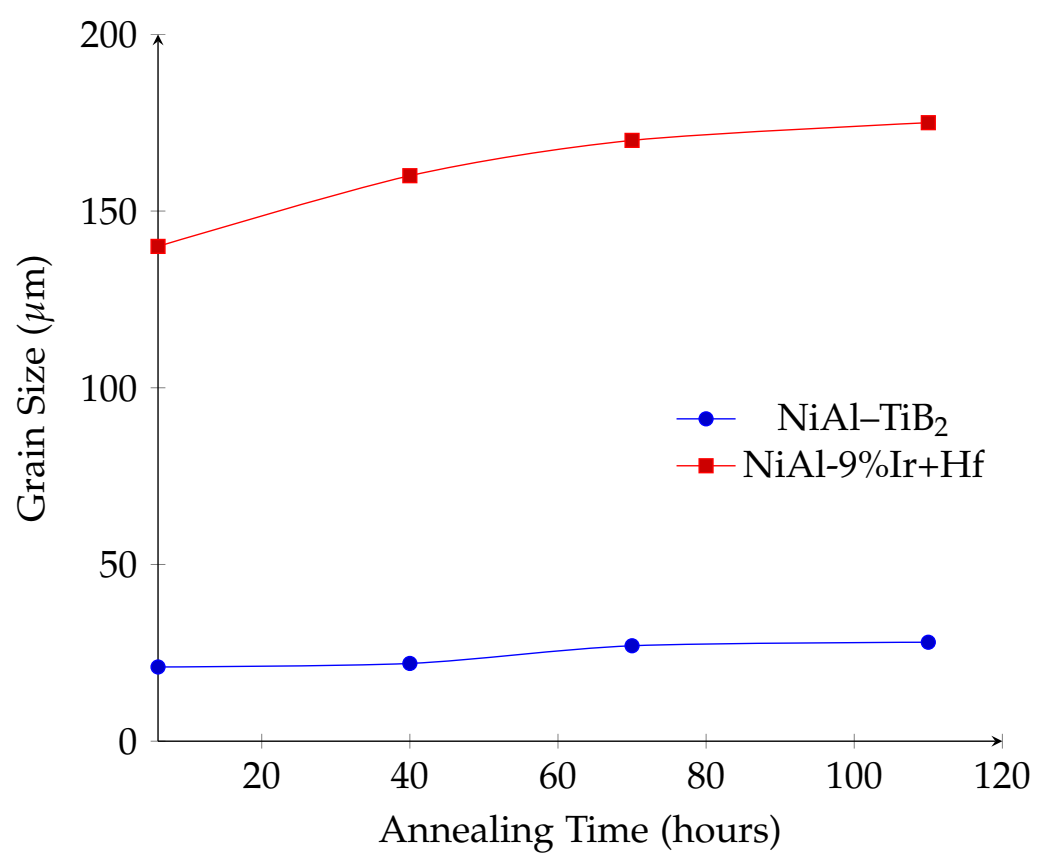

Figure 2.6: Grain Growth Kinetics of this $\mathrm{NiAl}-\mathrm{TiB}_{2}$ composite compared to NiAl-9\%Ir+Hf as synthesized by Brammer[5]

this model is for spherical particles, it does give a reasonable approximation for the size of the $\mathrm{TiB}_{2}$ features, which indicates that the $\mathrm{TiB}_{2}$ particles are pinning the grain boundaries.

\subsubsection{Oxidation of $\mathrm{NiAl}-\mathrm{TiB}_{2}$}

The NiAl- $\mathrm{TiB}_{2}$ composites were isothermally oxidized at $1100^{\circ} \mathrm{C}$ and $1200^{\circ} \mathrm{C}$ to see the effect of adding $\mathrm{TiB}_{2}$ to the oxidation performance of NiAl. At these temperatures NiAl forms a protective $\alpha-\mathrm{Al}_{2} \mathrm{O}_{3}$ scale, while $\mathrm{TiB}_{2}$ forms $\mathrm{TiO}_{2}$ and gaseous $\mathrm{B}_{2} \mathrm{O}_{3}[13]$.

\subsubsection{XRD}

Xray diffraction of both samples found $\alpha-\mathrm{Al}_{2} \mathrm{O}_{3}$ and $\beta-\mathrm{NiAl}$. No other oxides were detected on either coupon.

$1100^{\circ} \mathrm{C}$ After 24 hours of oxidation at $1100^{\circ} \mathrm{C}$ the $\mathrm{NiAl}^{-\mathrm{TiB}_{2}}$ composite had a mass change of $.05 \mathrm{mg} / \mathrm{cm}^{2}$. The oxidation of $\mathrm{NiAl}-\mathrm{TiB}_{2}$ composites is parabolic[3] and follows 
the relationship:

$$
\left(\frac{\Delta m}{A}\right)^{2}=k_{p} t
$$

Where $k_{p}$ is the parabolic rate constant. This mass gain corresponds to a $k_{p}$ of $0.0106 \mathrm{mg}^{2} \mathrm{~cm}^{-4}$ $\mathrm{h}^{-1}$. Pregger et al.[3] found the parabolic rate constant of a $10 \mathrm{vol} . \% \mathrm{NiAl}-\mathrm{TiB}_{2}$ composite to be $.0124 \mathrm{mg}^{2} \mathrm{~cm}^{-4} \mathrm{~h}^{-1}$, so the slightly smaller $k_{p}$ agrees with the literature. Grabke[14] found the parabolic rate constant of unmodified $\beta-\mathrm{NiAl}$ to be $3 \cdot 6 \cdot 10^{-4} \mathrm{mg}^{2} \mathrm{~cm}^{-4} \mathrm{~h}^{-1}$. The rate constant of the $\mathrm{NiAl}-\mathrm{TiB}_{2}$ composite is approximately 30 times larger than the unmodified $\mathrm{NiAl}$, so although the grain sizes are smaller, the addition of the $\mathrm{TiB}_{2}$ particles is negatively effecting the oxidation rates.

SEM The surface of the $\mathrm{NiAl}-\mathrm{TiB}_{2}$ composite that had been oxidized at $1100^{\circ} \mathrm{C}$ had a scale that was mostly intact throughout the entire surface. There were some small areas that exhibited spallation shown in 2.7a, but they were limited. Because the spalled scale

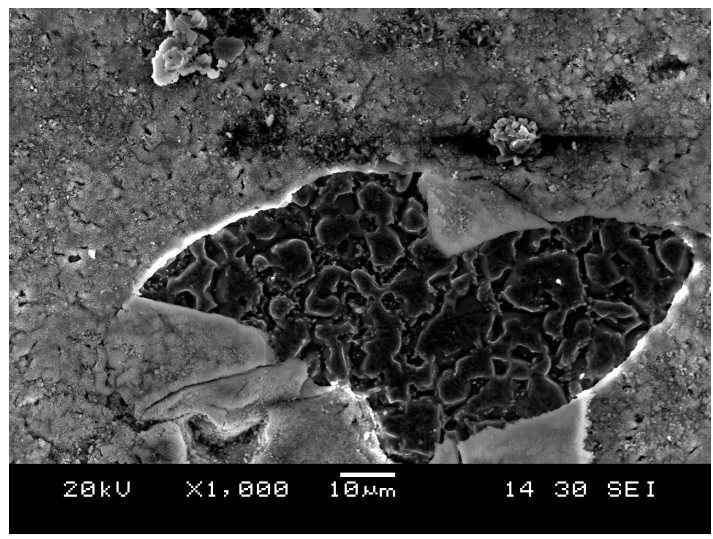

(a) Spalled Scale

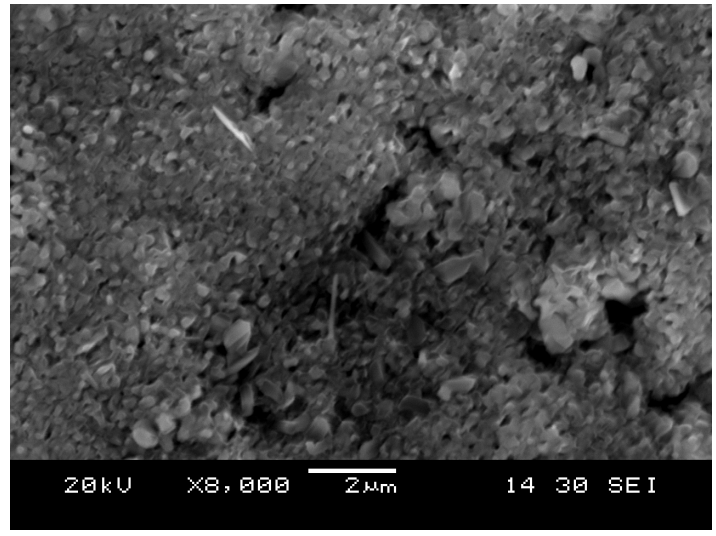

(b) Intact Scale

Figure 2.7: Coupon Surface after $1100^{\circ} \mathrm{C}$ Oxidation. The areas of spallation shown in (a) were very limited on the surface of the sample. The majority of the surface had a morphology consistent with (b)

was very limited, the estimation of the rate constant from the weight gain is still valid. EDS of the area beneath the spalled scale had a composition of 40.35 at.\% $\mathrm{Al}, 1.86$ at.\% $\mathrm{Ti}$, and 57.79 at.\% Ni. B was not quantified. The depleted amounts of $\mathrm{Al}$ and Ti compared to the starting nominal values are a result from the formation of the oxide scale. Chemical analysis of the 
oxide scale found mostly $\mathrm{Al}$ (94.92 at.\%) with small amount of $\mathrm{Ni}$ and Ti. This corresponds with a scale that is primarily $\mathrm{Al}_{2} \mathrm{O}_{3}$. The scale itself was composed of small plate like particles ranging from submicron size up to $1 \mu \mathrm{m}$ as seen in $2.7 \mathrm{~b}$ From examining the cross section of the oxidized coupon the scale was primarily composed of $\mathrm{Al}_{2} \mathrm{O}_{3}$, with some $\mathrm{TiO}_{2}$. When the $\mathrm{Al}_{2} \mathrm{O}_{3}$ scale was near a $\mathrm{TiB}_{2}$ particle, there was some subscale voids. The voids can decrease the adherence of the scale, which would lead to the spalling that was seen. Ti has been shown to diffuse through the $\mathrm{Al}_{2} \mathrm{O}_{3}$ scale[3] and form $\mathrm{TiO}_{2}$ on top of the $\mathrm{Al}_{2} \mathrm{O}_{3}$. At this temperature boron will form $\mathrm{B}_{2} \mathrm{O}_{3}$, which is known to volatilize at these temperatures[13]. These two mechanisms can explain the void formation between the $\mathrm{Al}_{2} \mathrm{O}_{3}$ and the NiAl- $\mathrm{TiB}_{2}$. Figure 2.8 shows the cross section of the oxide scale near $\mathrm{TiB}_{2}$ particles. The right portion

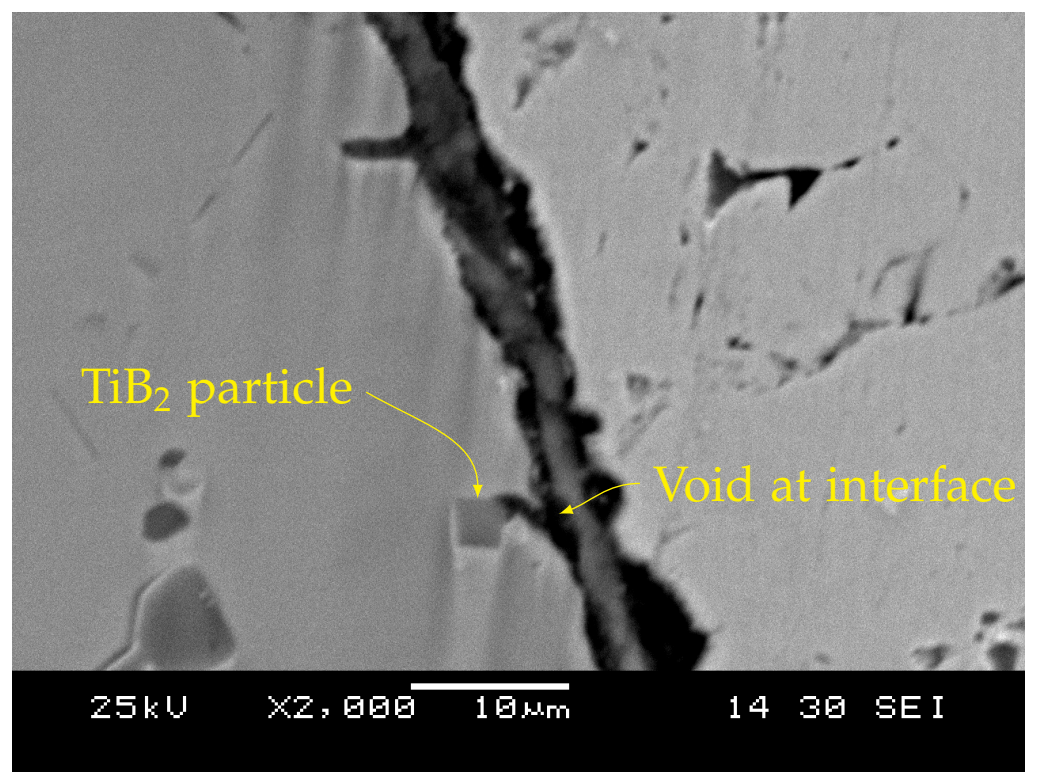

Figure 2.8: Cross Section of Oxide Scale at $1100^{\circ} \mathrm{C}$. The oxide is primarily $\mathrm{Al}_{2} \mathrm{O}_{3}$ with some Ti. There is an exposed $\mathrm{TiB}_{2}$ particle that has not been completely oxidized. There is some void formation underneath the $\mathrm{Al}_{2} \mathrm{O}_{3}$ scale where the $\mathrm{TiB}_{2}$ particle was present.

of the image is copper plating used to keep the oxide scale intact. The left is the $\mathrm{NiAl}-\mathrm{TiB}_{2}$ composite. A $\mathrm{TiB}_{2}$ particle can be seen near the surface with a void underneath the $\mathrm{Al}_{2} \mathrm{O}_{3}$ scale. EDS of the scale showed small amounts of $\mathrm{Ti}$, although XRD did not detect and $\mathrm{TiO}_{2}$. The small amount of $\mathrm{TiO}_{2}$ could be below the detection limit, or the $\mathrm{Ti}$ did not have enough time to diffuse through to the surface to form $\mathrm{TiO}_{2}$. The oxide scale itself is approximately 
$3 \mu \mathrm{m}$ thick, which is similar to unmodified $\beta-\mathrm{NiAl}[5]$. The main difference in the oxide scale between unmodified $\beta-\mathrm{NiAl}$ and this $\mathrm{NiAl}-\mathrm{TiB}_{2}$ composite is the $\mathrm{Ti}$ in the scale and the void formation under the oxide scale.

$1200^{\circ} \mathrm{C}$ After 24 hours of oxidation at $1200^{\circ} \mathrm{C}$ the $\mathrm{NiAl}-\mathrm{TiB}_{2}$ composite had a mass change of $-0.05 \mathrm{mg} / \mathrm{cm}^{2}$. Once the alloy had cooled down some of the scale spalled off, which lead to the mass loss. The spallation of the scale makes estimation of the parabolic rate constant impossible. Brammer[5] found that after isothermal oxidation at $1200^{\circ} \mathrm{C}$ that unmodified $\beta-\mathrm{NiAl}$ exhibited scale spallation, so the spallation exhibited by the $\mathrm{NiAl}-\mathrm{TiB}_{2}$ composite was not unexpected.

SEM As expected from the weight loss during isothermal oxidation, the oxide scale exhibited much more spallation than the sample oxidized at $1200^{\circ} \mathrm{C}$. As seen in 2.9 a the scale has spalled off, exposing the underlying material. The lack of oxidation on the surface of the spalled areas indicates that the scale had spalled off upon cooling when the temperature was low enough to limit any further oxidation on the surface. EDS of the exposed area

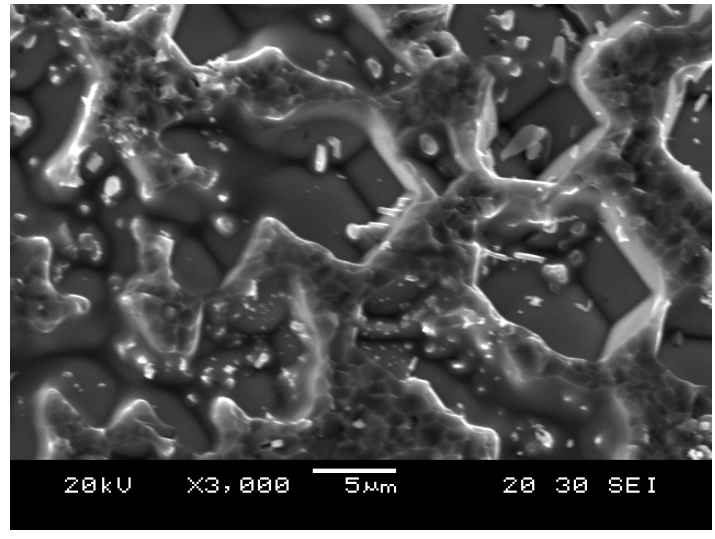

(a) Spalled Scale

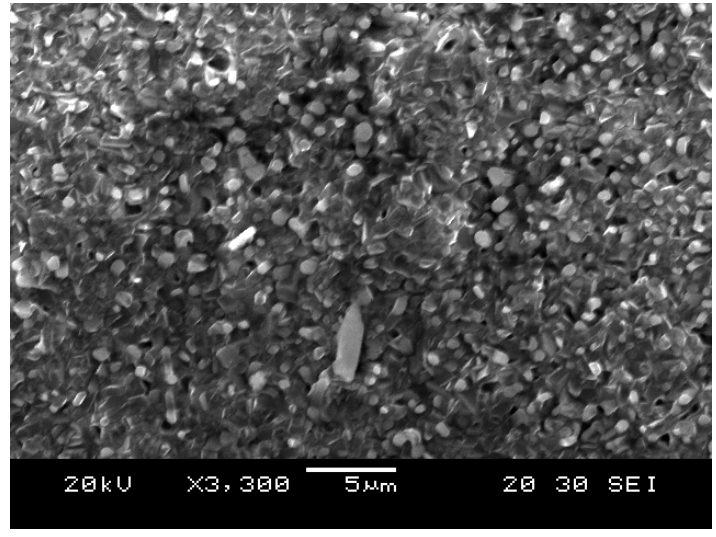

(b) Intact Scale

Figure 2.9: Coupon Surface after $1200^{\circ} \mathrm{C}$ Oxidation. Regions as shown in (a) are much more common than at $1100^{\circ} \mathrm{C}$. All areas that had the scale intact had the appearance of $(b)$

consisted of $\mathrm{Ni}$ and $\mathrm{Al}$ close to a 1:1 ratio, but slightly $\mathrm{Ni}$ rich, which is consistent with $\mathrm{Al}$ consumption from oxidation. The oxide scale itself was much more coarse then at $1100^{\circ} \mathrm{C}$ 
with the oxides exhibiting two distinct morphologies. Plate particles were still present, but there were also more spherical particles. The plate like particles had a composition consistent with $\mathrm{Al}_{2} \mathrm{O}_{3}$, while the spherical particles had a composition closer to a mix of $\mathrm{TiO}_{2}$ and $\mathrm{Al}_{2} \mathrm{O}_{3}$ shown in Table 2.3. The particle sizes were small so accurate quantification of the spherical

Table 2.3: EDS of Spherical Oxide Particles shown in 2.9b

\begin{tabular}{ccc}
\hline Element & at.\% & wt.\% \\
\hline $\mathrm{Al}$ & 77.52 & 65.46 \\
$\mathrm{Ti}$ & 20.02 & 30.01 \\
$\mathrm{Ni}$ & 2.46 & 4.52 \\
\hline
\end{tabular}

particles was difficult because of the interaction volume of the electron beam, which would also interact with the $\mathrm{Al}_{2} \mathrm{O}_{3}$. Figure $2.9 \mathrm{~b}$ shows a region of the oxide scale that was still intact. Examining the cross section of the oxide scale showed that it was thicker than the oxide scale that formed at $1100^{\circ} \mathrm{C}$. Figure 2.10 shows the oxide scale, with copper plating on the top of the image. There were numerous other areas where no oxide was present, as seen in the examination of the coupon surface. The scale is substantially thicker than seen in unmodified $\beta-\mathrm{NiAl}$, most likely due to formation of $\mathrm{TiO}_{2}$ at the surface.

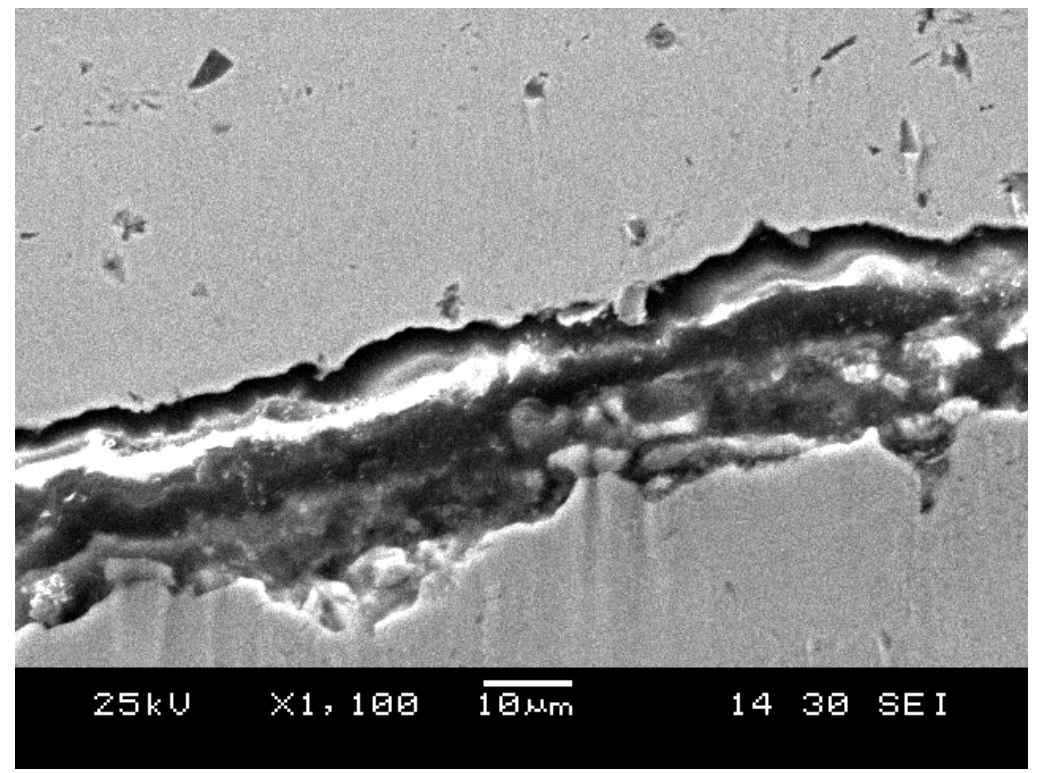

Figure 2.10: Cross Section of $1200^{\circ} \mathrm{C}$ Oxide Scale. The oxide is much thicker compared to $1100^{\circ} \mathrm{C}$ 


\subsection{Conclusions}

A two phase NiAl- $\mathrm{TiB}_{2}$ composite was synthesized using a two step arc melting process followed by drop casting. The resulting alloy consisted of a $\beta-\mathrm{NiAl}$ matrix with small $\mathrm{TiB}_{2}$ particles that consisted of two different morphologies. Larger $(10-30 \mu \mathrm{m})$ faceted particles were present within the grains, while smaller plate like $\mathrm{TiB}_{2}$ particles were present at the grain boundaries, which was confirmed with OIM. The $\mathrm{TiB}_{2}$ was an effective grain pinning agent, and suppressed grain growth during long annealing times at $1300^{\circ} \mathrm{C}$. No interaction between the $\mathrm{NiAl}$ and $\mathrm{TiB}_{2}$ took place during the long term annealing.

Oxidation of the NiAl-TiB 2 composites was not as good as the unmodified NiAl. Although the grain size of the composite was smaller, which would improve oxidation performance, the addition of $\mathrm{TiB}_{2}$ particles complicated the oxidation. Rather than just pure $\mathrm{Al}_{2} \mathrm{O}_{3}$ forming, an oxide scale consisting of both $\mathrm{Al}_{2} \mathrm{O}_{3}$ and $\mathrm{TiO}_{2}$ formed. At $1100^{\circ} \mathrm{C}$ the oxide scale was mostly $\mathrm{Al}_{2} \mathrm{O}_{3}$ with almost no $\mathrm{TiO}_{2}$. The $\mathrm{Ti}$ that was present was in the $\mathrm{Al}_{2} \mathrm{O}_{3}$ scale.. At $1200^{\circ} \mathrm{C} \mathrm{Al}_{2} \mathrm{O}_{3}$ was still the main oxide, $\mathrm{TiO}_{2}$ was more prevalent than at $1100^{\circ} \mathrm{C}$, but still in small amounts.

The presence of $\mathrm{TiB}_{2}$ complicated the oxidation process with $\mathrm{B}$ becoming volatile $\mathrm{B}_{2} \mathrm{O}_{3}$ and Ti diffusing through the $\mathrm{Al}_{2} \mathrm{O}_{3}$ scale. These two processes promoted void formation at the metal oxide interface. These voids make the scale less adherent, which can promote scale spallation, especially during cyclic oxidation conditions.

Although the oxidation of the $\mathrm{NiAl}-\mathrm{TiB}_{2}$ composite is not as good as unmodified $\beta-\mathrm{NiAl}$, the composite still has some interesting properties that can make it useful. The limited grain size, and subsequent grain growth strengthen the material, which can make it attractive for applications without such harsh oxidation conditions. The limited grain growth allows the composite to retain its strength over long intervals at high temperatures. 


\section{BIBLIOGRAPHY}

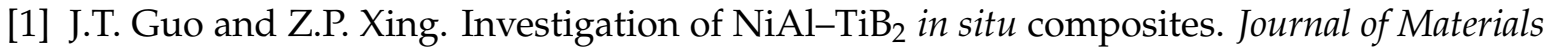
Research, 12(4):1083-1090, 1996.

[2] L. Wang and R.J. Arsenault. Microstructure of $\mathrm{TiB}_{2}-\mathrm{NiAl}$. Materials Science and Engineering, 127:91-98, 1990.

[3] B.A. Pregger, T. Kircher, and A. Khan. Oxidation behavior of a NiAl/ $\mathrm{TiB}_{2}$ intermetallic composite. Materials Science and Engineering, 153:567-572, 1992.

[4] SK Bhaumik, C. Divakar, L. Rangaraj, and AK Singh. Reaction sintering of nial and tib ${ }_{2}$-nial composites under pressure. Materials Science and Engineering: A, 257(2):341348, 1998.

[5] Travis Brammer. Improving the phase stability and oxidation resistance of $\beta-\mathrm{NiAl}$. Master's thesis, Iowa State University, 2011.

[6] K. Rzyman and Z. Moser. Calorimetric studies of the enthalpies of formation of $\mathrm{Al}_{3} \mathrm{Ni}_{2}$, AlNi and $\mathrm{AlNi}_{3}$. Progress in Materials Science, 49(3):581 - 606, 2004. ISSN 0079-6425.

[7] P.H. Kitabjan, A. Garg, R.D. Noebe, and W.D. Nix. submitted to the 7th int. cond. on creep and fracture of engineering materials and structures (CFEMS). In Mat. Res. Soc. Symp. Proc., volume 463, 1997.

[8] J Daniel Whittenberger, Ronald D Noebe, and Ram Darolia. Elevated temperature creep deformation in solid solution strengthened $\langle 001\rangle$ NiAl-3.6Ti single crystals. Materials Science and Engineering: A, 367(1):143 - 151, 2004. ISSN 0921-5093.

[9] ASTM. Standard test methods for determining average grain size. In E 112-10. Philadelphia, Pa., 2010.

[10] David A. Porter, Kenneth E. Easterling, and Mohamed Y. Sherif. Phase Transformations in Metals and Alloys. CRC Press, 2009. ISBN 9781420062106. 
[11] G.K. Dey, A. Arya, and J.A. Sekhar. Micropyretic synthesis of NiAl containing Ti and B. Journal of Materials Reaearch, 15:63-75, 2000.

[12] T. Gladman. On the theory of the effect of precipitate particles on grain growth in metals. Proceedings of the Royal Society of London. Series A, Mathematical and Physical Sciences, 294 (1438):pp. 298-309, 1966.

[13] Y.H. Koh, S.Y. Lee, and H.E. Kim. Oxidation behavior of titanium boride at elevated temperatures. Journal of the American Ceramic Society, 84(1):239-241, 2001.

[14] H.J Grabke. Oxidation of NiAl and FeAl. Intermetallics, 7(10):1153 - 1158, 1999. ISSN 0966-9795. 


\title{
CHAPTER 3. Improvement of Oxidation Performance of Mo-Ni-Al Alloys by Pack Cementation
}

\author{
Kevin Severs, Matt Kramer, \& Mufit Akinc \\ Ames Laboratory and Department of Materials Science and Engineering \\ Iowa State University, Ames, IA 50011 \\ To be submitted to: Surface and Coatings Technology
}

\begin{abstract}
3.1 Abstract
$\beta-\mathrm{NiAl}$ has shown promise as a high temperature structural material because of its low density, high melting temperature, and good oxidative stability. However, the low fracture toughness of unmodified $\beta-\mathrm{NiAl}$ limits its use. In order to use $\beta-\mathrm{NiAl}$ as a high temperature structural material, alloying additions must be made. The work of Ray et al.[1] has shown that alloys based on the Mo-Ni-Al system show promise. However, the high temperature oxidation of the alloy system described in Ray et al. is inferior to $\beta-\mathrm{NiAl}$ due to Mo forming volatile $\mathrm{MoO}_{3}$ at temperatures above $700^{\circ} \mathrm{C}$. A coating strategy based on electroplating and subsequent pack cementation was developed to attain a coating of $\beta-\mathrm{NiAl}$ on top of the Mo-Ni-Al base alloy. This coating process can produce consistent coatings regardless of the composition of the base alloy. Isothermal oxidation performance at 100 hours at $1200^{\circ} \mathrm{C}$ was significantly improved by the addition of the coating.
\end{abstract}

\subsection{Introduction}

Oxidation resistance of high temperature alloys is extremely important in the ability of the alloy to provide long service life at high temperatures. With the goal of increasing operating 
temperatures to about $1300^{\circ} \mathrm{C}$, current $\mathrm{Ni}$-base superalloys will not meet the requirements due to low incipient melting points [2]. Alloys produced by Ray et al.[1] based on the Mo$\mathrm{Ni}-\mathrm{Al}$ system have the capability to run at high temperatures $\left(\mathrm{T}_{\text {eutectic }}=1600^{\circ} \mathrm{C}\right)$, but lack oxidation resistance due to the (Mo) that volatilizes at temperatures above $700^{\circ} \mathrm{C}$ to form $\mathrm{MoO}_{3}$. Even in current Ni-base superalloys, the inherent oxidation resistance is not sufficient, and requires a coating [3]. Improvement in oxidation performance usually involves additions of elements that form stable oxides ( $\mathrm{Al}, \mathrm{Si}, \mathrm{Cr})$ or reactive elements $(\mathrm{Y}, \mathrm{Zr}, \mathrm{Hf})[4]$. While this technique helps the oxidation, another method is to use a protective coating on the alloy. Coating methods include thermal spray[5], CVD[6], and pack cementation[7, 8, 4, 9, 10]. These coating methods develop an intermetallic coating on top of the alloy that acts as the oxidation resistant phase. In the case of $\mathrm{Ni}$-base alloys, this phase is $\beta-\mathrm{NiAl}$, which has excellent oxidation properties and a high melting point[11].

For this work, the main coating method of consideration is pack cementation. Pack cementation can be thought of as an in situ CVD process. The alloy that is going to be coated is placed in a partially sealed container with an inert filler, a halide activator, and a metal powder. When the system is heated in an inert atmosphere to temperatures above $700^{\circ} \mathrm{C}$, the halide activator reacts with the metal to form volatile metal halides. These metal halides are reduced on the surface of the part to be coated, which diffuses the coating metal into the surface of the part [7]. The inert filler is present to act as a gas transport for the metal halide vapors, and does not interfere with the composition of the coating. The amount of metal deposited on the alloy that is being coated depends on the pack composition, time, and temperature. The process is not limited to direct line of sight as some coating processes and is therefore amenable to complex geometries.

Pack cementation continues to be an important industrial process. As of 1998 More than $80 \%$ of turbine blades are coating with an aluminizing or chromizing pack cementation process[12]. These parts first go through a grit blasting process to clean the surface, followed by degreasing[13]. After degreasing, the pack cementation process is carried out normally as described in chapter 1 . The position of the parts is carefully controlled to ensure consistent results[14]. After removal from the pack the parts can either be cleaned and used as is, or 
annealed to form the desired phases[15].

\subsection{Experimental Details}

\subsubsection{Substrate Materials}

The substrate alloys were based on the Mo-Ni-Al region, within the two phase region containing a (Mo) solid solution and $\beta-\mathrm{NiAl}$ as the constituent phases. The coatings were produced on alloys containing 20 at.\% and 75 at.\% Mo. The high Mo alloys were produced by mixing appropriate amounts of $\mathrm{Ni}, \mathrm{Al}$, and Mo powders in a SPEX mill. The mixed powders were then pressed into $10 \mathrm{~mm}$ diameter disks with a height of approximately 15 $\mathrm{mm}$, followed by sintering at $1800^{\circ} \mathrm{C}$ for 30 minutes. The $\mathrm{Ni}$ and $\mathrm{Al}$ powders were obtained from the Materials Preparation Center (USDOE, Ames Laboratory, Ames, Iowa). The Mo was from Alfa Aesar with a particle size of 3-7 $\mu \mathrm{m}$ (purity 99.5\%).

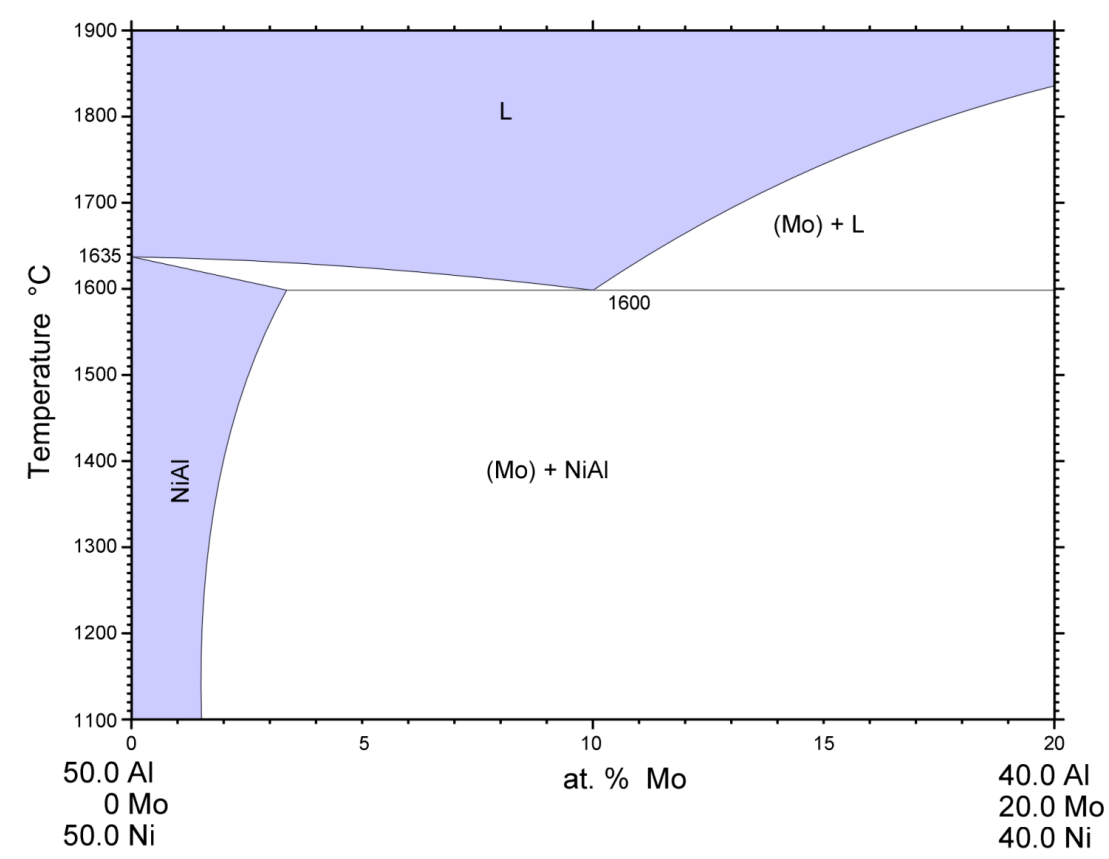

Figure 3.1: NiAl-Mo Psuedobinary Phase Diagram [16]

As seen in Figure 3.1 the sintering temperature of $1800^{\circ} \mathrm{C}$ is above the $\beta-\mathrm{NiAl}$ melting point, but below the melting point of Mo, therefore the process essentially is a liquid phase sintering. 
The 20 at.\% Mo containing alloys were made from the same powders as the 75 at.\% Mo alloys, however these alloys were melted three times using a non-consumable tungten electrode on a chilled copper hearth in an Ar atmosphere. The resulting button was then drop-cast into a $10 \mathrm{~mm}$ diameter cylinder in an Ar atmosphere. The drop-casting process could not be applied to the 75 at.\% alloys because the viscosity of the melt was too high to be drop-cast or vacuum-cast effectively, so they were processed from powders as described in the previous paragraphs.

\subsubsection{Coating Process}

Producing a coating with pack cementation is relatively straightforward on Ni-base superalloys because the high $\mathrm{Ni}$ content in the base alloy reacts with the $\mathrm{Al}$ introduced in the pack cementation to produce the $\beta-\mathrm{NiAl}$. In the (Mo)-NiAl alloys, the presence of Mo requires the alloy to be coated in $\mathrm{Ni}$ before pack cementation to avoid the formation of $\mathrm{Mo}-\mathrm{Al}$ intermetallics. The composition of the Ni-plating solution is shown in Table 3.1 The plat-

Table 3.1: Ni Plating Solution

\begin{tabular}{lc}
\hline Chemical & Concentration \\
\hline Nickel Sulfate $\left(\mathrm{NiSO}_{4}\right)$ & $175 \mathrm{~g} / \mathrm{L}$ \\
Nickel Chloride $\left(\mathrm{NiCl}_{2}\right)$ & $85 \mathrm{~g} / \mathrm{L}$ \\
Boric Acid $\left(\mathrm{H}_{3} \mathrm{BO}_{3}\right)$ & $20 \mathrm{~g} / \mathrm{L}$ \\
\hline
\end{tabular}

ing bath was raised to a temperature of $60-70^{\circ} \mathrm{C}$ before plating. The alloys were polished to $1200 \mathrm{C}$ grit paper, and washed in an ultrasonic bath in ethanol to remove any oils on the surface. The alloys were plated with constant current, and pulsed to change the clamping location on the substrate to ensure even coverage over the entire sample. The plating time was dependant on the final desired coating thickness.

The starting pack composition is shown in Table 3.2. After the samples were cleaned ultrasonically in ethanol, they were placed in a semi-sealed alumina crucible, with the lid sealed with alumina cement. The crucible was then held in a quartz tube on an Inconel tray. The tube was evacuated and backfilled with Ar three times, then held at 1 atm pressure. The furnace was then held at the target temperature for the desired length of time. Determina- 
tion of the optimum time and temperature will be discussed later. Temperatures were kept between 850 to $950^{\circ} \mathrm{C}$, and process time was varied between 90 and 180 minutes. Details on the pack cementation furnace are shown in Appendix C.

Table 3.2: Pack Composition

\begin{tabular}{lc}
\hline \multicolumn{2}{c}{ Pack Composition, wt. $\%$} \\
\hline Aluminum & $15 \%$ \\
Ammonium Chloride & $4 \%$ \\
Alumina & $81 \%$ \\
\hline
\end{tabular}

\subsubsection{Oxidation}

Isothermal oxidation was conducted in a vertical tube furnace with flowing dry air at 60 $\mathrm{cc} / \mathrm{min}$ at $1200^{\circ} \mathrm{C}$. If there were any defects in the coating, the base (Mo)-NiAl alloy would be exposed to the oxidizing environment. One of the oxidation products of the (Mo)-NiAl alloys is $\mathrm{MoO}_{3}$, which is volatile at the oxidation temperatures used in this study. Due to the volatility of $\mathrm{MoO}_{3}$ TGA could not be used because the $\mathrm{MoO}_{3}$ would condense on the suspending wire, and give a false reading of the mass.

\subsubsection{Grain Size Characterization}

Grain size analysis of the as prepared coatings was done by using an AmRay 1845FE scanning electron microscope (SEM) utilizing an EDAX-TSL Delphi 2.5 Geneses model EBSDEXX for orientation imaging microscopy (OIM). Once the grain size was established, thermal etching was used to bring out the grain boundaries. Thermal etching was done in an argon atmosphere at $1030^{\circ} \mathrm{C}$ for 1 hour. The grain size analysis from the thermal etching was in agreement with results from OIM. 


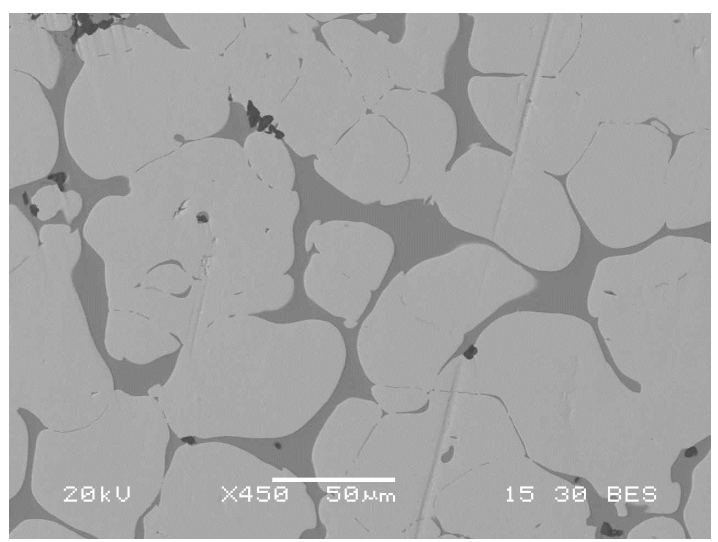

(a) 75 at.\%

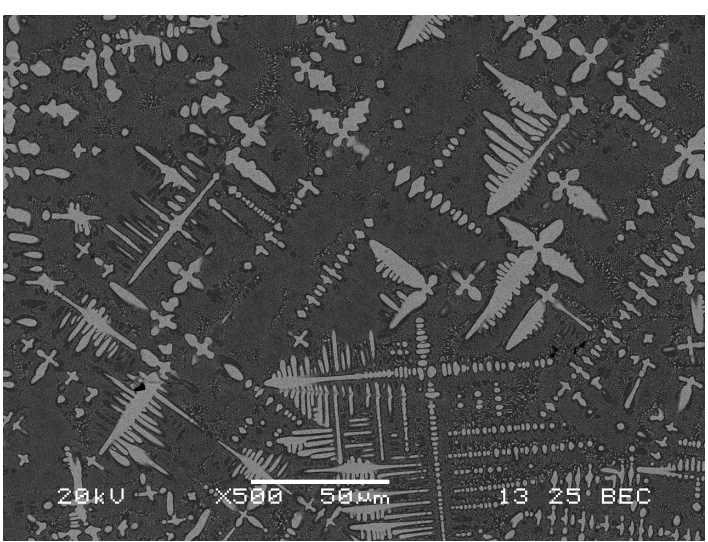

(b) 20 at. $\%$

Figure 3.2: SEM Micrographs of (Mo)-NiAl Alloys

\subsection{Results and Discussion}

\subsubsection{Alloy Synthesis}

As seen in Figure 3.2 the 75 at.\% shows a large volume fraction of nodular Mo with NiAl occupying the space in between the Mo phase. The sintered samples were $93.2 \pm 0.8 \%$ dense (Archimedes Method). Attempts at increasing the density of the 75 at.\% alloys was made by ball milling the powders in both ambient and inert atmospheres, but the highest density was achieved without ball milling the powders at all. The 20 at.\% structure clearly shows Mo dendrites, along with a (Mo)-NiAl eutectic region, which corresponds to $\approx 9$ at. $\%$ Mo.

\subsubsection{Coating Optimization}

Developing a coating process for Mo-Ni-Al alloys using nickel plating and pack cementation requires precise control over each step to introduce the correct amount of $\mathrm{Ni}$ and $\mathrm{Al}$ to form the desired $\beta-\mathrm{NiAl}$ coating without any excess of either $\mathrm{Ni}$ or Al. All of the processes used to coat the alloys are surface dominated, so the mass changes were recorded in terms of mass per unit area. Figure 3.3 shows the mass change per unit area of the sample, for a constant current of $.107 \mathrm{~A} / \mathrm{cm}^{2}$.

By knowing the mass gain per unit area of the alloys during Ni plating the pack cementation time and temperature can be tailored to deposit the correct amount of $\mathrm{Al}$ to form $\beta-\mathrm{NiAl}$ 


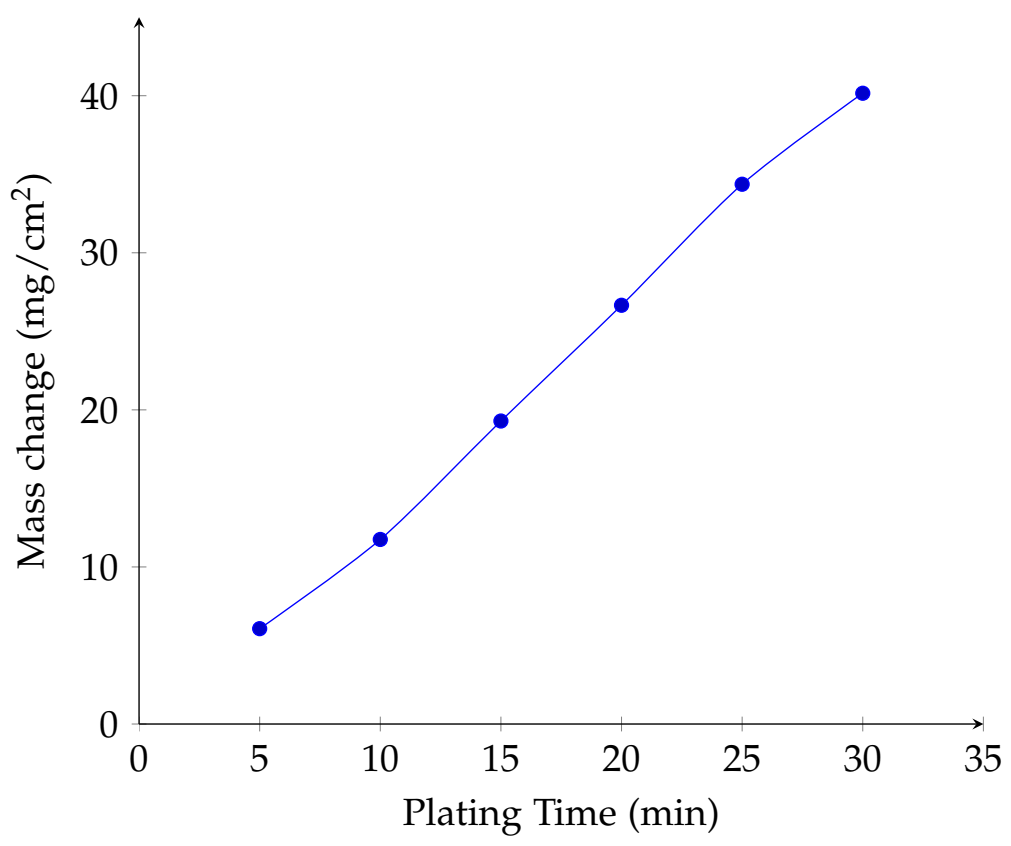

Figure 3.3: Ni Plating mass change for a constant current density of $0.11 \mathrm{~A} / \mathrm{cm}^{2}$. The mass change is essentially linear, which makes adjusting the amount of Ni plated simple.

Samples of Ni were coated with the pack composition shown in Table 3.2 for the schedule shown in Table 3.3. Each experiment was repeated twice.

Table 3.3: Pack Cementation on Ni Samples

\begin{tabular}{lccc}
\hline Sample & Time (min) & Temperature $\left({ }^{\circ} \mathbf{C}\right)$ & Mass Gain $\left(\mathbf{m g} / \mathbf{c m}^{2}\right)$ \\
\hline 1 & 90 & 850 & .08 \\
2 & 180 & 850 & 11.2 \\
3 & 90 & 950 & 26.8 \\
4 & 180 & 950 & 53.1 \\
\hline
\end{tabular}

The mass of each Ni sample was recorded before and after pack cementation, along with the surface area. By knowing the surface area of the sample, the mass change per unit area was able to be calculated for each step. Figure 3.4 plots the resulting mass gain from pack cementation for the parameters shown in Table 3.3. When these data are plotted in time-temperature space they produce a surface that represents the mass gain per unit area of the sample. Pack cementation is a diffusion limited process[15] which exhibits a $\sqrt{D t}$ relationship for mass gain. However, for simplicity in estimating the mass gain for this 
process the surface was taken as a plane because of the limited area in time-temperature space. The dots that are not on the corners of Figure 3.4 show other coating experiments that were used to test the assumption of the surface being represented by a plane. These points lie close to the approximated plane, so the mass gain for the process can be tailored to a specific amount by adjusting the time and temperature.

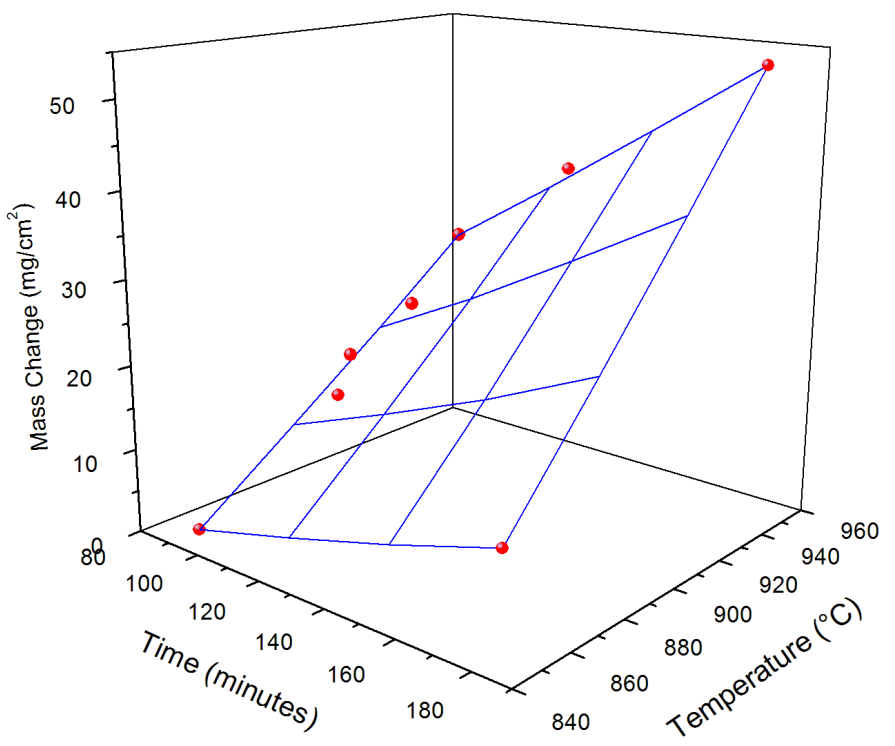

Figure 3.4: Pack cementation mass change as a function of time and temperature. The longer the time and temperature, the higher the mass gain. The resulting surface in timetemperature space was approximated as a plane for use in determining the optimal parameters for the pack process.

To determine the change in temperature and/or time the derivative of the surface was taken as follows

$$
d m=\left(\frac{\partial m}{\partial T}\right)_{t}(d T)
$$

Starting at one of the endpoints where the mass gain is known, and knowing the required difference in mass $(\mathrm{dm})$ to introduce the correct amount of aluminum to produce a 1:1 atomic ratio of $\mathrm{Al}: \mathrm{Ni}$, the change in the other variable (time or temperature) can be determined.

For example if the amount of aluminum deposition required is $21.85 \mathrm{mg} / \mathrm{cm}^{2}$, first find the closest endpoint, which in this case is $950^{\circ} \mathrm{C}$ for 90 minutes $\left(26.75 \mathrm{mg} / \mathrm{cm}^{2}\right)$. Taking the 
derivative of the surface, keeping the temperature constant is

$$
\left(\frac{\partial m}{\partial t}\right)_{950}=0.29 \frac{m g}{c^{2} \min }
$$

The difference in mass from the point at $950^{\circ} \mathrm{C}$ for 90 minutes and the desired mass gain is

$$
\Delta m=21.85-26.75
$$

This results in a $\Delta m$ of $-4.9 \mathrm{mg} / \mathrm{cm}^{2}$. The resulting change in time is

$$
\frac{-4.9 \frac{\mathrm{mg}}{\mathrm{cm}^{2}}}{.29 \frac{\mathrm{mg}}{\mathrm{cm}^{2} \mathrm{~min}}}=-16.9 \text { minutes }
$$

So the change is time is -16.9 minutes, which changes the pack parameters to $950^{\circ} \mathrm{C}$ for 73 minutes.

\subsubsection{Coating on (Mo)-NiAl Substrate}

The optimized process described in the previous section was used to produce $\beta-\mathrm{NiAl}$ coatings on the (Mo)-NiAl substrates.

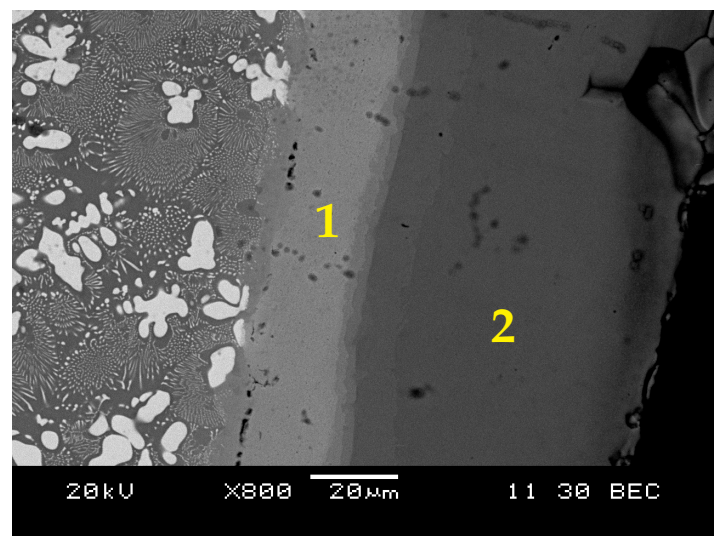

(a) As coated

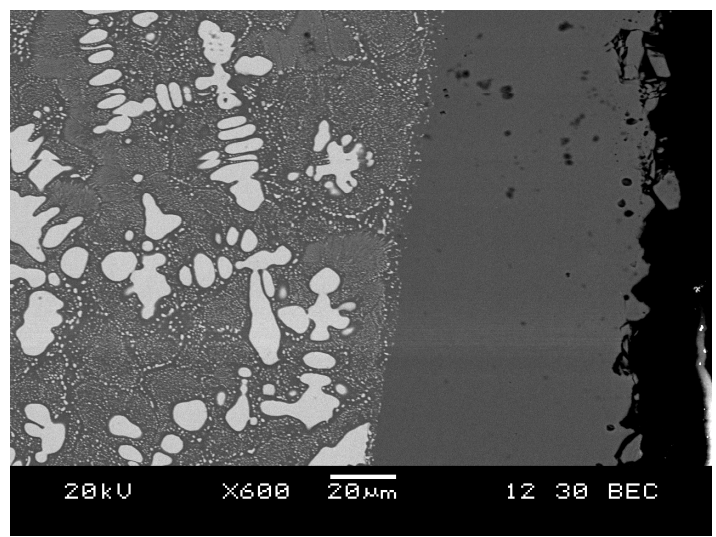

(b) $1350^{\circ} \mathrm{C}$ Anneal

Figure 3.5: Coating on 20 at.\% Alloy. The inital coating was not completely homoegnous, so a subsequent high temperature anneal at $1350^{\circ} \mathrm{C}$ was implemented.

20 at.\% Mo Alloys Figure 3.5 shows the results of the coating process on a 20 at.\% Mo sample. Figure 3.5a shows clear segregation in the as coated sample, with composition 
shown in Table 3.4. Figure 3.5 shows a single phase $\beta-\mathrm{NiAl}$ coating on top of the (Mo)-NiAl alloy, with a composition of 46.7 at.\% $\mathrm{Al}$ and 53.3 at.\% Ni. To obtain the single phase coating the sample was annealed at $1350^{\circ} \mathrm{C}$ for 2 hours in an argon atmosphere.

Table 3.4: Composition of 3.5a. The as coated sample has a layer of almost pure nickel at the original substrate-coating interface. After annealing at $1350^{\circ} \mathrm{C}$ the aluminum had sufficient time to diffuse inward and homogenize the coating.

\begin{tabular}{lcc}
\hline Area & Al at. $\%$ & Ni at. $\%$ \\
\hline 1 & 5.2 & 94.8 \\
2 & 60.8 & 38.9 \\
\hline
\end{tabular}

The pack cementation process is mainly limited by the solid-state diffusion[15], as is evidenced in 3.5a. The pack cementation process can only drive $\mathrm{Al}$ into the surface as long as the activity of the $\mathrm{Al}$ in the $\mathrm{AlCl}_{x}$ gas phase is higher than the activity of $\mathrm{Al}$ in the coating. This limits the thickness of the coatings than can be applied in reasonable amounts of time because the temperatures during the coating process are not high enough to allow sufficient diffusion of aluminum. As soon as the Al concentration on the surface of the coating reaches the activity of the $\mathrm{Al}$ in the gas phase the reaction essentially stops. Since the process is taking place at sufficiently high temperatures $\left(850^{\circ} \mathrm{C}-950^{\circ} \mathrm{C}\right)$ there is enough thermal energy to diffuse $\mathrm{Al}$ further into the coating. This process lowers the concentration of $\mathrm{Al}$ at the surface, thereby decreasing the activity of $\mathrm{Al}$ at the surface, which causes the pack cementation process to continue.

75 at.\% Mo Samples The same coating process discussed above was conducted on the 75 at.\% Mo samples, with the microstructures of the samples shown in Figure 3.6. The micrograph shows the microstructure after a $1350^{\circ} \mathrm{C}$ anneal for 2 hours to reach the equilibrium composition of the coating. There is no significant diffusion of Mo into the coating, even with the large chemical gradient that is present. There is a diffusion zone of $\approx 10 \mu \mathrm{m}$, where the (Mo) phase is present as smaller features as compared to the large $>40 \mu \mathrm{m}$ Mo particles, but there is no significant diffusion of Mo outward which would lead to degradation of the oxidation performance of the $\beta-\mathrm{NiAl}$ coating. 


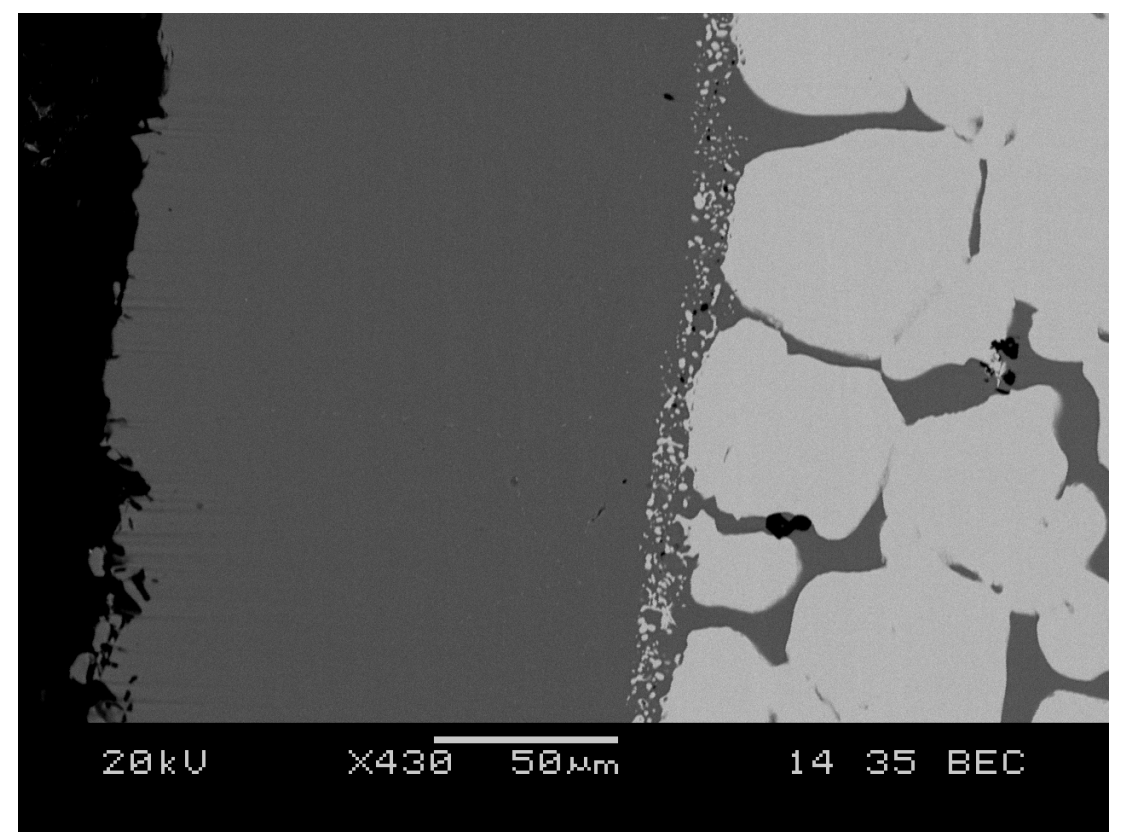

Figure 3.6: Coating on 75 at.\% Mo Alloy. The coating can be synthesized on the base alloy regardless of the composition of the underlying alloy. Mo diffusion into the coating was limited to less than 10 microns.

\subsubsection{Oxidation Behavior at $1200^{\circ} \mathrm{C}$}

Oxidation of uncoated (Mo)-NiAl alloys (20 at.\% Mo) shows an initial mass loss due to the volatilization of $\mathrm{MoO}_{3}$. Once the $\mathrm{Mo}$ has been volatilized, $\beta-\mathrm{NiAl}$ is exposed, which forms a protective $\mathrm{Al}_{2} \mathrm{O}_{3}$ scale, and limits further oxidation. Oxidation temperature was limited to $1200^{\circ} \mathrm{C}$, because $\beta-\mathrm{NiAl}$ exhibits significant scale spallation at $1300^{\circ} \mathrm{C}$.

As seen in Figure 3.7 the base alloy shows weight loss down to $-8 \mathrm{mg} / \mathrm{cm}^{2}$, at which point the weight loss begins to level off, indicating the formation of a protective oxide, whereas the coated sample exhibited a weight loss of $-1.8 \mathrm{mg} / \mathrm{cm}^{2}$ after 100 hours at $1200^{\circ} \mathrm{C}$. Brammer[17] found that isothermal oxidation of $\beta-\mathrm{NiAl}$ at $1200^{\circ} \mathrm{C}$ exhibited a protective scale during testing that fell off during retrieval from the testing apparatus.

As seen in Figure 3.8 the underlying alloy is protected by the $\beta-\mathrm{NiAl}$ coating. There is a continuous $\mathrm{Al}_{2} \mathrm{O}_{3}$ scale along the length of the alloy. Figure 3.9 shows a closer view of the scale itself. It is approximately $4 \mu \mathrm{m}$ thick, and dense. Subsurface depletion of $\mathrm{Al}$ can be seen, as evidenced by the lighter contrast in the backscattered electron image, due to the 


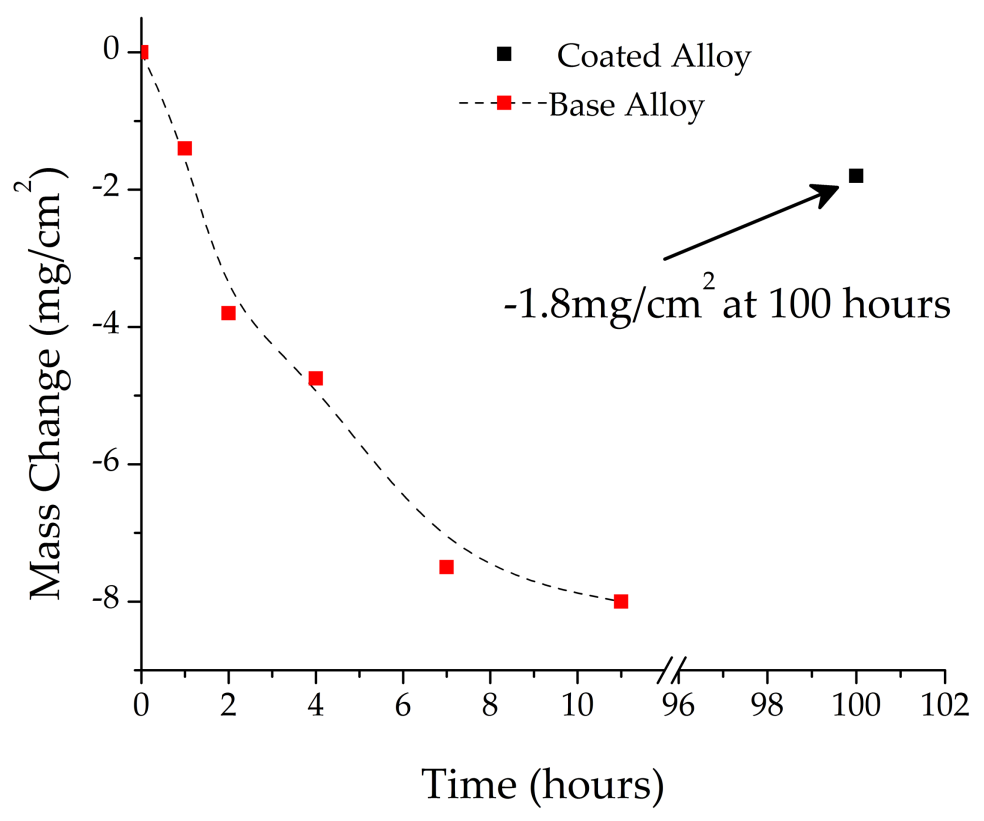

Figure 3.7: Isothermal Oxidation Comparison of Coated and Uncoated (Mo)-NiAl at $1200^{\circ} \mathrm{C}$

relatively higher concentration of $\mathrm{Ni}$ compared to the base alloy. The depletion of $\mathrm{Al}$ from the coating is caused by consumption of $\mathrm{Al}$ to form the $\mathrm{Al}_{2} \mathrm{O}_{3}$ scale. The depletion of $\mathrm{Al}$ was not enough to cause any phase change in the coating.

If the coating on the base alloy is $100 \%$ protective then only a weight gain is to be expected, due to the formation of the alumina scale. The weight loss of $-1.8 \mathrm{mg} / \mathrm{cm}^{2}$ of the coated sample indicates that the coating is not completely protective, so some Mo oxidized to $\mathrm{MoO}_{3}$ and was volatilized. Examining the coating optically shows that some cracks may form at the corners during the coating process, but the large areas of the coupon are protected. The sharp edges on the sample surface make producing the coating without any defects is difficult, since the whole process is carried out in the solid state. The inital Ni electroplated coating undergoes a phase change to $\beta-\mathrm{NiAl}$ which is accompanied by a volume expansion. The expansion can produce a stress within the coating that forms the cracks throughout the coating process[18]. However, compared to the uncoated alloy the coating provides a large improvement in oxidation resistance, although not quite as good as $\beta-\mathrm{NiAl}$. 


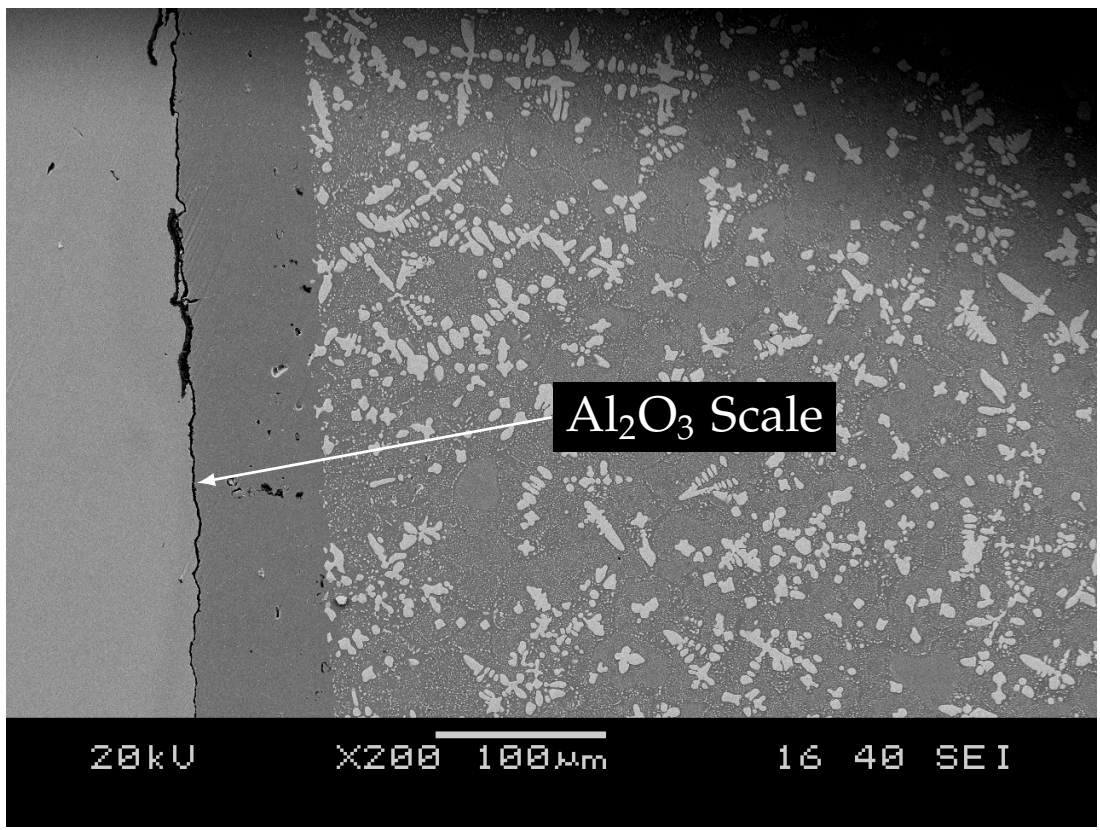

Figure 3.8: Coated Sample after 100 hours Isothermal Oxidation

\subsubsection{Initial Grain Size}

Brammer[17] and Yang et al.[19] have shown that smaller grained NiAl performed better during isothermal and cyclic oxidation. Rashidi and Amadeh[20] has shown that electroplated nickel coatings using the same type of plating solution as shown in Table 3.1 can give Ni grains on the order of $20-50 \mathrm{~nm}$. Combined with the pack cementation process and subsequent annealing, the resulting grains could be small, especially compared to conventional casting.

Figure 3.10 shows a $\beta-\mathrm{NiAl}$ coating which has been synthesized on top of a cast $\beta-\mathrm{NiAl}$ substrate to demonstrate the difference in grain size. The grain size of the cast NiAl had been found to be approximatley $600 \mu \mathrm{m}[17]$.

The grains in the coating are columnar, with the long axis perpendicular to the original surface of the substrate alloy. The effective area of the exposed grain is on the order of $20-40 \mu \mathrm{m}$, while the long axis is around $80 \mu \mathrm{m}$. There does not appear to be any specific orientation relationship between the coating and the substrate.

Examining of the surface of the coating (Figure 3.11) shows that the exposed grain area agrees with the grain size obtained from OIM. The smaller grains that are synthesized from 


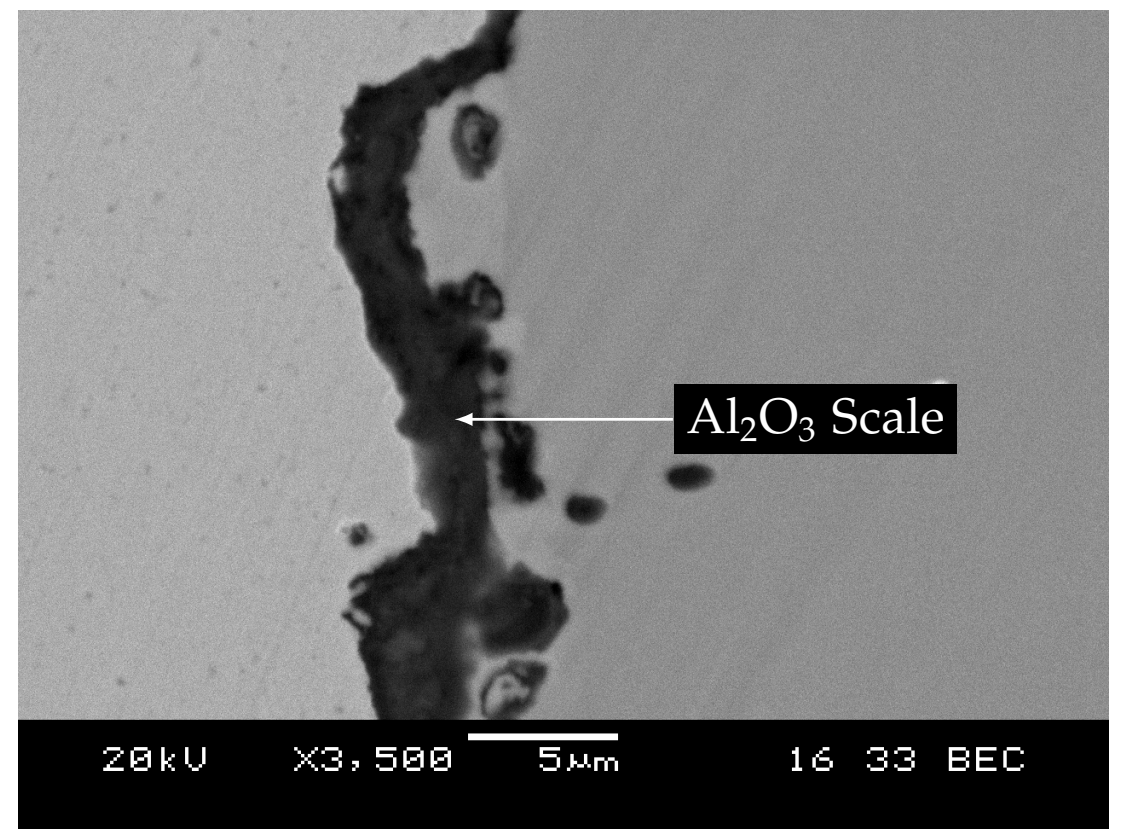

Figure 3.9: Coated Sample after 100 hours Isothermal Oxidation. The alumina scale is dense and protective of the underlying alloy.

the combination of electroplating and pack cementation can be beneficial for oxidation performance.

\subsection{Conclusions}

A coating process has been developed using a combination of electroplating nickel followed by pack cementation of aluminum that dramatically improves the isothermal oxidation resistance of (Mo)-NiAl alloys. The process is flexible and was used to produce coatings of $\beta-\mathrm{NiAl}$ on top of $\mathrm{Mo}-\mathrm{Ni}-\mathrm{Al}$ alloys with Mo content as high as 75 at.\%. The coating is stable after exposure to long times at high temperatures. This is mostly due to the similarity of composition of the coating and intermetallic in the substrate alloy, which limits diffusion between the coating and the base alloy that could lead to coating failure. The Mo in the base alloy remains at the original interface and does not diffuse into the coating.

Isothermal oxidation of the coated alloy system exhibits an improvement over the base alloy at the test temperature of $1200^{\circ} \mathrm{C}$ by showing a weight change of $-1.8 \mathrm{mg} / \mathrm{cm}^{2}$ after 100 hours of testing compared to $-8 \mathrm{mg} / \mathrm{cm}^{2}$ for the base alloy. 


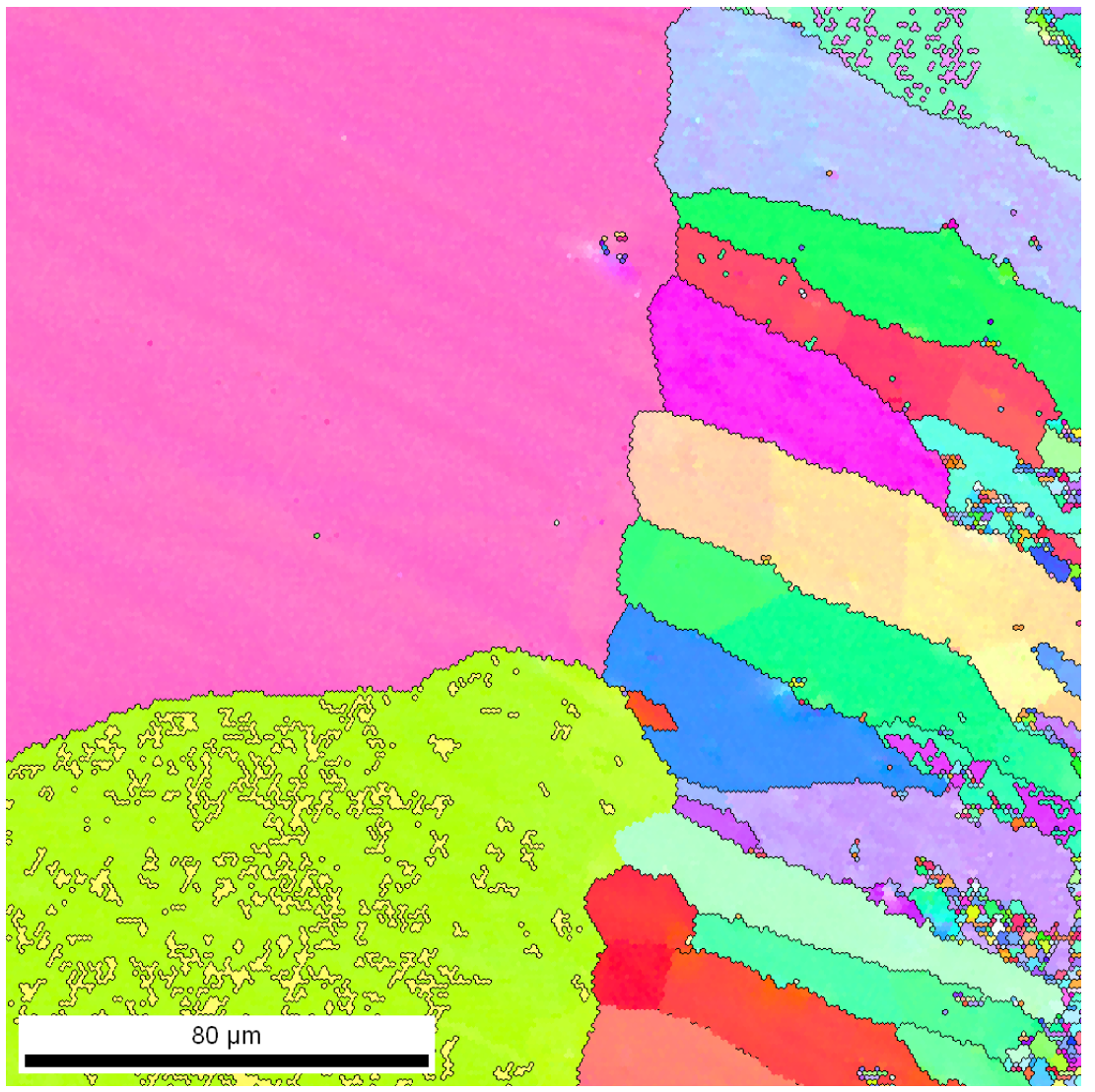

Figure 3.10: OIM of $\beta-\mathrm{NiAl}$ Coating. Grains are columnar and extend to be as thick as the coating. The cross sectional area of the coating that will be exposed to oxidation is much smaller.

\subsection{Acknowledgement}

This work was supported by the DOE-FE (AMR program) through Ames Laboratory contract no. DE-AC02-07CH11358 through Iowa State University. 


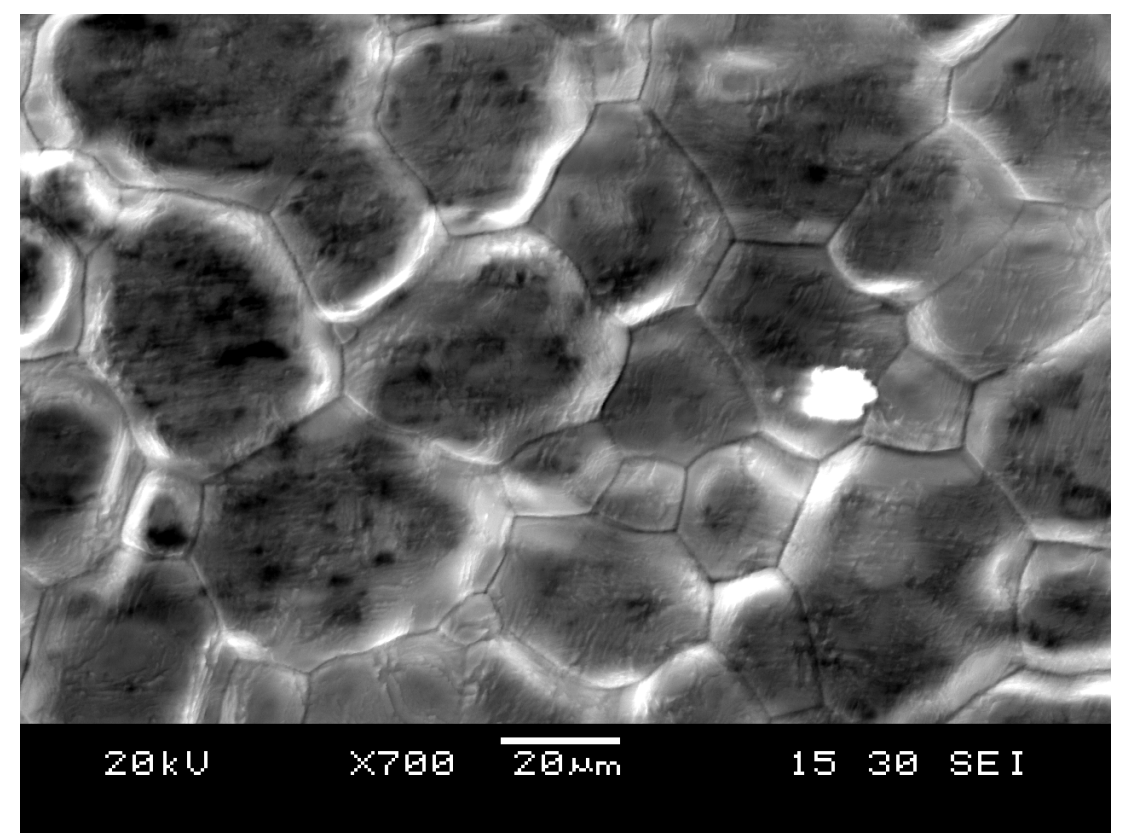

Figure 3.11: SEI of $\beta-\mathrm{NiAl}$ Coating. The grain size of the exposed $\beta-\mathrm{NiAl}$ grains are on the order of $20-40 \mu \mathrm{m}$, which agrees with OIM of the cross section of the coating. 


\section{BIBLIOGRAPHY}

[1] P.K. Ray, T. Brammer, Y.Y. Ye, M. Akinc, and M.J. Kramer. A multi-stage heirarchical approach to alloy design. Journal of Materials, 62, 2010.

[2] Matthew J Donachie. Superalloys - A Technical Guide (2nd Edition). ASM International, Materials Park, Ohio, 2002.

[3] C.T. Sims, N.S. Stoloff, and W.C. Hagel. Superalloys II. Wiley-Interscience publication. Wiley, 1987. ISBN 9780471011477.

[4] Ching-Yuan Bai, Yi-Jun Luo, and Chun-Hao Koo. Improvement of high temperature oxidation and corrosion resistance of superalloy IN-738LC by pack cemenetation. Surface $\mathcal{E}$ Coatings Technology, 183:74-88, 2004.

[5] J.A. Hearley, J.A. Little, and A.J. Sturgeon. The effect of spray parameters on the properties of high velocity oxy-fuel NiAl intermetallic coatings. Surface and Coatings Technology, 123(2):210 - 218, 2000. ISSN 0257-8972.

[6] J.A. Haynes, B.A. Pint, K.L. More, Y. Zhang, and I.G. Wright. Influence of Sulfur, Platinum, and Hafnium on the Oxidation Behavior of CVD NiAl Bond Coatings. Oxidation of Metals, 58:513-544, 2002.

[7] Z.D. Xiang. Aluminide coating formation on nickel-base superalloys by pack cementation process. Journal of Materials Science, 36(1):5673-5682, 2001.

[8] Z.D. Xiang and P.K Datta. Pack cementation process for the formation of refractory metal modified aluminide coatings on nickel-base superalloys. Journal of Materials Science, 38: 3721-3728, 2003.

[9] Robert Bianco and Robert A. Rapp. Pack cementation aluminide coatings on superalloys: codeposition of $\mathrm{Cr}$ and reactive elements. J Electrochemical Society, 140(4):1181-1190, 1993. 
[10] C. Houngninou, S. Chevalier, and J.P Larpin. Synthesis and characterization of pack cemented aluminide coatings on metals. Applued Surface Science, 236:256-269, 2004.

[11] N. Rusovic and H. Warlimont. The elastic behaviour of B2-NiAl alloys. Physica Status Solidi (A), 44(2):609-619, 1977. ISSN 1521-396X.

[12] G.W Goward. Progress in coatings for gas turbine airfoils. Surface and Coatings Technology, 108-109(0):73 - 79, 1998. ISSN 0257-8972.

[13] GW Goward and LW Cannon. Pack cementation coatings for superalloys, history, theory and practice. ASME paper, 1988.

[14] ASM International Handbook Committee. ASM Handbook, Volume 5 - Surface Engineering. ASM International, Materials Park, Ohio, 1994.

[15] R. Mevrel, C. Duret, and R. Pichoir. Pack cementation processes. Materials Science and Technology, 2:201-206, 1986.

[16] S.B. Maslenkov and V.A Rodimkina. Phase equilibria of the Ni-Al-Mo system for the Ni-NiAl-Mo composition range. Russian Metallurgy, 3:215-220, 1986.

[17] Travis Brammer. Improving the phase stability and oxidation resistance of $\beta-\mathrm{NiAl}$. Master's thesis, Iowa State University, 2011.

[18] V. Teixeira. Residual stress and cracking in thin PVD coatings. Vacuum, 64:393-399, 2002.

[19] Songlan Yang, Fuhui Wang, and Weitao Wu. Effect of microcrystallization on the cyclic oxidation behavior of $\beta$-NiAl intermetallics at $1000^{\circ} \mathrm{C}$ in air. Intermetallics, 9(8):741 - 744, 2001. ISSN 0966-9795.

[20] A.M. Rashidi and A. Amadeh. Effect of electroplating parameters on microstructure of nanocrystalline nickel coatings. Journal of Materials Science Technology, 26(1):82-86, 2010. 


\title{
CHAPTER 4. Cyclic Oxidation of Coated and Uncoated Cast Mo-Ni-Al Alloys
}

\author{
Kevin Severs, Pratik Ray, Matt Kramer, \& Mufit Akinc \\ Ames Laboratory and Department of Materials Science and Engineering \\ Iowa State University, Ames, IA 50011 \\ To be submitted to: Oxidation of Metals
}

\begin{abstract}
4.1 Abstract
Cyclic oxidation behavior of a Mo-Ni-Al alloy with composition $\mathrm{Mo}_{20} \mathrm{Ni}_{40} \mathrm{Al}_{40}$ was studied for both samples coated with $\mathrm{NiAl}$ as described in chapter 3 and uncoated samples. The coated alloy showed a significant improvement in the cyclic oxidation performance compared to the uncoated alloy. The coated alloy gained $18.8 \mathrm{mg} / \mathrm{cm}^{2}$ of mass compared to a weight loss of $47.5 \mathrm{mg} / \mathrm{cm}^{2}$ for the uncoated system. A damage mechanism for the coating has also been proposed to explain cracking in the coating during oxidation.
\end{abstract}

\subsection{Introduction}

The drive for increased efficiencies of turbine engines necessitates higher operating temperatures. The US Department of Energy, Nationals Energy Technology Laboratory (NETL), has set a goal temperature of $1300^{\circ} \mathrm{C}$ in order to boost fuel efficiencies. Current superalloys are not sufficient for this task because of their relatively low melting temperatures[1]. In order to meet the high temperature requirements an alloy based on the Mo-Ni-Al system has been proposed by Ray et al.[2]. The Mo is present in the alloy to provide high temperature strength, and to improve fracture toughness, whereas the $\mathrm{NiAl}$ phase provides the oxidation resistance. The inherent oxidation resistance of the $\mathrm{Mo}-\mathrm{Ni}-\mathrm{Al}$ alloys is not adequate for the 
temperature regimes that are being considered, so a coating method involving electroplating and pack cementation has been developed in order to improve the oxidation resistance of the Mo-Ni-Al alloys by coating with a $\beta-\mathrm{NiAl}$ layer[3]. The resulting coating had been shown to increase the isothermal oxidation performance when compared to uncoated alloys[4]. The cyclic oxidation performance of the coated Mo-Ni-Al alloys were investigated.

\subsection{Experimental Details}

\subsubsection{Materials and Synthesis}

A Mo-Ni-Al alloy with the composition of $\mathrm{Mo}_{20} \mathrm{Ni}_{40} \mathrm{Al}_{40}$ was synthesized from elemental powders of Mo (Alfa Aesar, 99.5\%), Ni (Materials Preparation Center, Ames Laboratory, 99.6\%) and Al(Alfa Aesar, 99.8\%). The powders were weighed in appropriate amounts, then subsequently mixed for 15 minutes in a SPEX 8000 mixer/shaker mill followed by pelletizing in a hydraulic press at a pressure of $12.5 \mathrm{MPa}$. The pellets were then arc-melted on a water cooled copper hearth in an argon atmosphere using a $\mathrm{Zr}$ getter. The arc melted buttons were then drop cast into a 10mm diameter chilled copper mold in an argon atmosphere. Coupons of $1 \mathrm{~mm}$ thickness were cut from the drop cast cylinder.

Coated samples were prepared by using a combination of electroplating and pack cementation as described in chapter 3

\subsubsection{Oxidation Testing}

Oxidation tests were carried out at $1100^{\circ} \mathrm{C}$. Two samples for each temperature were used and the results averaged because of the stochastic nature of the oxidation of these alloys. The oxidation of the uncoated alloys was carried out in ambient air in a horizontal cylindrical tube furnace. The coated samples were oxidized in ambient air in a vertical tube furnace using an automatic cyclic oxidation rig as described in Appendix A. Each cycle consisted of 2 hours in the furnace at the target temperature followed by cooling at ambient conditions for 30 minutes. When the samples were cooled, the mass was measured before being put 
back into the furnace. The mass changes were normalized to the geometric surface area to determine the oxidation kinetics.

\subsubsection{Characterization}

The alloys were characterized using scanning electron microscopy and x-ray diffraction. A JEOL 5910LV scanning electron microscope was used to examine the microstructure and oxide scale of the alloys. A thin layer of gold was sputtered onto oxidized alloys to ensure electrical conductivity. The cross sections of the oxidized coupons were coated with copper to maintain the oxide layer during metallographic sample preparation. The oxide phases formed were analyzed with an x-ray diffractometer (PANalytical, Philips), with a Bragg-

Brentano geometry using a monochromatic $\mathrm{Cu} \mathrm{K}$ radiation (wavelength $=1.54059 \AA$ ). The data was collected between 20 and $90^{\circ}$ with a step size of $0.0167^{\circ}$.

\subsection{Results and Discussion}

\subsubsection{Oxidation at $1100^{\circ} \mathrm{C}$}

As seen in Figure 4.1 the coated 20-Mo alloy shows a dramatic improvement in the cyclic oxidation kinetics compared to the uncoated alloy. After 10 cycles (20 furnace hours) the coated sample had gained $18.8 \mathrm{mg} / \mathrm{cm}^{2}$ of mass, while the uncoated sample lost 47.5 $\mathrm{mg} / \mathrm{cm}^{2}$. The mass gain of the coated sample was higher than for just $\beta-\mathrm{NiAl}[5]$, which indicates that the scale was not just alumina. As seen in chapter 3 the coating is not $100 \%$ protective so there would be some oxidation of the Mo in the underlying alloy. There was some green colored oxide present on the surface of the samples, which is indicative of a Ni containing oxide.

\subsubsection{XRD}

XRD of three coupons after 2, 5, and 10 cycles of oxidation showed the presence of $\beta$ $\mathrm{NiAl}, \alpha-\mathrm{Al}_{2} \mathrm{O}_{3}$, and $\mathrm{NiAl}_{2} \mathrm{O}_{4}$. There was a small amount of $\mathrm{NiMoO}_{4}$ in the sample after 2 


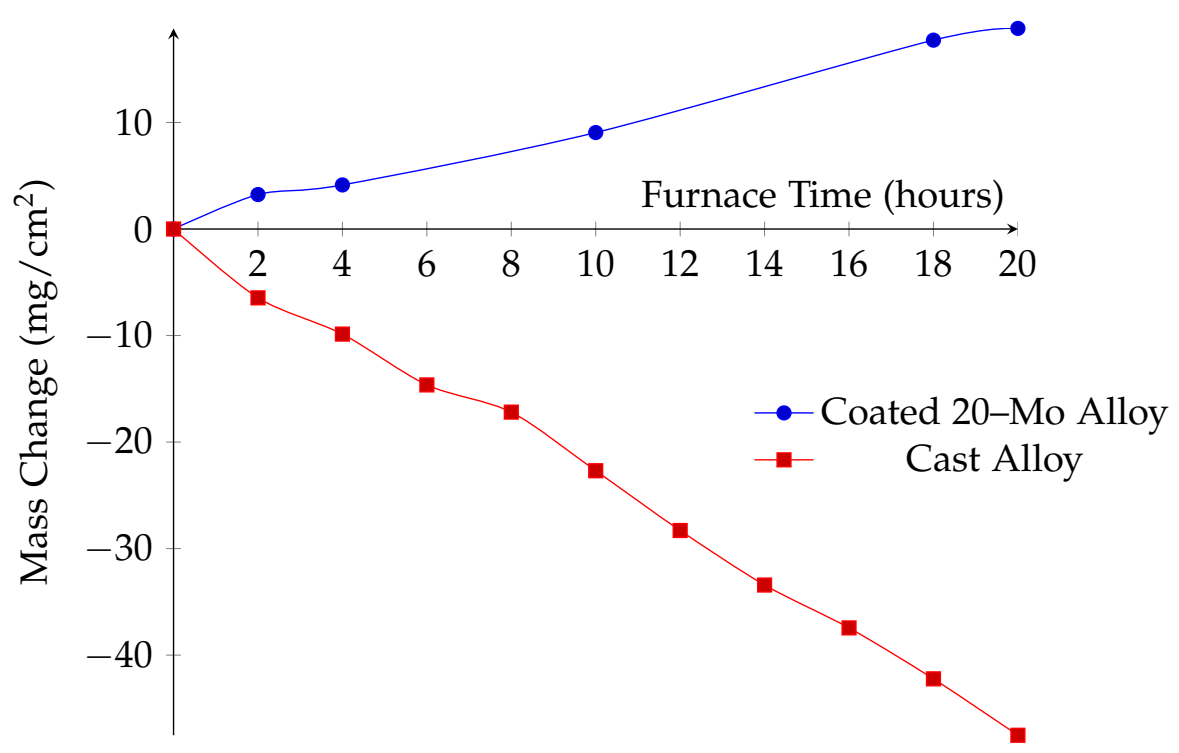

Figure 4.1: Cyclic Oxidation at $1100^{\circ} \mathrm{C}$ of coated 20-Mo Alloy. The uncoated alloy exhibited weight loss throughout the entire test, indicating loss of Mo, whereas the coated sample gained mass.

cycles, but it was not present in any of the other coupons. The XRD patterns are shown in Figure 4.2

The diffraction patterns of all the oxidized samples all have the same peaks present, except for the sample at 2 cycles which has the small peak at $14.4^{\circ}$, which is indicative of $\mathrm{NiMoO}_{4}$. The large peak to at $37^{\circ}$ is the most intense peak of the $\mathrm{NiAl}_{2} \mathrm{O}_{4}$ spinel phase. The relative amount of this phase initially decreases from 2 to 5 cycles, but it then present as the main phase after 10 cycles. The peak at $44^{\circ}$ is the main peak of $\beta-\mathrm{NiAl}$, which decreases in relative intensity with increasing cycles. This peak decreases with increasing furnace time due to the growth of the oxide scale.

The relative amounts of the two main oxides $\left(\alpha-\mathrm{Al}_{2} \mathrm{O}_{3}\right.$ and $\left.\mathrm{NiAl}_{2} \mathrm{O}_{4}\right)$ can differ substantially from sample to sample, due to starting defects in the coating, so a direct comparison between individual samples is not necessarily indicative of an oxidation mechanism.

\subsubsection{SEM}

Examining the cross sections of the oxidized coupons confirmed the XRD results. $\mathrm{NiAl}_{2} \mathrm{O}_{4}$ and $\mathrm{Al}_{2} \mathrm{O}_{3}$ were the primary oxides. Very small amounts of $\mathrm{NiMoO}_{4}$ were seen within the 


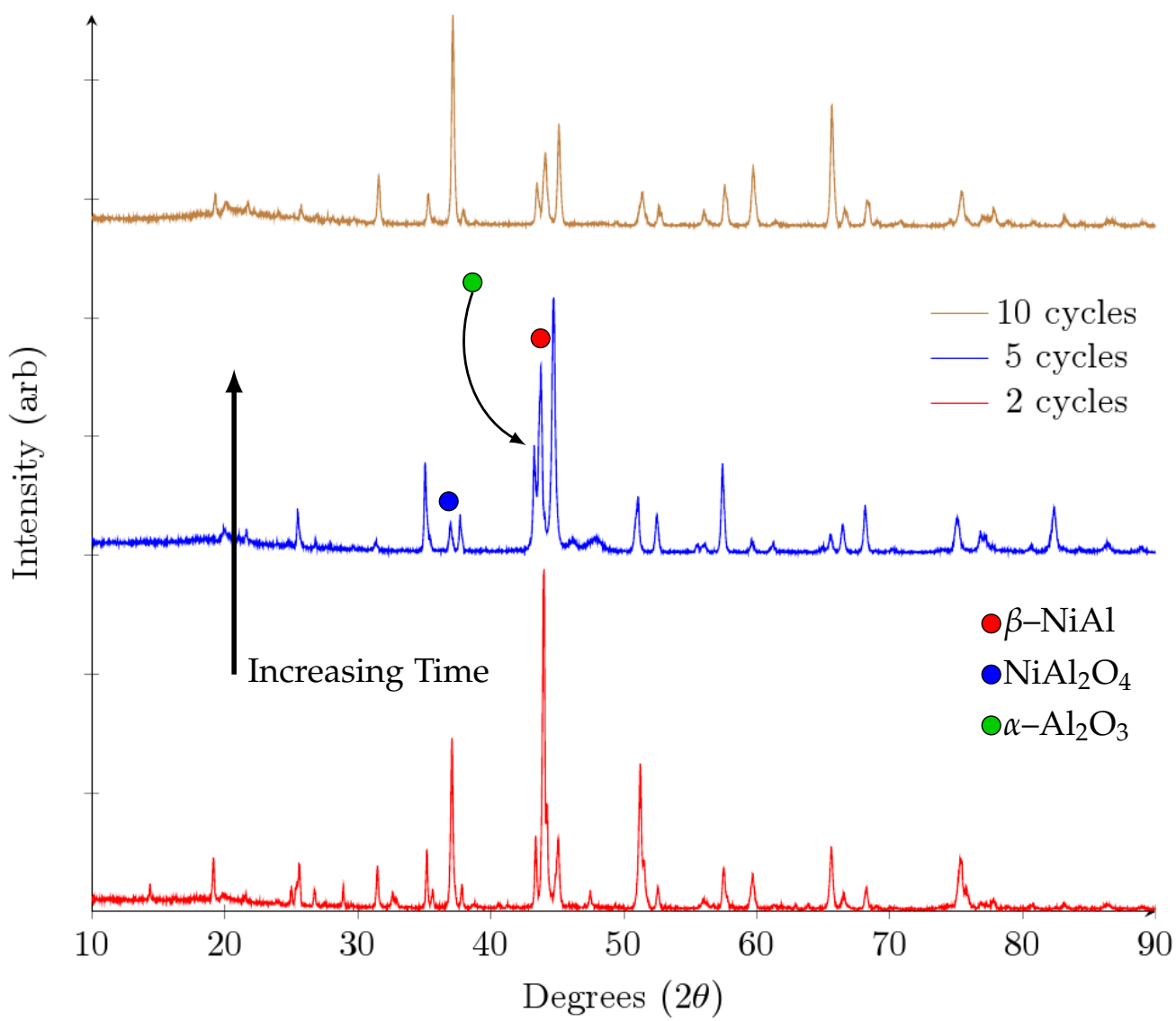

Figure 4.2: XRD of Oxidized Coated Samples. The most intense peak of $\beta-\mathrm{NiAl}$ is at $44^{\circ}$, which is decreasing in intensity with increasing oxidation time, indicating a thicker oxide scale. Both the most intense peaks of the $\mathrm{NiAl}_{2} \mathrm{O}_{4}\left(37^{\circ}\right)$ and $\mathrm{Al}_{2} \mathrm{O}_{3}\left(43^{\circ}\right)$ do not show any systematic pattern throughout oxidation.

spinel phase, but it was in very limited amounts. The $\alpha-\mathrm{Al}_{2} \mathrm{O}_{3}$ formed at the NiAl interface, with the spinel present in large quantities in between the oxidized sample as seen in Figure 4.3. The darkest phase oxide is $\alpha-\mathrm{Al}_{2} \mathrm{O}_{3}$, while the slightly brighter phase is the $\mathrm{NiAl}_{2} \mathrm{O}_{4}$. The brightest oxide phase is the $\mathrm{NiMoO}_{4}$. There is a substantial amount of cracking into the base alloy present, which would expose the NiAl-(Mo) to the oxidizing environment.

After 5 cycles the oxide scale looks similar to the 2 cycle sample, but with more cracking in the coating and some sub-coating oxidation. Figure 4.4 shows the condition of the oxide scale after 5 cycles. There are multiple areas that show large amounts of oxidation into the base alloy. 4.4a also shows more substantial cracking of the coating into the base alloy. After 10 cycles the oxide of the alloy essentially looks the same as the 5 cycle, but with a thicker 


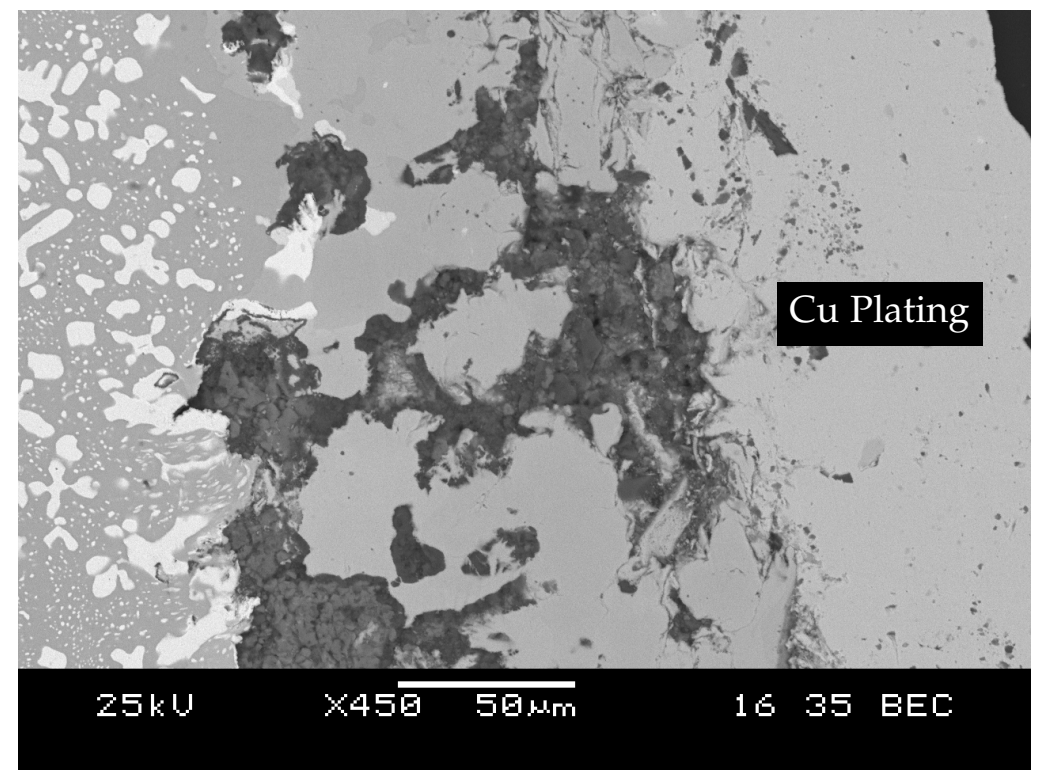

Figure 4.3: Oxide Scale after 2 Cycles

oxide scale.

\subsubsection{Damage Mechanism}

As shown in subsubsection 4.4.1.2 there is a substantial amount of oxidation during cyclic oxidation. The oxidation is not limited to just the coating, but penetrates into the base alloy. Although the synthesized coating does have some initial flaws, the coating is mostly free of flaws especially on the large areas of the coupons that are away from corners. During isothermal oxidation the alloy did not have any sub-coating oxidation in areas that were free of defects in the beginning. Thermal cycling causes the coating to fail and reveal the underlying alloy to the oxidizing environment. Schutze[6] approximated the thermal stress in coatings upon cooling with the equation:

$$
\sigma_{\text {therm }}=\frac{E_{c} \Delta T\left(\alpha_{c}-\alpha_{c}\right)}{\frac{E_{c}}{E_{s}} \frac{d_{c}}{d_{s}}\left(1-v_{s}\right)+\left(1-v_{c}\right)}
$$

where $\alpha$ is CTE, $v$ is Poisson's ratio, $\Delta T$ is the temperature difference, $d$ is the thickness, and subscripts $c$ and $s$ refer to the coating and substrate, respectively. Because $d_{c} \ll d_{s}$, the above 


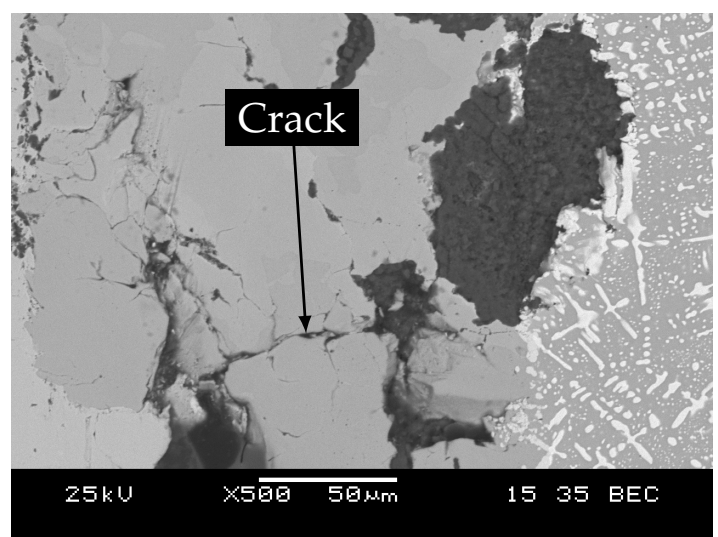

(a) Cracks in Coating

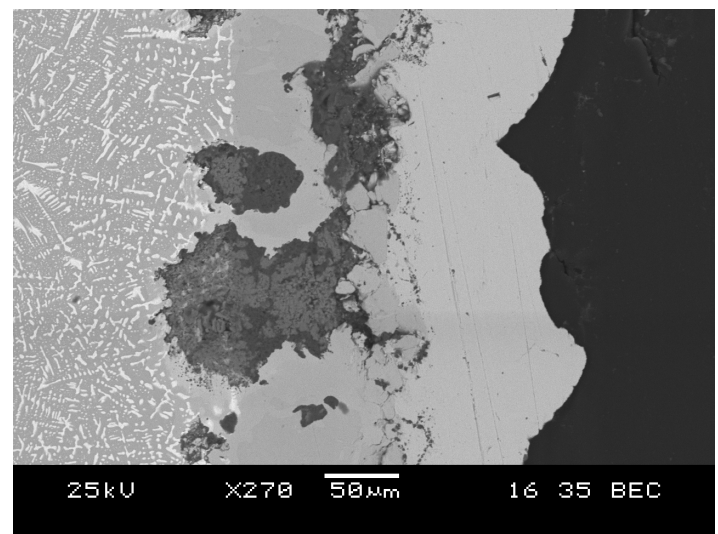

(b) Oxide Layer

Figure 4.4: Oxide Scale after 5 Cycles

equation can be simplified to[7]

$$
\sigma_{\text {therm }}=\frac{E_{c} \Delta T\left(\alpha_{c}-\alpha_{s}\right)}{\left(1-v_{c}\right)}
$$

The interfaces in question are between the $\beta-\mathrm{NiAl}$ coating and the (Mo)-NiAl substrate. Because the thermal stresses are derived from the difference in thermal expansion, there will not be any thermally induced stress between the NiAl coating and the NiAl in the substrate, so the only interface will be between the Mo and NiAl. The Table 4.1 summarized the values used in the calculation The ductile to brittle transformation temperature (DBTT) of NiAl

Table 4.1: Mechanical and Thermal Properties of Mo and NiAl

\begin{tabular}{cccc}
\hline Material & $\alpha 10^{-6}\left(\mathrm{~K}^{-1}\right)$ & $E(\mathrm{GPa})$ & $v$ \\
\hline $\mathrm{Mo}$ & $6.5[8]$ & - & - \\
$\mathrm{NiAl}$ & $12.6[9]$ & $239[10]$ & $.31[10]$ \\
\hline
\end{tabular}

is between 550 and $750 \mathrm{~K}$ depending on processing. Smaller grained NiAl typically exhibit a lower DBTT, so in the case of the coating the DBTT is probably more towards $550 \mathrm{~K}$. The yield strength of NiAl varies considerably as a function of composition and grain size. For the grain sizes of the coating, yield stresses can vary from 400-800 $\mathrm{MPa}[11]$, with aluminum deficient compositions exhibiting a higher yield stress. Figure 4.5 plots the thermal stress as a function of the DBTT, along with the yield stress of $\beta-\mathrm{NiAl}$. The points where these two lines cross can be considered critical values of the DBTT (DBTT $)$. If the NiAl has a DBTT 
above $\mathrm{DBTT}_{y}$ then cracks would form in the coating due to thermal cycling. In the best

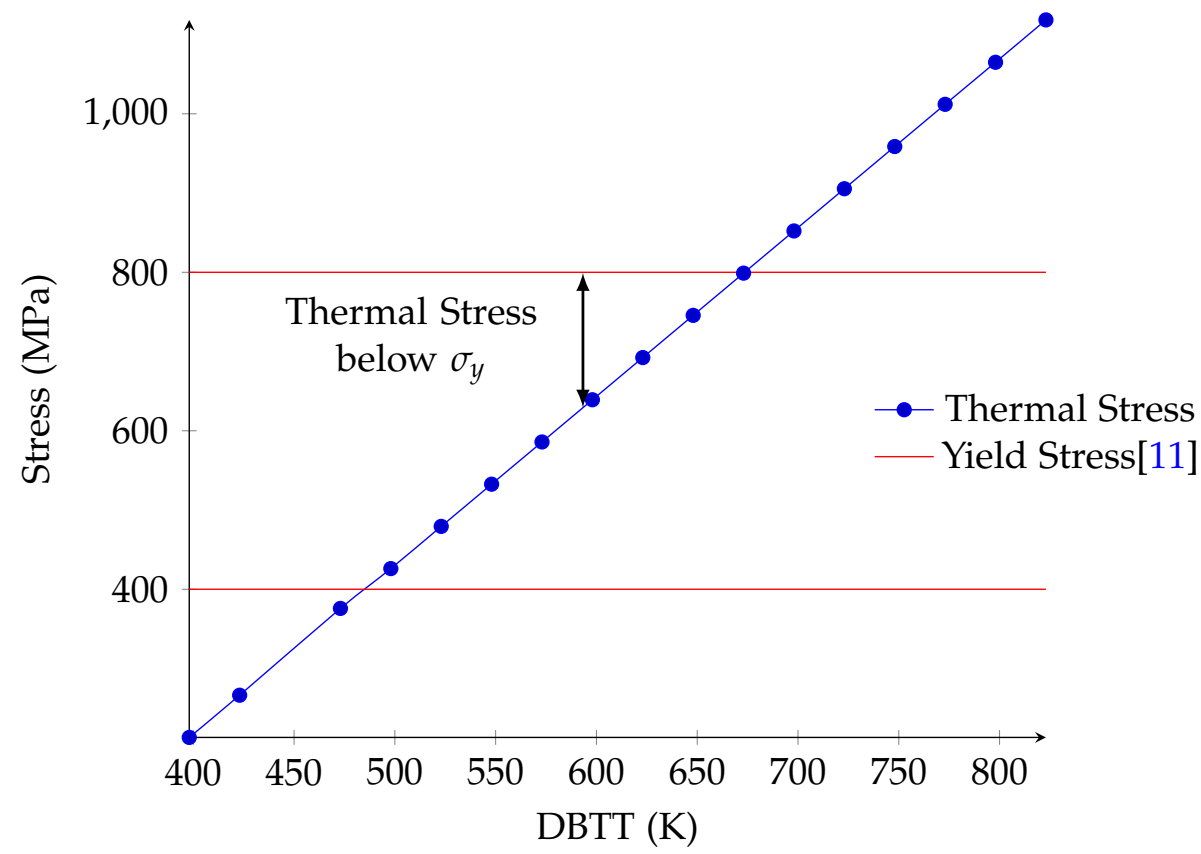

Figure 4.5: Thermal Stress between NiAl and Mo. The thermal stress was calculated with Equation 4.2. The horizontal lines represent the lowest and highest possible yield strengths for $\beta-\mathrm{NiAl}$. The arrows show how much the thermal stress will be under the yield stress if a yield stress of $800 \mathrm{MPa}$ is assumed with a DBTT of $600 \mathrm{~K}$

case scenario of the NiAl having a yield stress of $800 \mathrm{MPa}$, as long as the DBTT is below the high $\mathrm{DBTT}_{y}$ of $675^{\circ} \mathrm{C}$ then no cracking in the coating should occur. However 45 at.\% $\mathrm{Al}$ exhibits the highest yield stress, while the nominal composition of the coating is 50 at.\% $\mathrm{Al}$, which will lower the yield stress. The vertical line with a DBTT of $600 \mathrm{~K}$ shows how much the thermal stress will be below the yield stress of $800 \mathrm{MPa}$. If at any point the thermal stress line is above the yield stress lines, then there will be a crack in the coating. Likewise, if the thermal stress is below the yield stress, then the coating should remain intact. By calculating the stress from the DBTT, it is assuming that above the DBTT the coating can handle the thermal stress by deformation. This also would imply that the oxidation temperature of these alloys should not have any effect on the cracks present in the coating because the $\mathrm{NiAl}$ would be ductile at oxidation temperatures. Mo does not have any dramatic effect on the DBTT, and can raise the yield strength substantially in small amounts $(70 \%$ increase at room temperature for 0.2 at.\% addition)[12]. There will be a small amount of Mo in the NiAl due 
to the coating process, but not very much. Even with an increase in the yield strength of the $\mathrm{NiAl}$, the thermal stress can be over the yield strength and produce cracks in the coating near Mo features. These cracks will allow oxygen to interact with the base alloy, producing sub-coating oxidation. $\mathrm{NiAl}_{2} \mathrm{O}_{4}$ has a specific volume of $0.222 \mathrm{~cm}^{3} \mathrm{~g}^{-1}$ compared to $\mathrm{NiAl}$ which has a specific volume of $0.169 \mathrm{~cm}^{3} \mathrm{~g}^{-1}$ [13]. This increase in volume will produce more stress in the coating, further promoting cracking.

Fracture Toughness Considerations $\beta-\mathrm{NiAl}$ has a low fracture toughness, routinely reported as 4-6 MPa $\sqrt{\mathrm{m}}$ for bulk polycrystalline samples. This low fracture toughness also contributes to the cracking seen during thermal cycling. Wellner et al.[14] found that the $K_{C}$ values for thin films of $\beta-\mathrm{NiAl}$ decreased to $2.2-2.9 \mathrm{MPa} \sqrt{\mathrm{m}}$. Figure 4.6 shows the amount of stress necessary to fracture the NiAl coating based on Griffith's crack equation[15]

$$
K_{I}=\sigma \sqrt{\pi a}
$$

As stated earlier, the DBTT of $\beta-\mathrm{NiAl}$ is between $550-750 \mathrm{~K}[11]$. This corresponds to a thermal stress of 540-960 MPa, respectively. Comparing these stress values to the calculated stress shown in Figure 4.6, the critical flaw size can be determined. As seen in Figure 4.6 the critical crack length can be between 1.6 and $5.6 \mu \mathrm{m}$ depending on the DBTT. Initial inspection of as coated samples, did not show the presence of any cracks of that size. The isothermal oxidation samples described in chapter 3 only lost $1.8 \mathrm{mg} / \mathrm{cm}^{2}$ of mass after 100 hours of oxidation at $1200^{\circ} \mathrm{C}$, so the inital flaw population is low. The thermal cycling has the ability to produce cracks as shown in Figure 4.5, which could produce the flaw that can exceed the critical crack size.

\subsection{Conclusions}

(Mo)-NiAl alloys show promise for high temperature applications because of the high temperature strength provided by the Mo solid solution, along with the oxidation resistance of NiAl. However, inherent oxidation resistance of (Mo)-NiAl alloys is somewhat poor due to the presence of Mo. In order to increase the oxidation resistnace of these alloys, a $\beta-\mathrm{NiAl}$ 


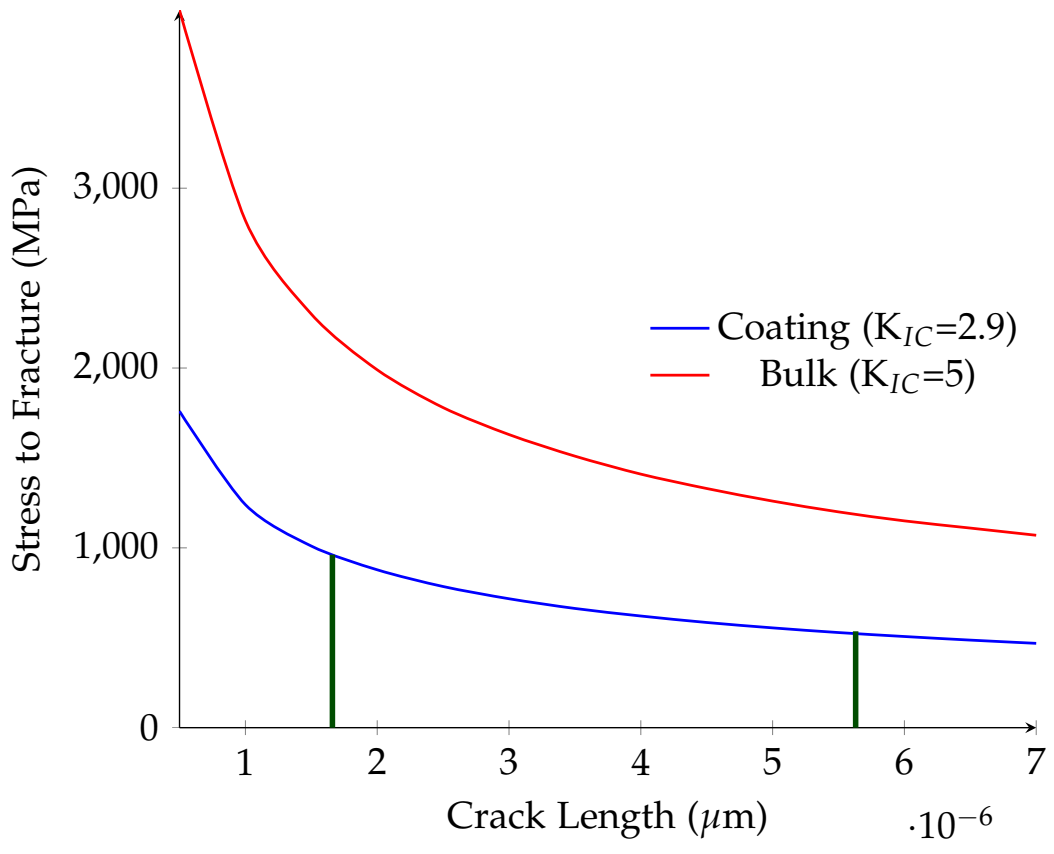

Figure 4.6: Stress required for fracture of $\beta-\mathrm{NiAl}$ Coatings. The vertical lines correspond to the stress from thermal cycling. The intersection of these lines with the $\mathrm{x}$ axis represent the critical crack size that would cause failure in the coating.

coating was synthesized using a combination of electroplating and pack cementation[4]. The cyclic oxidation performance of this coated alloy system was significantly improved over the uncoated alloy. Despite the improvement, the cyclic oxidation performance was not as good as unmodified $\beta-\mathrm{NiAl}$. Examination of the oxidized samples showed sub-coating oxidation and cracking within the coating. Thermal stresses along the Mo and NiAl interface were calculated to be substantial enough to cause cracking within the coating, providing a path for oxygen. When the initial flaws due to thermal cycling are formed, they can be large enough for the coating to fail from repeated thermal cycling according to Griffith's crack theory. The subsequent oxidation of the base alloy produced large amounts of $\mathrm{NiAl}_{2} \mathrm{O}_{4}$ which introduced more stress into the coating. 


\section{BIBLIOGRAPHY}

[1] Matthew J Donachie. Superalloys - A Technical Guide (2nd Edition). ASM International, Materials Park, Ohio, 2002.

[2] P.K. Ray, T. Brammer, Y.Y. Ye, M. Akinc, and M.J. Kramer. A multi-stage heirarchical approach to alloy design. Journal of Materials, 62, 2010.

[3] Kevin Severs. High temperature coatings based on $\beta-N i A l$. Master's thesis, Iowa State University, 2012.

[4] Kevin Severs, Matt Kramer, and Mufit Akinc. Improvement of oxidation performance Mo-Ni-Al alloys through pack cementation. To be published, 2012.

[5] Travis Brammer. Improving the phase stability and oxidation resistance of $\beta-\mathrm{NiAl}$. Master's thesis, Iowa State University, 2011.

[6] Michael Schutze. Fundamentals of High Temperature Corrosion, pages 67-130. Wiley-VCH Verlag GmbH, 2008. ISBN 9783527619306.

[7] ASM International Handbook Committee. ASM Handbook, Volume 5 - Surface Engineering. ASM International, Materials Park, Ohio, 1994.

[8] F. Chu, DJ Thoma, KJ McClellan, and P. Peralta. Mos $\mathrm{si}_{3}$ single crystals: physical properties and mechanical behavior. Materials Science and Engineering: A, 261(1):44-52, 1999.

[9] RW Clark and JD Whittenberger. Ta hahan, editor, thermal expansion 8, 1984.

[10] R. D. Noebe, R. R. Bowman, and M. V. Nathal. Physical and mechanical properties of the B2 compound NiAl. International Materials Reviews, 38(4):193-232, 1993-01-01T00:00:00.

[11] I. Baker, P. Nagpal, F. Liu, and PR Munroe. The effect of grain size on the yield strength of feal and nial. Acta metallurgica et materialia, 39(7):1637-1644, 1991.

[12] C.T. Liu and J.A. Horton Jr. Effect of refractory alloying additions on mechanical properties of near-stoichiometric nial. Materials Science and Engineering: A, 192-193, Part 1 
(0):170 - 178, 1995. ISSN 0921-5093. 3rd International Conference on High Temperature Intermetallics.

[13] O. Abe and Y. Ohwa. Oxidation of $\mathrm{NiAl} / \mathrm{Al}_{2} \mathrm{O}_{3}$ composites for controlled development of surface layers and toughening. Solid state ionics, 172(1):553-556, 2004.

[14] P. Wellner, O. Kraft, G. Dehm, J. Andersons, and E. Arzt. Channel cracking of $\beta$-NiAl thin films on Si substrates. Acta Materialia, 52(8):2325 - 2336, 2004. ISSN 1359-6454.

[15] A.A. Griffith. The phenomena of rupture and flow in solids. Philosophical transaction of the royal society of London, 221:163-198, 1921. 


\section{CHAPTER 5. General Conclusions}

High temperature materials and coatings based on $\beta-\mathrm{NiAl}$ show promise for use in gas turbine engines because of the combination of properties. Performance of unmodified $\beta$ $\mathrm{NiAl}$ is not adequate at high temperatures because of limitations of creep resistance and oxidation resistance. In order to increase the high temperature strength and creep resistance of the alloy Ray et al.[1] have added Mo as a "backbone" material. However, these additions lower the oxidation resistance of the alloy to an unacceptable level, especially at higher temperatures. To increase the oxidation resistance of the alloy a coating strategy based on a combination of electroplating and pack cementation was developed that could coat the NiAl-(Mo) alloys with $\beta-\mathrm{NiAl}$. The resulting coated alloy system performed well during isothermal oxidation tests at $1200^{\circ} \mathrm{C}$ and only lost $1.8 \mathrm{mg} / \mathrm{cm}^{2}$ of mass, as compared to a loss of $-8 \mathrm{mg} / \mathrm{cm}^{2}$ for the uncoated alloy.

Cyclic oxidation of the alloys is an even more demanding test. A cyclic oxidation rig was built which automated the process to allow for more consistent oxidation conditions without the need for constant operator attendance. This furnace was used to cyclically oxidize coated (Mo)-NiAl, which gained $18.8 \mathrm{mg} / \mathrm{cm}^{2}$ after 10 cycles at $1100^{\circ} \mathrm{C}$ as opposed to the uncoated alloy which lost $47.5 \mathrm{mg} / \mathrm{cm}^{2}$. Although the cyclic oxidation was improved by coating the alloy, the oxidation performance is still not as good as $\beta-\mathrm{NiAl}$. Further inspection of the coating found cracking and sub-coating oxidation. Calculating the stress between the Mo and $\mathrm{NiAl}$ showed that upon cooling, there is sufficient thermal stress to produce cracks in the coating. These cracks provide a free path for oxygen to further oxide the base alloy. This produced $\mathrm{NiAl}_{2} \mathrm{O}_{4}$ beneath the coating, which has a specific volume 33\% larger than NiAl. This produces more stress in the coating, which further promotes cracking.

Brammer[2] found that smaller grained $\mathrm{NiAl}$ performed better during oxidation because 
of the increased diffusion of $\mathrm{Al}$ to the oxide-metal interface. However, unmodified NiAl showed massive grain growth when exposed to high temperatures $\left(1300^{\circ} \mathrm{C}\right)$. $\mathrm{Hf}$, and to a lesser extent platinum group metals, were found to decrease the initial grain size and pin the grain boundaries. Both additions are expensive, so a more cost effective solution was developed. By in situ formation of $\mathrm{TiB}_{2}$ particles a $\mathrm{NiAl}-\mathrm{TiB}_{2}$ composite was fabricated. The NiAl grains for the composite were much smaller than cast NiAl: $22 \mu \mathrm{m}$ vs $635 \mu \mathrm{m}$ respectively. Over long term annealing the grains of the composite only grew to $28 \mu \mathrm{m}$, which resulted in a grain growth constant of an order of magnitude less that the NiAl-9\% $\mathrm{Ir}+\mathrm{Hf}$ alloy. Isothermal oxidation of the $\mathrm{NiAl}-\mathrm{TiB}_{2}$ composite at $1100^{\circ} \mathrm{C}$ had a rate constant of $.0106 \mathrm{mg}^{2} \mathrm{~cm}^{-4} \mathrm{~h}^{-1}$, compared to unmodified NiAl which has a rate constant of $3.6 \cdot 10^{-4}$ $\mathrm{mg}^{2} \mathrm{~cm}^{-4} \mathrm{~h}^{-1}$. So although the $\mathrm{NiAl}-\mathrm{TiB}_{2}$ had smaller grains, the oxidation performance was not as good as unmodified $\beta-\mathrm{NiAl}$ due to the presence of the $\mathrm{TiB}_{2}$ particles. 


\section{BIBLIOGRAPHY}

[1] P.K. Ray, T. Brammer, Y.Y. Ye, M. Akinc, and M.J. Kramer. A multi-stage heirarchical approach to alloy design. Journal of Materials, 62, 2010.

[2] Travis Brammer. Improving the phase stability and oxidation resistance of $\beta-\mathrm{NiAl}$. Master's thesis, Iowa State University, 2011. 


\title{
APPENDIX A. Design and Building of a Cyclic Oxidation Furnace
}

\author{
Kevin Severs, Matthew Kramer, Mufit Akinc \\ Ames Laboratory and Department of Materials Science and Engineering \\ Iowa State University, Ames, IA 50011
}

\begin{abstract}
A.1 Abstract
When testing the oxidation resistance of high temperature alloys both isothermal and cyclic oxidation tests are performed. Cyclic oxidation tests are much more aggressive, because they introduce stresses that are derived from the CTE mismatch between the alloy and the protective oxide scale. The cyclic tests are run with predetermined amount of time in the furnace at a specified temperature, followed by time outside of the furnace at ambient conditions. With as aggressive as the cyclic oxidation tests are, the equipment to perform the test must be able to perform reliably under harsh conditions. The materials must be extremely oxidation resistant along with high thermal shock resistance. The process must be reliable and repeatable in order to run long term tests. The following chapter will describe the design and building of a cyclic oxidation furnace capable of operating temperatures up to $1500^{\circ} \mathrm{C}$.
\end{abstract}

\section{A.2 Introduction}

Cyclic oxidation tests are some of the most aggressive tests that can be performed on high temperature alloys. The difference in the coefficient of thermal expansion between the base metal and the protective oxide introduces stresses within the oxide scale, which cause it to spall off. With the FutureGen project aiming for operating temperatures of around $1300^{\circ} \mathrm{C}$, 
these tests become even more aggressive. Some work on cyclic oxidation of platinum group metal (PGM) modified $\beta-\mathrm{NiAl}$ has been done by Brammer [1]. His cyclic tests at $1300^{\circ} \mathrm{C}$ were performed by manually moving the samples into and out of the furnace. This process is time consuming and relies on a human operator to perform the correct cycles. Many long term tests can expose the alloy to 1000 hours in the oxidizing environment[2], which would be impractical for a single person to do manually. In order to make the process more reliable, consistent, and less time consuming a system was built that could cyclicly oxidize a large number of samples at temperatures up to $1500^{\circ} \mathrm{C}$.

\section{A.3 Design and Building}

\section{A.3.1 Design}

When designing the cyclic oxidation rig the three main considerations were:

\section{Temperature capabilities}

2. Ease of use and maintenance

3. Sample capacity

Temperature Capabilities With the goal of the FutureGen project to have oxidatively stable alloys at temperatures around $1300^{\circ} \mathrm{C}$, the oxidation rig would need to attain those temperatures or higher. The furnace would also need to be able to run in air. This limits the heating element choices to $\mathrm{SiC}$ or $\mathrm{MoSi}_{2}$. Either type of heating element would work for this application because both have operating temperatures well exceeding $1300^{\circ} \mathrm{C}$.

There are also multiple choices to consider for the material that will move the sample in and out of the furnace. It should be able to stand up to the high temperatures for long periods of time and be resistant to thermal shock, which could abruptly end the test. Possible materials to consider are a) alumina b) mullite or c) sapphire wire. While all of those materials would be able to stand up to the high temperatures, the sapphire wire is very brittle and hard to shape. Alumina does not have very good thermal shock resistance, so the risk of 
cracking is high, especially with repeated thermal cycling[3]. Mullite $\left(3 \mathrm{Al}_{2} \mathrm{O}_{3} \cdot 2 \mathrm{SiO}_{2}\right)$ is the best choice for this job because of its low thermal expansion, good creep resistance, high thermal shock resistance, and cost[4]. As seen in the phase diagram (Figure A.1) for $\mathrm{Al}_{2} \mathrm{O}_{3}$ and $\mathrm{SiO}_{2}$, mullite has a high melting temperature $\left(>1800^{\circ} \mathrm{C}\right)$. The low thermal expansion will

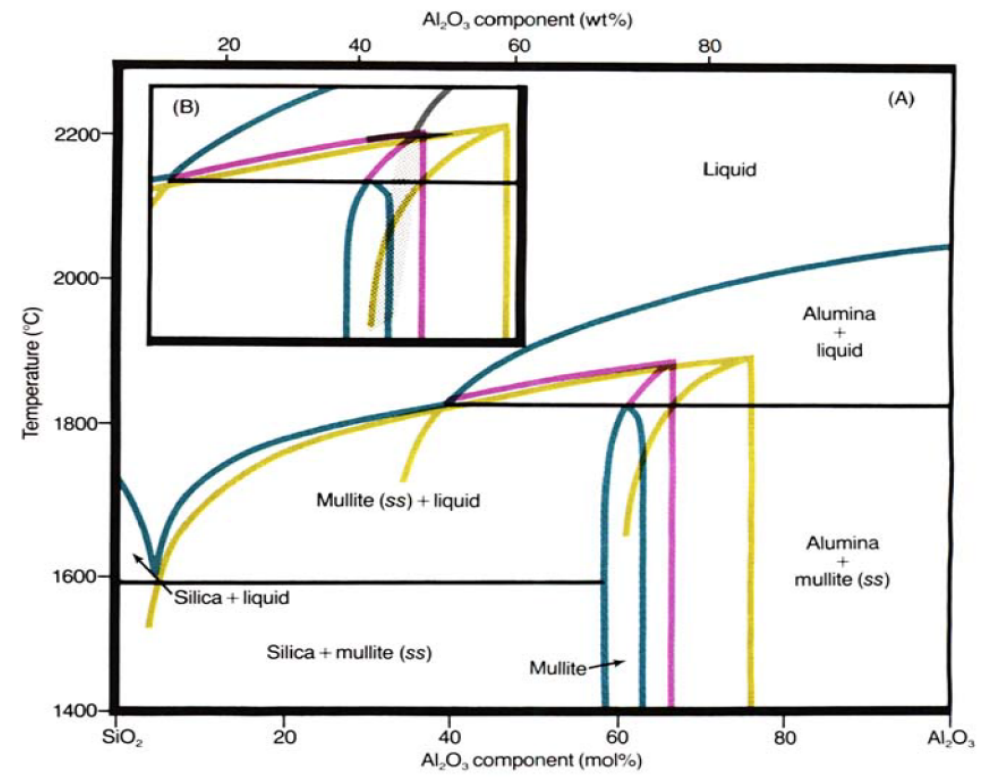

Figure A.1: $\mathrm{Al}_{2} \mathrm{O}_{3}-\mathrm{SiO}_{2}$ Phase Diagram[5]

allow for precise placement of the sample into the hot zone of the furnace, and contributes to the high thermal shock resistance. High creep resistance is beneficial because of the long testing times that the mullite will be subjected to. Mullite can be made with methods such as slip casting, so the cost remains low even if replacements are needed.

Ease of use and maintenance Another key consideration in the building of the cyclic oxidation rig was the ease of use and maintenance. In order to take up the least space, and allow for easy sample insert and removal a vertical tube furnace would work best. The tube furnace should also be split to allow for easy maintenance. There are vertical $\mathrm{MoSi}_{2}$ tube furnaces available, but $\mathrm{SiC}$ furnaces are much more common for vertical applications. Either choice would work, and just depends on the availability and cost of the furnace.

In order to move the sample in and out of the furnace the easiest and most flexible way is to use a programmable stepper motor. The motor could be programmed to precisely position 
the samples, and perform the cycles at any specified schedule.

Sample Capacity To make the entire system as flexible as possible, the ability to oxidize a large number of samples simultaneously would be highly desirable. When using a tube furnace the biggest limiter would be the diameter of the furnace. Depending on the dimensions of the samples, and holder requirements may vary. Assuming a sample diameter of 10 $\mathrm{mm}$, and a thickness of $1 \mathrm{~mm}$, a furnace with a usable diameter of 6 inches gives plenty of room for a large number of samples.

\section{A.3.2 Fabrication and Assembly}

Furnace To meet the needs of high temperatures, large sample capacity, easy maintenance, and ease of use a vertical $\mathrm{SiC}$ tube furnace was chosen with a maximum operating temperature of $1540^{\circ} \mathrm{C}$ (ATS Model 3420). The particular model has an inside diameter of 6 inches to allow for a large number of samples with a heated length of 18 inches. The furnace was mounted vertically as shown in Figure A.2, with rails extending to the ceiling to allow for mounting of additional hardware.

Sample Control To move the samples into and out of the furnace a linear actuator stepper motor from Intelligent Motion Systems (IMS) was used, Model KMLI1FRD23A7LA1M240ZZ. This motor is fully programmable with RS-422/485 communications, using both the IMS software and other popular software (i.e. LabView). An example cyclic oxidation program, written in the IMS language, is shown in Appendix B. The lead screw provides 21 inches of travel to move the samples into and out of the furnace. The shaft was guided up and down by the apparatus shown in Figure A.3.

Part 1 in Figure A.3 shows the tray to which the motor was affixed. The tray has a cut out to fit the motor in with horizontal slots for the mounting bolts to allow adjustment for easy centering. The edges of the tray has vertical slots to allow for further adjustment. Part 6 is a $\frac{3}{8}$ inch tube supported by part 4 to guide the lead screw up and down. Part 7 is a guide block shown in Figure A.4. This part clamps into the lead screw to keep it from rotating, so 


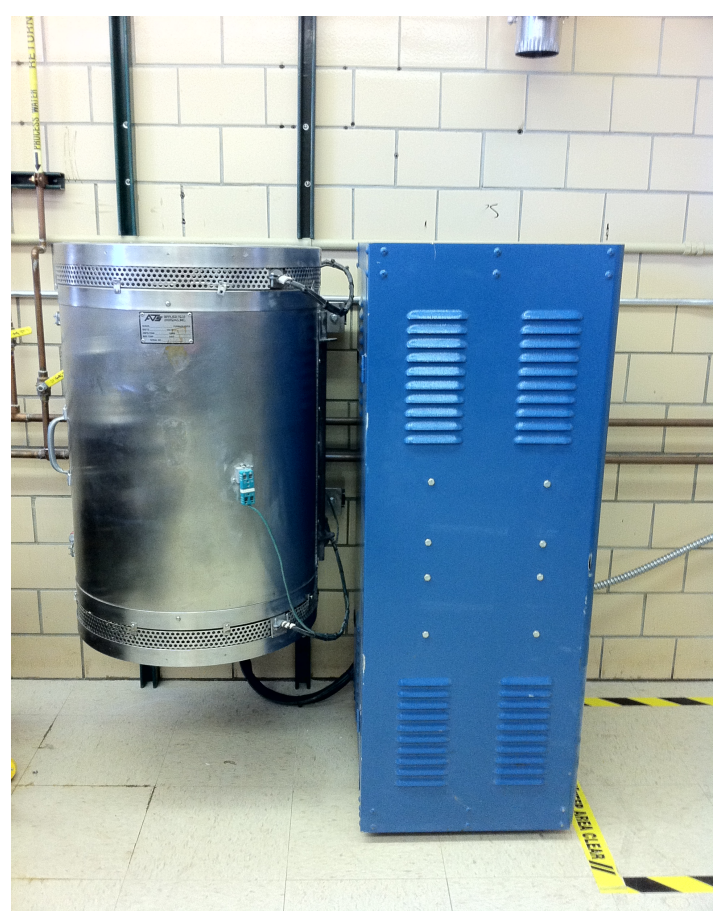

Figure A.2: ATS Model 3420 Furnace (left) with the controller (right). Rails extend to the ceiling to mount additional hardware

it can move through the motor. The other end is guided by the rod (Part 6). The guide block was made tall enough so it would not bind on the guide rod.

As discussed on page section A.3.1, mullite is the material of choice to be exposed to the furnace environment. To attach the mullite tube to the lead screw, a coupler was designed that would connect the mullite tube (0.375"OD, 0.250"ID) to the lead screw (M6x1mm). The end of the coupler that was inserted into the mullite tube was undersized by 0.004 " to allow epoxy (Miller-Stephenson Epoxy 907) to fill the gap and hold on to the mullite tube. This way, even if the mullite tube broke, replacement would be quick and easy.

To attach oxidation samples to the mullite tube a 0.125 " hole was drilled 0.25 " from the end to allow crucibles to be hung. Platinum wire was fed through the end of the rod and through a crucible that holds the samples. Alumina crucibles have been used, but for longevity and thermal shock resistance, mullite crucibles should be used. 


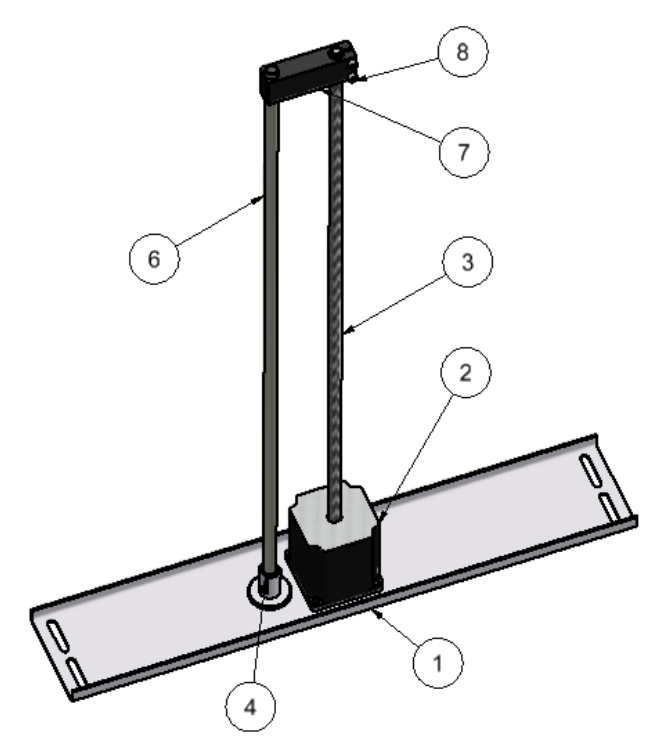

Figure A.3: Stepper Motor Configuration

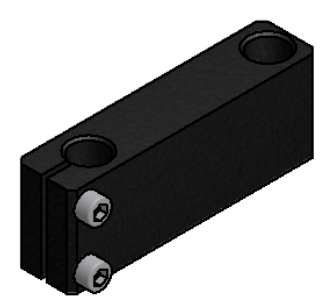

Figure A.4: Part 7, Guide Block

\section{A.4 Results}

The cyclic oxidation rig was used to cyclically oxidize all of the coated samples described in chapter 4. After many repeated cycles the mullite tube shows no signs of cracking and appears to be in almost new condition. When the furnace is not being used to cyclically oxidize samples, it has also been used to isothermally oxidize Mo-Si-B type alloys at temperatures up to $1300^{\circ} \mathrm{C}$. Although the furnace has not been used at the maximum operating temperature of $1500^{\circ} \mathrm{C}$, there should not be any problems considering the condition of the equipment after many oxidation runs at temperatures ranging between 1100 and $1300^{\circ} \mathrm{C}$. 


\section{BIBLIOGRAPHY}

[1] Travis Brammer. Improving the phase stability and oxidation resistance of $\beta-\mathrm{NiAl}$. Master's thesis, Iowa State University, 2011.

[2] J.A Nesbitt, E.J Vinarcik, C.A Barrett, and J Doychak. Diffusional transport and predicting oxidative failure during cyclic oxidation of $\beta-\mathrm{NiAl}$ alloys. Materials Science and Engineering: $A, 153(1,2): 561-566,1992$. ISSN 0921-5093. Proceedings of the Second International ASM Conference on High Temperature Aluminides and Intermetalics: Part 2.

[3] Dov Sherman and Doron Schlumm. Thickness effect in thermal shock of alumina ceramics. Scripta Materialia, 42(8):819-825, 2000.

[4] Cemail Aksel. The effect of mullite on the mechanical properties and thermal shock behaviour of aluminaâĂŞmullite refractory materials. Ceramics International, 29(2):183 188, 2003. ISSN 0272-8842.

[5] Ilhan A. Aksay, Daniel M. Dabbs, and Mehmet Sarikaya. Mullite for structural, electronic, and optical applications. Journal of the American Ceramic Society, 74(10):2343-2358, 1991. 


\section{APPENDIX B. Cyclic Oxidation Rig}

\section{Cyclic Oxidation Rig Sample Code}

The following shows an example code for the IMS program to perform cyclic oxidation. The code has been over commented so the code can be clearly deciphered by someone with no knowledge of this programming language. It will also he helpful if the original file is ever lost or corrupted so the researcher does not have to start from scratch.

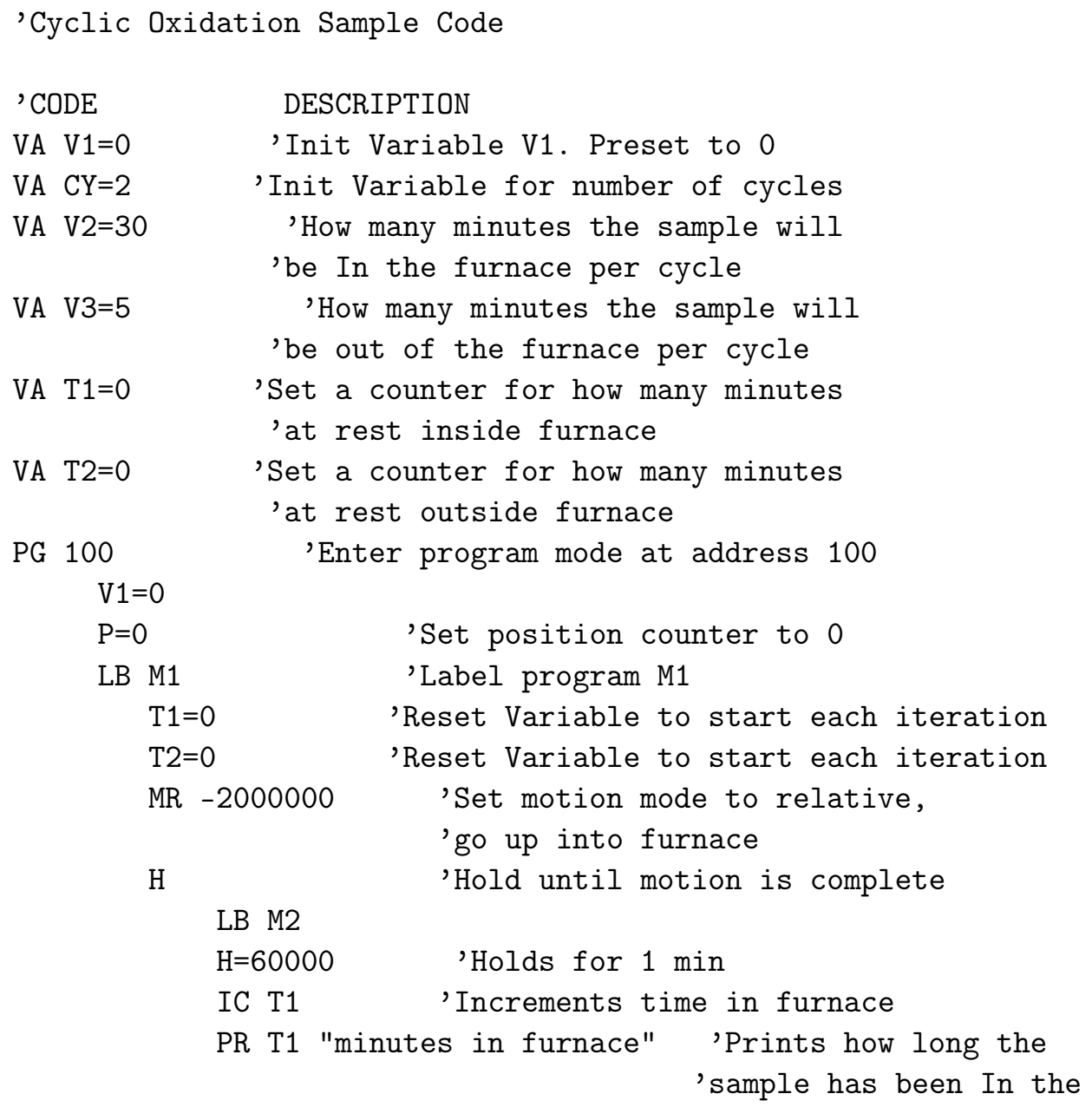




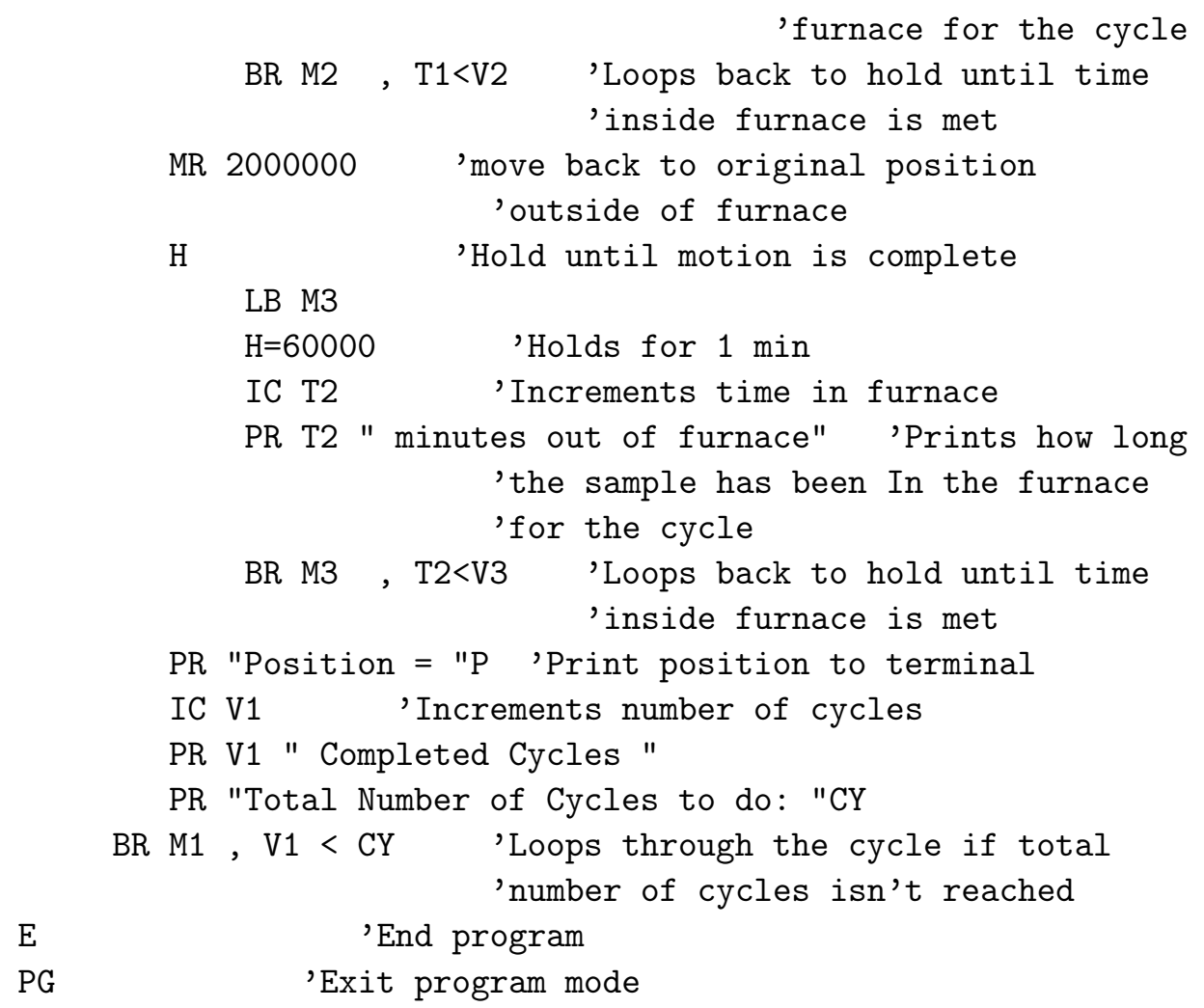

\section{Standard Operating Procedure}

\section{Principles of operation}

This equipment is designed to move samples into and out of a vertical tube furnace at a set time and temperature. The furnace is an ATS vertical tube furnace capable of operating at temperatures up to $1500^{\circ} \mathrm{C}$, while the motor controlling the sample movement is a stepper motor manufactured by Schneider Electric.

\section{Training/Certification}

It is mandatory to be trained prior to using this equipment. See Kevin Severs, Room 322 Spedding hall for training. Upon completion of training and demonstration of competence in the use of this equipment you will certified to use this equipment. User privileges may be revoked at the direction of Kevin Severs. 


\section{Specifications}

Electrical: 110V/73A (Furnace), 15V2A Max (Motor)

Maximum operating temperature: $1500^{\circ} \mathrm{C}$

\section{Health and Safety Hazards}

- To prevent burns, never open furnace or touch furnace when internal temperature is above $50^{\circ} \mathrm{C}$

- Do not heat flammable or combustible materials since this instrument may ignite such materials

- Lockout and tagout electrical power before removing any panels on the apparatus or disconnecting furnace leads

\section{Equipment Restriction}

- Do not attempt to repair or perform any maintenance to the instrument. Contact Kevin SEvers, Room 322 Spedding Hall if there are any problems

- Under no circumstances should the furnace exceed a temperature of $1500^{\circ} \mathrm{C}$

- Do not heat materials which evolve a large amount of volatiles

\section{Operating Instructions}

Note: No formal operatorâĂŹs Manual exists for this apparatus since this apparatus is combination of several individual instruments. Copies for the individual instruments are located on the top shelf of the cabinet in 318 Spedding.

\section{Furnace Control}

To operate the furnace, turn on the breaker on the south wall. Make sure that the circuit breaker on the control panel is on and working. If not, trip the circuit breaker and turn it on 
again. Move the toggle switch on the front of the control panel to operate mode. This should turn on both the temperature controller and the over-temperature controller.

The furnace can operate in two modes: Manual and Automatic. In manual mode the user inputs the power output of the heating elements and has no control over the temperature. Automatic mode should be used exclusively with this instrument.

Automatic mode inputs a temperature and adjusts the power to the heating elements accordingly. The user can toggle between the Automatic and Manual mode by pushing the Auto/Manual button. In Automatic mode you can toggle through the menus by pushing the "Display" button.

Note: There are two setpoints in the controller. The small number in the middle of the controller indicates which set point the controller is going to. Set Point 1 is the default.

The first display is the target temperature. Use the arrow buttons to set the desired temperature. The following screens show the furnace power output, set point the furnace should be at, then the discrepancy between the set point and actual temperature. Finally the furnace will show the second set point. You can either change this or leave it how it is; it will not affect the temperature of the furnace as long as the controller is set to set point 1 .

\section{Motor Control}

To control the motor open up the program IMS Terminal

IMPORTANT: Do not hit the Upgrade! button within the program. This puts the motor into "Upgrade" mode and renders the motor unusable until an upgrade is done, which can take a while.

A program has already been written to perform a standard cyclic oxidation test with 2 hours in the furnace followed by 30 minutes outside of the furnace. Any of the parameters can be changed to make the motor move how you want.

The program to run the standard cyclic test is shown on the last page. Important variables that can be changed are as follows:

CY - This variable controls the total number of cycles the motor will complete

V2 - Controls how many minutes the sample will be oxidized per cycle 
V3 - Controls how many minutes the sample will rest outside of the furnace

The rest of the program is already set and should not be changed.

1. To download the program to the motor first click the Transfer $\rightarrow$ Download

2. Select the file to transfer to the motor

3. Click the download button

4. Click through if the program says the data type is incompatible

The terminal window should list the percentage downloaded. This process should only take a few seconds.

The program is now ready to be run. The motor should be at the bottom of the furnace, where you can load your samples. If the motor is not at the bottom of the furnace type in the command "SL 10000" into the terminal and hit enter. The motor should start to move downwards. Hit escape once the sample holder reaches the bottom of the furnace. To run the program type EX M1 into the terminal, and the program will start.

The screen will display the amount of time the samples have been in the furnace, the amount of time out of the furnace, and the number of cycles completed. To perform any other types of cyclic programs, consult Kevin Severs, Spedding 322, to discuss writing a program to suit your needs. EMERGENCY SHUTDOWN PROCEDURE: turn off the furnace power switch on the main control panel. There is also a breaker located on the south wall of 318 Spedding.

\section{Maintenance}

1. Inspect electrical cords every 180 days and replace as neccesary

2. Calibrate thermocouples yearly 


\section{APPENDIX C. Pack Cementation Furnace}

The following appendix discusses the building of an apparatus to conduct pack cementation.

\section{C.1 Materials}

The pack cementation apparatus consists of

- Furnace

- Sealed Tube with gas control

\section{C.1.1 Furnace}

The furnace used was a Lindberg Blue M (Model \#STF55433PBC-1), with a maximum operating temperature of $1500^{\circ} \mathrm{C}$.

\section{C.1.2 Tube and Gas Control}

To contain the process a quartz tube was used to fit within the diameter of the tube furnace (75mm OD, 70mm ID). Stainless steel flanges (McMaster Carr P/N 4322K165) were epoxied onto the ends with Miller-Stephenson Epoxy 907. The ID of the flanges were machined out in order to fit over the tube. A sleeve was welded over the flange in order to facilitate flowing water to cool the ends, as seen in Figure C.1. The ends of the flanges are sealed with a cap (McMaster Carr P/N 4322K224). The cap has a hole drilled, which allowed for a Swagelok fitting (P/N SS-6-UT-A-6) to be welded to the cap. This allowed for a tube $3 / 8^{\prime \prime}$ OD (Inconel 600) to be inserted into the quartz tube. 


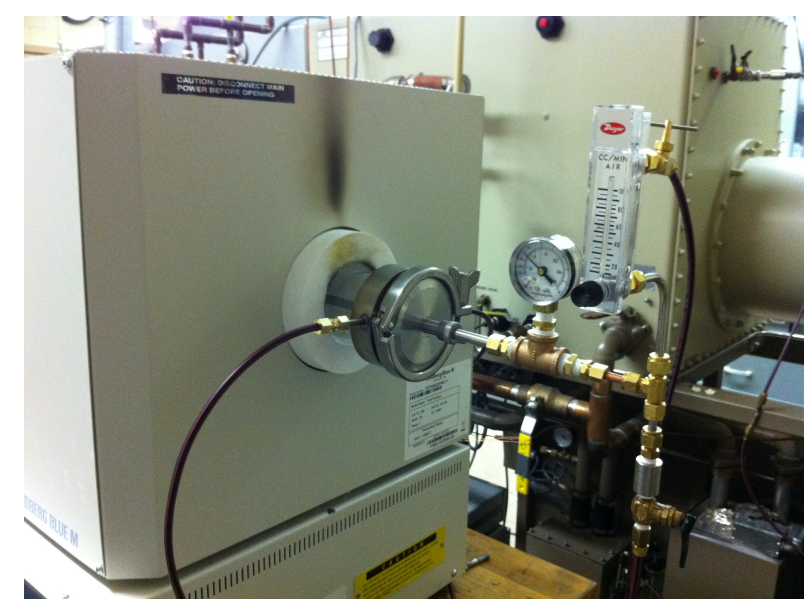

Figure C.1: Pack Cementation Apparatus End

Figure C. 2 shows a basic schematic on how the gas control works for the apparatus. One end allows flow of argon (or any other gas) into the furnace. The other end splits off and has an exhaust port that does not allow gas flow back into the furnace. The other split end is attached to a vacuum pump to evacuate the tube.

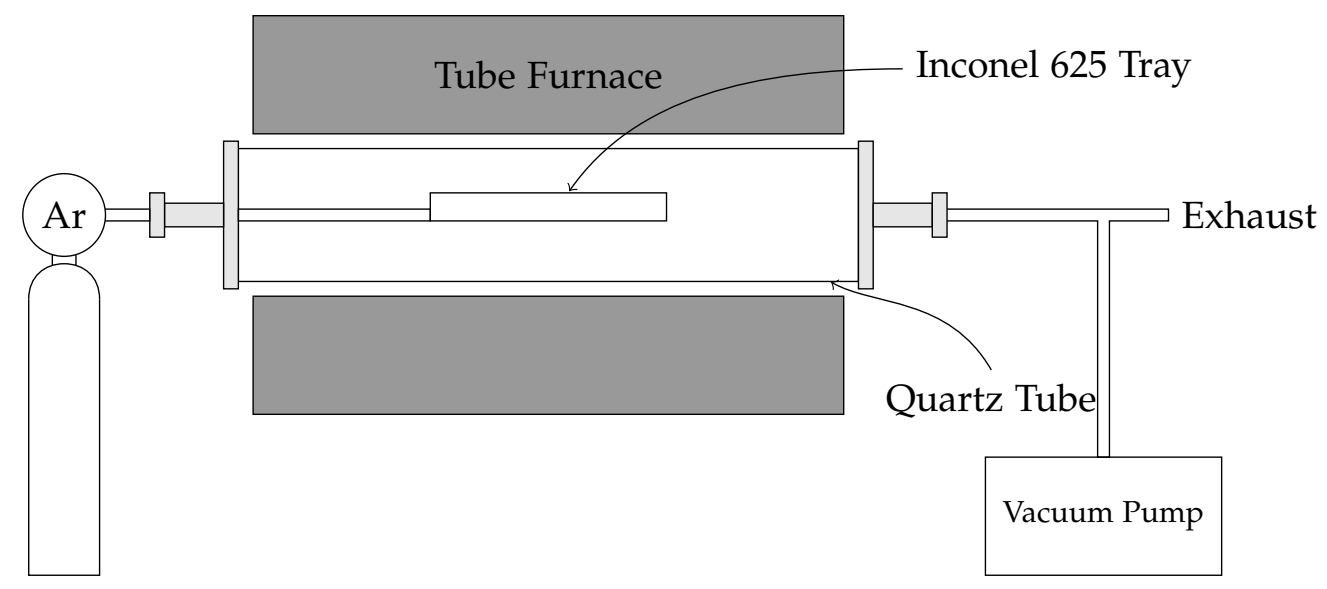

Figure C.2: Pack Cementation Schematic

An Inconel 625 tray was fabricated and attached to the end of the $3 / 8^{\prime \prime}$ tube that was inserted into one end of the tube. The tube served both as a support for the tray and for an inlet of gas. The ends of the tray were burnished to avoid scratching the quartz, and was made large enough to handle a large number of samples. 


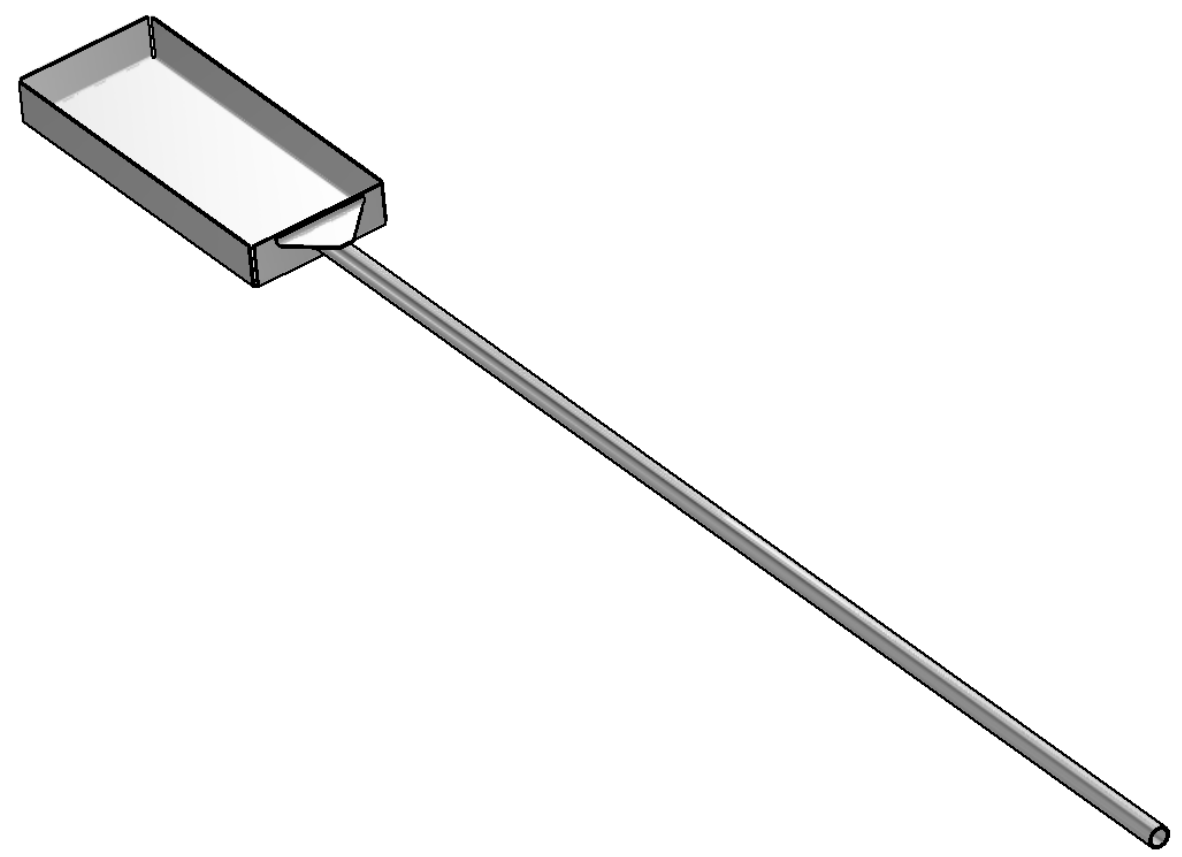

Figure C.3: Inconel Tray

\section{C.2 Operation}

To operate the furnace, the semi-sealed crucibles containing the pack mixture and the alloys to be coated are inserted on the Inconel tray. The vacuum pump is used to evacuate the quartz tube, and backfilled with argon. The vacuum and backfill process is repeated three times. Steady state flow of argon is established through the quartz tube. Cooling water is turned on to the flanges, and the furnace is programmed to run for the specified time and temperature. Once the furnace has cooled down the samples can be removed. 